\title{
Agriculture
}

Canada

Publication $1532 / F$

\section{Entreposage commercial des fruits et des légumes}
630.4
C212
P 1532
1988
fr.
OOAg
c.3 


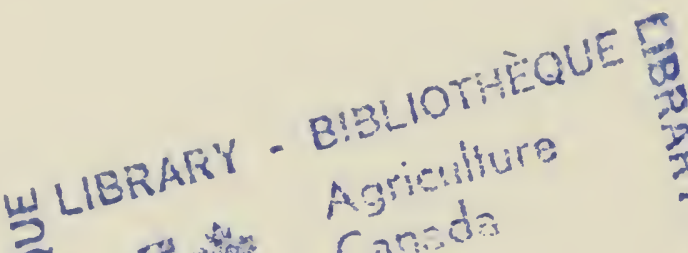

尊

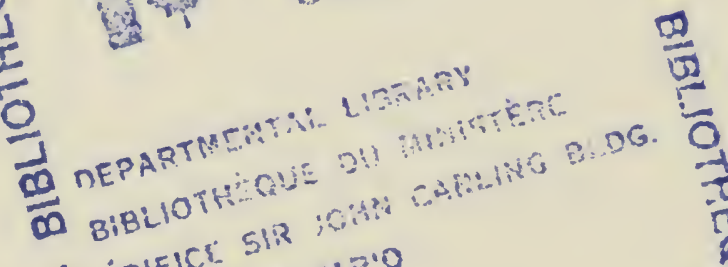

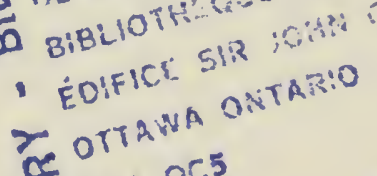

cécia OC5

OLIBRARY - BIBLIOTHEQUE 


\section{Entreposage commercial des fruits et des légumes}

P.D. Lidster et P.D. Hildebrand

Station de recherches, Kentville (N.-É.)

L.S. Bérard

Station de recherches, St-Jean-sur-Richelieu (Québec)

S.W. Porritt (retraité)

1711, rue Wharf, Summerland (C.-B.)

Les recommandations de la présente publication sur l'usage des pesticides et d'autres produits chimiques ne sont données qu'à titre d'indication. Toute application d'un pesticide ou autre produit chimique doit être conforme au mode d'emploi inscrit sur l'étiquette du produit, aux termes de la Loi sur les produits antiparasitaires. II faut toujours lire l'étiquette. Un pesticide homologué ou autre produit chimique doit aussi être recommandé par les autorités provinciales. Les modes d'emploi recommandés pouvant varier d'une province à l'autre, consulter le représentant agricole de la province pour obtenir des conseils particuliers.

PUBLICATION 1532/F On peut en obtenir des exemplaires à la

Direction générale des communications, Agriculture Canada,

Ottawa K1A $0 \mathrm{C} 7$.

- Ministre des Approvisionnements et Services Canada 1988

No. de cat. A53-1532/1988F ISBN: 0-662-94735-5

Impression 1975 Révision $1988 \quad 2 \mathrm{M}-2: 88$

Also available in English under the title

Commercial storage of fruits and vegetables. 


\section{TABLE DES MATIĖRES}

Liste des tableaux, $v$

Liste des figures, $\mathrm{v}$

Remerciements, vi

Introduction, vi

Refroidissement et entreposage, 1

Entreposage en atmosphère contrôlée $(\mathrm{AC}), 12$

Conditions d'entreposage des fruits, 20

Conditions d'entreposage des légumes, 37

Conception et construction des entrepôts frigorifiques, 62

Bibliographie, 78 


\section{LISTE DES TABLEAUX}

1. Conditions d'entreposage en atmosphère contrôlée de certains cultivars de pommes et de poires, 13

2. Durée, température et humidité relative d'entreposage recommandées, et point maximal de congélation des fruits frais, 21

3. Périodes d'entreposage normale et maximale de certains cultivars communs de pommes et sensibilité de ces fruits aux désordres d'entreposage, 22

4. Épreuve de maturité au pénétromètre de certains cultivars de poires et durée approximative d'entreposage, 30

5. Durée, température et humidité relative d'entreposage recommandées, et point maximal de congélation des légumes frais, 38

6. Durée de conservation de divers cultivars de choux d'hiver à $0{ }^{\circ} \mathrm{C}, \quad 46$

7. Résistance thermique de quelques matériaux de construction isolants, 65

8. Chaleur approximative de respiration de certains fruits et légumes frais entreposés aux températures indiquées, 69

9. Chaleur de respiration cumulée de pommes réfrigérées à raison d'une tonne par jour, 70

10. Établissements des besoins de réfrigération, 72

11. Table de conversion des températures, 74

12. Facteurs de conversion de la chaleur, 77

\section{LISTE DES FIGURES}

1. Relation entre l'humidité relative de l'air d'une pièce et la température de l'air évacué par les serpentins évaporateurs, 6

2. Relation entre la température d'une pièce, l'humidité relative et la température de surface de l'objet au point de condensation ou de suintement, 7

3. Chute de la pression en fonction du temps dans un contrôle d'étanchéité d'entrepôts à AC, 15

4. Perte de fermeté de pommes McIntosh entreposées initialement dans des atmosphères contrôlées et à l'air, et perte subséquente de fermeté durant l'entreposage additionnel à l'air, 19

5. Charge thermique de 40 caisses-palettes de pommes par jour, mises en entrepôt à des températures comprises entre 0,0 et $25,0^{\circ} \mathrm{C}$, et refroidies à $0,0^{\circ} \mathrm{C}$ en 7 jours, 68 


\section{REMERCIEMENTS}

MM. W.R. Phillips et J.G. Armstrong, Agriculture Canada, ont rédigé la première édition de la présente publication parue en 1967 sous le $n^{\circ} 1260$. L'information avait alors été fournie par les chercheurs des universités et le personnel des ministères fédéral et provinciaux de l'Agriculture. La deuxième édition est parue en 1974 sous le no 1532 à la suite d'une révision en profondeur de la version originale, avec apport de données sur l'entreposage des fruits par S.W. Porritt.

Cette troisième édition, préparée par les Drs P.D. Lidster, P.D. Hildebrand et L.S. Bérard, présente les dernières découvertes concernant l'entreposage des fruits et légumes et de l'information plus détaillée sur l'atmosphère contrôlée. Des recommandations supplémentaires ont été ajoutées pour l'entreposage du bleuet et de certains légumes dont la carotte et le chou.

\section{INTRODUC'TION}

La présente publication fournit des renseignements aux entreposeurs et manutentionnaires de produits en gros et au détail. On y trouve des données biologiques et techniques générales et des indications précises sur l'entreposage des fruits et des légumes, ainsi qu'une liste d'ouvrages de référence pour des renseignements plus détaillés. Au Canada, les cultivars de fruits et de légumes cultivés et les conditions de culture varient considérablement d'une région à l'autre. Par conséquent, les exigences d'entreposage et de manutention diffèrent suivant la région. Les renseignements donnés dans la présente publication proviennent de l'expérience et des essais effectués dans diverses parties du Canada et dans d'autres régions fruitières et légumières où les conditions sont les mêmes.

Les auteurs recommandent des traitements chimiques pour améliorer les conditions d'entreposage de certains fruits et légumes. Avant d'en faire usage, il est important de connaître les dispositions de la loi qui limite leur application à des produits horticoles particuliers. Ces règlements, destinés à protéger la santé et le bien-être des consommateurs, concernent surtout la quantité de résidus chimiques retrouvés sur ou dans les fruits ou les légumes à la suite d'application. Au Canada, avant d'appliquer des pesticides, il faut consulter la Direction des aliments et drogues de Santé et Bien-être Canada à Ottawa ou l'un de ses inspecteurs ou directeurs en région. 


\section{REFROIDISSEMENT ET ENTREPOSAGE}

Le rôle d'un entrepôt de fruits et légumes est de maintenir les conditions idéales qui permettent de les conserver aussi longtemps que possible sans perte de saveur, de texture, d'humidité ou de quelque autre caractéristique recherchée par le consommateur. Ces conditions sont créées en réglant la température et la composition de l'atmosphère de l'entrepôt.

Les fruits et les légumes sont séparés de la plante au moment de la récolte et donc de leur source naturelle d'eau et de nourriture. Dès lors, ils commencent à se détériorer. La récolte accélère les changements métaboliques qui accompagnent le mûrissement et la sénescence. Des phénomènes comme la respiration, le ramollissement, les pertes d'eau et les modifications biochimiques de pectine, de l'amidon, des sucres et des acides, sont grandement influencés par la température. La qualité des fruits et des légumes et leur durée de conservation en entrepôt peuvent être ainsi sérieusement compromises durant les heures qui suivent la récolte, s'il n'y a pas refroidissement rapide des produits récoltés pour en empêcher la détérioration. Une manipulation soignée et un entreposage adéquat ne sauraient réparer ces dommages par la suite. Des facteurs autres que la température influencent aussi l'entreposage. Les fruits et les légumes récoltés, étant toujours vivants, absorbent de l'oxygène et dégagent du gaz carbonique ainsi que d'autres substances volatiles pendant l'entreposage. Il faut maintenir la concentration de ces gaz en dessous des seuils préétablis, sous peine de voir les fruits et les légumes s'avarier. La perte excessive d'eau des produits cause du dessèchement alors que la condensation favorise la croissance des microorganismes et la détérioration.

\section{CHALEUR SENSIBLE ET CHALEUR DE RESPIRATION}

La chaleur contenue dans un produit lors de son entrée en entrepôt et qui doit être retirée pour abaisser la température au degré désiré, est désignée par l'expression chaleur sensible. Lorsque le produit n'est pas prérefroidi avant l'entreposage, la chaleur sensible contenue dans le produit venant du champ impose, dès le chargement, la plus forte charge de réfrigération de l'entrepôt durant la période d'entreposage. La mécanisation à la récolte et l'entreposage en vrac favorisent l'entrée journalière de gros volumes de produits horticoles; lors du chargement d'anciens entrepôts, il est à craindre que la chaleur sensible excède les capacités de réfrigération et occasionne des sommets inhabituellement élevés et nocifs de température.

La chaleur que dégagent les produits horticoles lors de leurs activités métaboliques en entrepôt contribue aussi à la charge de 
réfrigération de l'entrepôt; cette charge est importante mais moindre que la chaleur sensible au chargement. Cette chaleur métabolique dite de respiration, persiste tant que le produit est en entrepôt; elle varie en intensité selon la nature, l'âge et la température à laquelle le produit est gardé. Chez les produits à forte intensité respiratoire, la chaleur accroît la charge de réfrigération; elle nuit au refroidissement rapide et, si la circulation de l'air est insuffisante, peut provoquer un échauffement localisé puis la détérioration du produit.

\section{PRÉREFROIDISSEMENT}

Il est impossible de bien refroidir le produit et de contrôler la température si l'emballage et le mode de manutention du produit empêchent le transfert rapide de la chaleur du produit au système de refroidissement. Certaines circonstances pourraient justifier l'utilisation de méthodes de prérefroidissement particulières pour maintenir la qualité du produit à un niveau acceptable.

La plus forte demande de froid a lieu lorsque l'entrepôt est rempli d'un produit chaud dont il faut abaisser la température au degré de conservation voulu. Une fois la chaleur sensible éliminée, la demande de froid est grandement allégée et consiste principalement à combattre la chaleur extérieur qui s'infiltre dans l'entrepôt et la chaleur de respiration. Les entrepôts frigorifiques doivent être conçus en vue d'un refroidissement rapide des nouveaux arrivages de produit, tout en maintenant stable la température des produits déjà entreposés. Dans certains cas, il faut recourir à une forme quelconque de prérefroidissement, telle la ventilation forcée, l'eau glacée ou le refroidissement sous vide.

La ventilation forcée consiste à produire une circulation d'air très active dans des chambres ou à l'intérieur de tunnels spécialement conçus à cette fin; les produits y sont empilés de manière à en exposer la plus grande superficie possible à l'air. Cette méthode de prérefroidissement est surtout utilisée pour les produits expédiés sur le marché immédiatement après la récolte $(60,119)$.

Les modèles récents de prérefroidisseur à air forcé soufflent de l'air froid et humide à travers les produits pour les refroidir en limitant au minimum les pertes de poids par dessiccation. Les modèles Filacell ${ }^{\circledR}$ (Pressure Cool Co., Indio, Calif.) procèdent par réfrigération indirecte. Des serpentins évaporateurs refroidissent un réservoir d'eau qui descend en cascade du haut d'une tour verticale faite de filaments. Cette eau refroidit l'air de l'entrepôt dirigé très rapidement à contre-courant vers le haut dans la tour. L'air ainsi humidifié refroidit en second lieu le produit lors de son retour à l'entrepôt par forçage à travers les chargements de palettes. Les modèles Filacell ${ }^{\circledR}$ et les autres types de lessiveur d'air exercent leur pouvoir réfrigérant 
grâce à la réfrigération mécanique constante de l'eau caloportrice. Ces appareils sont conçus pour fonctionner en continu et peuvent être utilisés pour un entreposage à long terme où des températures légèrement voisines à $0^{\circ} \mathrm{C}$ sont désirées; l'usage de solution eutectique permet de refroidir en bas de $0^{\circ} \mathrm{C}$.

Un nouveau modèle de prérefroidisseur mis au point en Angleterre fonctionne sur le principe du lessiveur d'air; pendant les périodes de bas tarifs d'électricité, il transforme en glace une partie de l'eau caloportrice. La glace sert ensuite de source de refroidissement pendant les périodes à tarifs élevés d'électricité. Conçu à l'origine comme un prérefroidisseur à air forcé, l'ice bank cooler consomme environ deux fois moins d'électricité que les systèmes à réfrigération mécanique traditionnelle car le refroidissement est assuré par la réserve de glace accumulée. L'ice bank cooler a l'avantage de consommer de l'électricité, lorsqu'elle se vend à bon marché pour fabriquer de la glace et utilise donc moins de courant pendant les périodes de forte demande de froid. Ainsi, un compresseur de moindre puissance est nécessaire. Le principal inconvénient de ce système indirect est qu'il ne peut refroidir le produit à $0^{\circ} \mathrm{C}$. Généralement, des températures minimales de 1,0 à $2,5^{\circ} \mathrm{C}$ sont obtenues après 2 à 8 heures de fonctionnement.

Les produits ayant un rapport surface:volume élevé peuvent être prérefroidis de façon optimale en soufflant horizontalement de l'air froid sur les produits empilés. Toutefois, pour les produits ayant un faible rapport surface:volume, il est recommandé de souffler l'air froid de bas en haut (verticalement) sur les produits empilés pour obtenir un refroidissement maximal.

Le prérefroidissement à l'eau glacée est la méthode de prérefroidissement la plus efficace pour extraire la chaleur des produits horticoles. Elle est employée surtout pour refroidir le maïs, les asperges, le céleri, les carottes, les radis et les pêches $(5,83,119$, 185). Ce procédé indirect de réfrigération consiste à immerger le produit dans l'eau glacée ou à l'exposer à un fort courant d'eau froide pulvérisée. Le prérefroidissement à l'eau glacée donne des résultats insatisfaisants lorsque la période de refroidissement est trop courte, lorsque le compresseur est trop peu puissant ou lorsque le produit n'offre pas assez de surface à l'action de l'eau.

La glace râpée, concassée ou liquide est utilisée pour refroidir directement des produits horticoles en vrac ou en boîte. Ce procédé est surtout employé lors de l'expédition par rail pour rafraîchir les chargements en transit. Les légumes sensibles à la dessication tels la laitue, les épinards, les radis, les carottes et les brocolis se prêtent bien à ce type de refroidissement $(166,184)$. L'application de "glace-liquide", composée de $60 \%$ de glace concassée et de $40 \%$ d'eau, accélère le refroidissement du produit car elle est plus malléable pour l'entourer. 
Le prérefroidissement sous vide est très efficace pour les légumes feuillus offrant une grande surface. Des légumes comme la laitue, les épinards et le céleri se prêtent au prérefroidissement sous vide mais pas les choux et les choux de Bruxelles aux feuilles cirées et compactes. La méthode repose sur le principe que l'eau bout à une température d'autant plus basse que la pression diminue (sous un vide de $4,6 \mathrm{~mm}$ de mercure, l'eau bout à $0^{\circ} \mathrm{C}$ alors qu'à la pression atmosphérique normale $(760 \mathrm{~mm})$, elle bout à $\left.100^{\circ} \mathrm{C}\right)$. L'évaporation de l'eau aux basses pressions et l'absorption de la chaleur par la vapeur d'eau émise contribuent à refroidir les produits sous vide (la chaleur de vaporisation de l'eau à $0^{\circ} \mathrm{C}$ est de $2500 \mathrm{~kJ} / \mathrm{kg}$ ). La méthode de prérefroidissement sous vide permet de refroidir rapidement et uniformément un produit entassé et même empaqueté telle la laitue. Elle entraîne cependant une perte de poids due à l'eau évaporée. De fait, $1 \%$ du poids est perdu par évaporation d'eau lors d'un abaissement de $6{ }^{\circ} \mathrm{C}$ de la température à la surface du produit. L'arrosage préalable des charges à refroidir atténue quelque peu cet inconvénient $(9,10)$.

\section{HUMIDITÉ}

La fraîcheur du produit entreposé dépend, dans une large mesure, de la rétention de sa teneur initiale en eau, d'où l'importance de maintenir une humidité élevée dans l'entrepôt. Cette dernière est plus difficile à régler que la température et on ne lui accorde pas toujours assez d'importance lors de l'achat du système de réfrigération. Si l'air est trop sec, des pertes excessives en eau peuvent survenir et nuire à la texture du produit; celui-ci se flétrit et se ride au point de ne plus être vendable. Les fruits, comme les pommes et les poires, résistent mieux aux pertes d'eau; si l'entreposage dure plusieurs mois, ils peuvent perdre 2 à $3 \%$ de leur poids en eau, voire davantage. Après avoir perdu 4 à $5 \%$ de leur poids, leur chair devient cependant spongieuse et leur surface ratatinée. Par contre, trop d'humidité dans l'atmosphère de l'entrepôt favorise la croissance de moisissures et d'autres organismes de décomposition, particulièrement lorsque l'eau se condense à la surface des produits. De plus, une très forte humidité, particulièrement au début de la période d'entreposage, peut contribuer à l'apparition de certains désordres physiologiques chez les cultivars de fruits à pépins de drupes sensibles. Bien qu'un degré élevé d'humidité dans l'entrepôt soit souhaitable pour la plupart des produits, certains légumes comme les oignons, l'ail, la courge et la citrouille ne demandent qu'une faible humidité relative.

Les légumes en général sont très susceptibles de perdre leur eau au cours de l'entreposage, particulièrement les légumes feuillus à large 
surface exposée. Dans un milieu défavorable, une fanaison irréversible peut survenir en quelques heures seulement. Des pertes d'eau de $4 \%$ ou plus peuvent être allégées en parant les feuilles extérieures fanées (200). Chez les légumes-racines et les choux, la fanaison et le ramollissement apparaissent lorsque les pertes d'eau totalisent 5 ou $6 \%$ du poids; des pertes d'eau dépassant $8 \%$ rendent le produit invendable. La plupart des légumes nécessitant une humidité relative élevée en entrepôt résistent bien à la dégradation et aux désordres physiologiques, par contraste aux pommes et aux drupes. Aux basses températures recommandées, la condensation d'eau à la surface des légumes sujets au flétrissement ne favorise généralement pas la pourriture.

Dans une atmosphère de même humidité relative, plus la température du produit est élevée, plus ses pertes en eau sont grandes. Aussi, pour réduire ces pertes au minimum, il est indispensable de refroidir le produit le plus tôt possible après la récolte.

La meilleure façon de maintenir une humidité relative élevée dans un entrepôt frigorifique est d'y installer un serpentin évaporateur de capacité suffisante. Ainsi, un petit différentiel de température entre la surface du serpentin et l'atmosphère à réfrigérer peut être maintenu. Un serpentin de dimension insuffisante met un temps beaucoup plus long à réfrigérer la masse de produit fraîchement entreposé. Si son différentiel de température avec l'atmosphère de l'entrepôt est accru, la réfrigération est plus rapide mais l'humidité relative est abaissée car beaucoup de vapeur d'eau se condense sous forme de givre sur le serpentin. Cette faible humidité relative entraîne des pertes inutiles d'eau du produit horticole entreposé, donc une perte de poids vendable. De plus, l'accumulation de givre diminue le contact de l'air avec le serpentin et réduit d'autant sa capacité de refroidissement. La figure 1 montre le rapport entre l'humidité atmosphérique de l'entrepôt et la température de l'air qui se dégage du serpentin. L'utilisation de chambres à doubles parois offre une grande surface de refroidissement qui permet de minimiser les pertes d'eau du produit. Toutefois, elles ne permettent pas de refroidir les produits entreposés très rapidement. Si ces produits n'ont pas été préalablement prérefroidis, la croissance de microorganismes et des changements de saveur et de texture du produit peuvent survenir en haute humidité. A ces inconvénients s'ajoutent les coûts de construction plus élevés de la bâtisse $(93,94,147)$. En l'absence de moyen pour obtenir un haut degré d'humidité, il faut introduire de l'eau dans l'entrepôt au moyen d'humidificateurs pulvérisateurs ou arroser le plancher. Il est extrêmement important de ne pas vaporiser l'eau directement sur le produit, car ceci encourage la croissance des pathogènes de surface. Pour maintenir une humidité relative de l'atmosphère entre 94 et $98 \%$, les produits peuvent être couverts de polyéthylène perforé de $38 \mu \mathrm{m}$ (ou l'équivalent) lorsque mis en vrac dans des caisses-palettes 
(environ $385 \mathrm{~kg}$ ) ou dans des cageots (environ $20 \mathrm{~kg}$ ). Il faut cependant être prudent car une barrière de polyéthylène autour d'un produit non refroidi ralentit le dégagement de la chaleur sensible et entraîne sa détérioration.

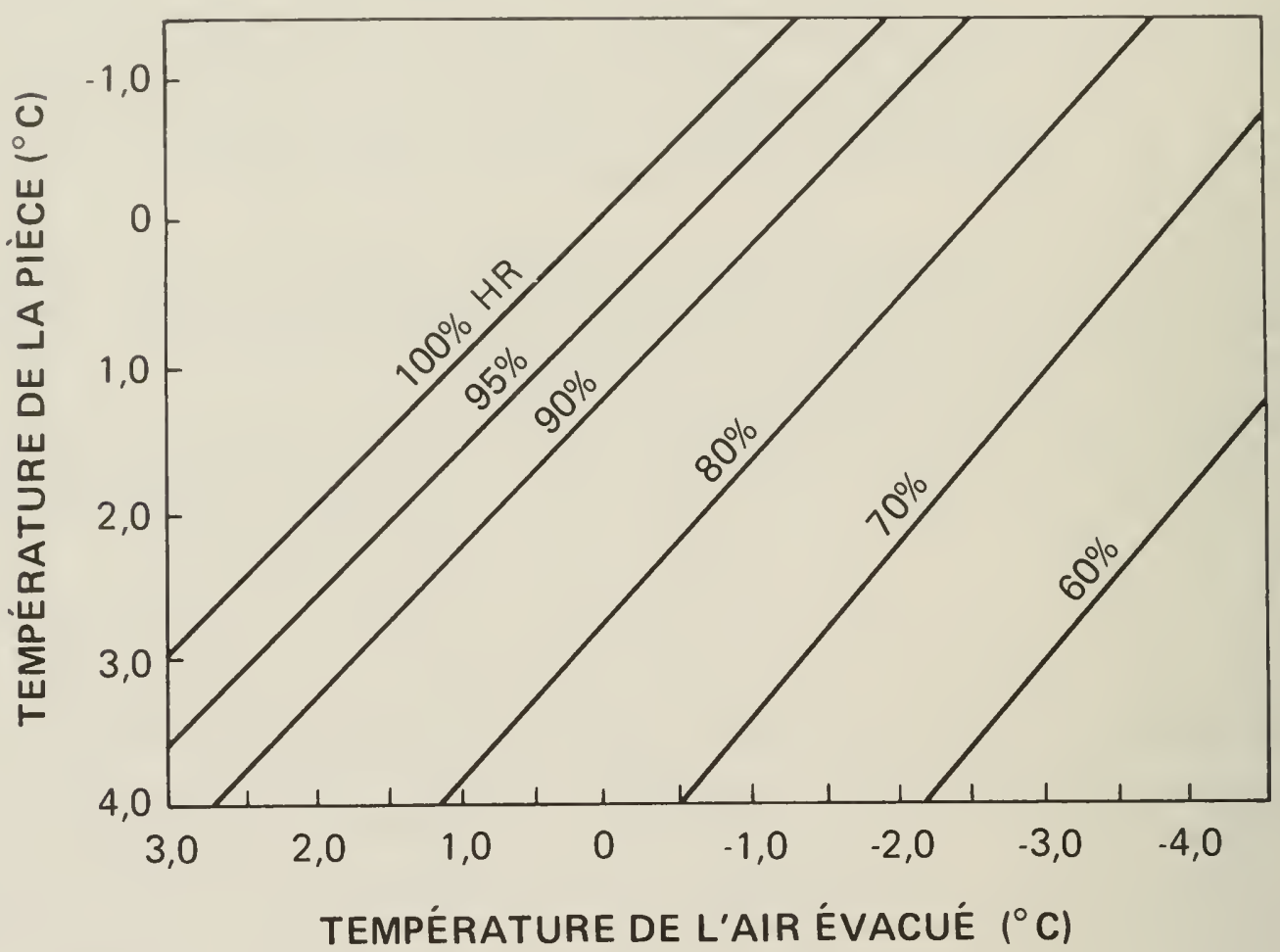

Figure 1. Relation entre l'humidité relative de l'air d'une pièce et la température de l'air évacué par les serpentins évaporateurs. Supposons que nous souhaitions maintenir une pièce à une température de $0{ }^{\circ} \mathrm{C}$ avec une humidité relative de $90 \%$. La température minimale à laquelle l'air peut être refroidi sans perdre d'humidité par condensation est alors donnée par l'abcisse du point d'intersection entre la droite de $90 \%$ d'humidité relative et la ligne de température de la pièce de $0{ }^{\circ} \mathrm{C}$, soit environ $-1,4^{\circ} \mathrm{C}$. Ce graphique a été établi à partir des valeurs indiquées dans le tableau 11 , Determination of Thermodynamic Properties of Moist Air dans ASHRAE Guide and Data Book, 1961.

Dans la présente publication, l'humidité est exprimée en terme d'humidité relative (HR); celle-ci décrit la quantité réelle (ou le pourcentage réel) de vapeur d'eau dans l'air, à un moment donné, par rapport à la quantité maximale de vapeur d'eau (100\%) que l'atmosphère pourrait retenir à cette température. Le mouvement d'humidité entre un objet quelconque et l'atmosphère dépend de l'humidité relative et non de l'humidité absolue. L'indice d'humidité 
relative de l'atmosphère varie avec la température. A mesure que cette dernière baisse, l'humidité relative augmente pour atteindre $100 \%$; à ce niveau, l'atmosphère est dite saturée. Ce point de saturation s'appelle point de rosée.

\section{CONDENSATION}

Tout produit froid exposé à de l'air chaud et humide se couvre de gouttelettes d'eau qui s'y condensent. Ce phénomène est attribuable au fait que l'air chaud perd de l'humidité en se refroidissant au contact avec le produit. La figure 2 montre comment la condensation, à une température donnée, est reliée à l'humidité et à la température de l'atmosphère.

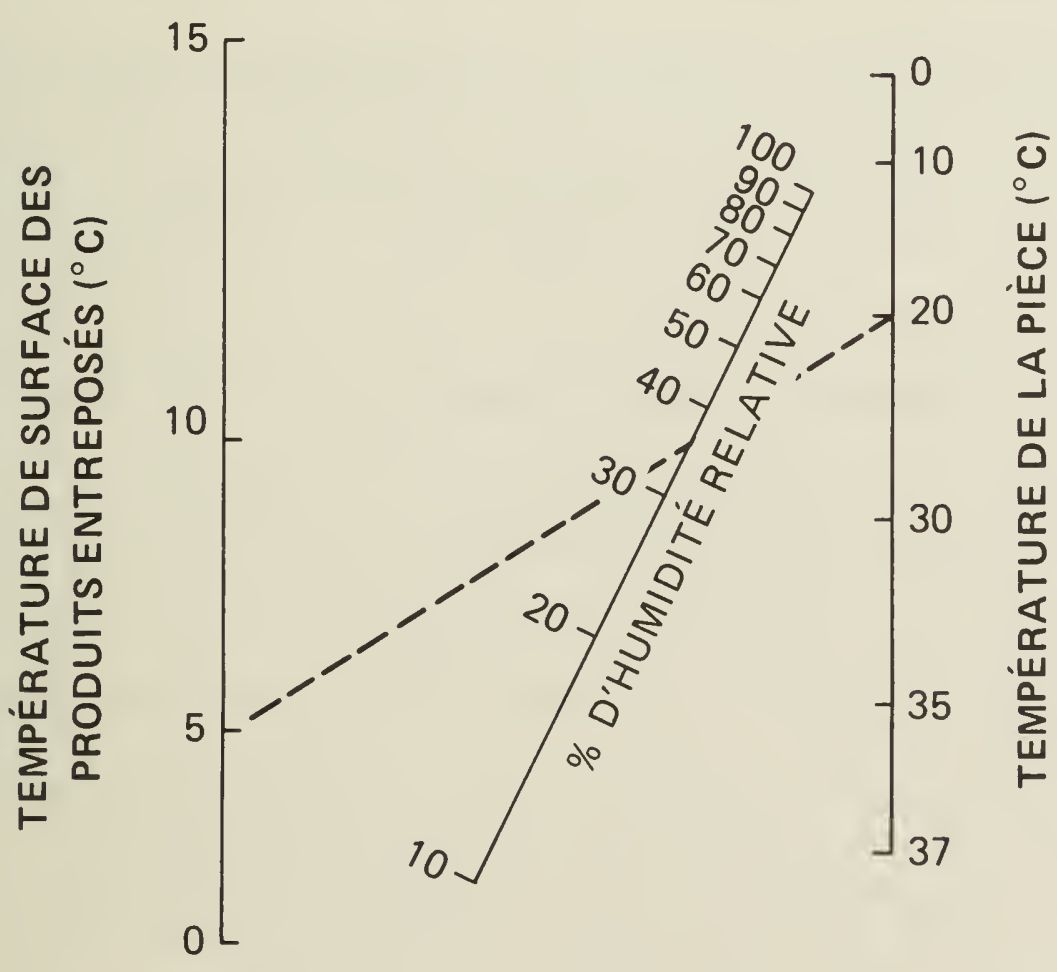

Figure 2. Relation entre la température d'une pièce, l'humidité relative et la température de surface de l'objet au point de condensation ou de suintement. Dans l'exemple donné, la température de la pièce est de $20^{\circ} \mathrm{C}$ et l'humidité relative est de $37 \%$. Le prolongement de la droite passant par ces points coupe l'échelle de température de surface à $5{ }^{\circ} \mathrm{C}$. Des produits dont la température de surface est égale ou inférieure à cette température suintent. Ces données ont été fournies par C.A. Eaves, Station de recherches, Kentville (N.-É.). 
Pour éviter la condensation d'eau sur les produits à leur sortie de l'entrepôt, on peut les porter graduellement à une température égale ou supérieure au point de rosée de l'atmosphère dans laquelle ils seront transférés. S'il est impossible d'éviter la condensation, les produits susceptibles de s'avarier doivent être écoulés rapidement à leur sortie de l'entrepôt frigorifique.

De la condensation d'eau peut recouvrir aussi les produits dans des entrepôts où l'humidité relative est maintenue près du point de rosée (HR 98-100\%). Ce phénomène est dû aux fluctuations de la température ambiante de l'entrepôt qui se produisent lors du cycle de dégivrage des serpentins. La température de l'évaporateur devrait être réduite au moins à la température des produits avant que les ventilateurs ne soient mis en marche pour empêcher toute condensation d'eau à leur surface.

\section{DÉSORDRES DUS AUX BASSES TEMPÉRATURES}

Il existe deux types de désordres physiologiques dus aux basses températures: ceux qui causent de l'engelure, et les désordres prégélifs qui ne font que perturber le métabolisme sans causer de gel. L'engelure survient lorsque la température est inférieure au point de congélation du produit, soit de l'ordre de -3 à $-1{ }^{\circ} \mathrm{C}(204)$. Un gel prononcé entraîne une décoloration vitreuse et un ramollissement général des tissus; les dommages sont alors très apparents. Selon sa durée, un gel modéré peut causer des dommages localisés dans les tissus, notamment le brunissement des éléments fibrovasculaires, ou encore n'entraîner aucun dommage apparent mais faire en sorte que le produit se détériore plus rapidement par la suite. Certains fruits et légumes, comme les pommes, les poires, les carottes, le panais et le chou ne sont pas immédiatement avariés par un gel modéré mais d'autres comme les pommes de terre, le céleri et le chou-fleur sont endommagés par toute formation de glace dans les tissus. Lorsque ces derniers sont exposés au gel, ils prennent une apparence translucide; les zones atteintes sont localisées dans le cas d'un gel peu prononcé. Sous l'effet d'un gel plus sévère, les pommes et les poires deviennent ridées; elles ratatinent et peuvent parfois perdre jusqu'à $10 \%$ de leur volume. Tout produit congelé doit être dégelé rapidement. S'il faut le transporter, il est indiqué de le manipuler avec le plus grand soin pour éviter les meurtrissures susceptibles d'aggraver l'avarie. Toute pression appliquée sur un produit congelé, aussi faible que celle exercée du bout du doigt, produit des zones abimées distinguables après le dégel.

La température des végétaux peut être abaissée pour une brève période sous leur point de congélation (surgélation), sans qu'il y ait formation de glace ou des dommages apparents. La température peut 
ainsi atteindre -5 ou $-6{ }^{\circ} \mathrm{C}$. Ainsi, des poires ont été gardées pendant 6 semaines à $0,5^{\circ} \mathrm{C}$ en-dessous de leur point de congélation sans qu'elles ne gèlent ni ne s'endommagent (114). Les secousses ou vibrations imprimées aux produits surgelés, causent la formation immédiate de glace; par conséquent, la congélation des produits en transit leur cause souvent des avaries inhabituelles et graves.

Les désordres physiologiques prégélifs résultent d'une perturbation du métabolisme consécutive à l'exposition du produit à des températures supérieures au point de congélation des tissus, mais plus basses que normales. Ces avaries peuvent être causées par une brève exposition à des températures critiques inférieures au degré requis pour le produit, pendant l'entreposage, lors du transit et même avant la récolte. La gravité des avaries dépend de la température et de la durée d'exposition. Des dommages sous forme de picots, de décoloration, de flétrissement, de brunissement, de détérioration et de modifications chimiques indésirables sont autant de symptômes de désordres prégélifs. Ceux-ci peuvent se manifester pendant l'entreposage ou peu de temps après la sortie de l'entrepôt. Ils sont un site propice à l'implantation des pathogènes. La température critique au-dessous de laquelle les fruits et les légumes sensibles aux désordres prégélifs peuvent s'avarier (aubergine, haricots verts, concombres, courges et tomates) se situe aux environs de 7 à $13^{\circ} \mathrm{C}(61$, $119,137,164,167)$.

\section{DÉSORDRES DUS AUX PRODUITS CHIMIQUES}

L'exposition à des produits chimiques volatils peut endommager les fruits et les légumes entreposés. Une fuite d'ammoniac frigorigène dans une chambre d'entreposage peut causer des dommages à la surface des fruits et des légumes, particulièrement au niveau des lenticelles (pores) et autres cavités naturelles. Une exposition à une concentration d'ammoniac de seulement $0,8 \%$, fut-elle $1 \mathrm{~h}$, endommage gravement les pommes, les poires, les bananes, les pêches et les oignons. Une exposition plus longue à une concentration d'ammoniac à peine décelable à l'odorat, peut causer des dommages $(106,159)$. La décoloration des pigments près des lenticelles des pommes et des poires, causée par l'ammoniac ne peut être réversible si la durée d'exposition et la concentration ne sont pas trop grandes et si l'entrepôt est bien aéré aussitôt qu'une fuite est décelée. Les petites fuites de fluide réfrigérant du type Freon sont normalement inoffensives, mais plusieurs rapports récents indiquent que des pommes ont été endommagées (zone régulière, creuse, à la surface des fruits) par de fortes fuites de Freon. 
Le paraffinage des fruits et des légumes frais sert surtout à rehausser leur apparence et à favoriser leur rétention en eau lors de la mise en marché $(66,69,149)$. La paraffine est habituellement appliquée à la sortie de l'entrepôt après le nettoyage et le parage des produits destinés à l'emballage. Parfois, les pommes et les poires sont remises en entrepôt après avoir été paraffinées et emballées. Le navet, et quelquefois le panais, peuvent être enduits de paraffine chaude $\left(120\right.$ à $\left.135^{\circ} \mathrm{C}\right)$ contenant $1 \%$ d'huile de paraffine (53). Un autre procédé, utilisé quelquefois pour les légumes tels les carottes, les betteraves, les concombres et les tomates, consiste à appliquer la paraffine en émulsion froide, au pinceau ou par pulvérisation. La plupart des pommes et des poires emballées au Canada et aux États-Unis, sont, de nos jours, enrobées d'une émulsion froide de cire de carnauba, de paraffine et, parfois, de laque (172).

Le paraffinage des pommes et des poires réduit les pertes d'eau et améliore leur apparence, particulièrement dans le cas des pommes rouges. Le niveau interne de gaz carbonique et d'éthylène est plus élevé dans les pommes cirées, mais il semble n'avoir que peu d'effets sur le degré d'acidité, la fermeté, les solides solubles et les désordres physiologiques (116). La qualité des guignes peut aussi être maintenue en les enrobant d'émulsions à base de laque ou d'émulsions de polysaccharide-protéine-huile (95). Le paraffinage des guignes empêche les pertes d'eau du fruit, la décoloration et le dessèchement du pédoncule et l'apparition des dommages mécaniques causés par ce dernier aux autres fruits. Le paraffinage des cerises prolonge aussi la durée du fruit sur les tablettes tout en rehaussant son éclat.

\section{PELLICULES DE PLASTIQUE}

L'utilisation de pellicules de plastique transparentes de tous genres est très répandue pour l'emballage des produits vendus au détail. On ne peut alors entreposer le produit que pour une courte durée; ordinairement, cette pellicule assure amplement la transmission des gaz et de la vapeur d'eau $(190,191)$.

Lorsqu'on utilise une pellicule de plastique, habituellement du polyéthylène de $38 \mu \mathrm{m}$ d'épaisseur, pour doubler les caisses de fruits durant l'entreposage frigorifique, il faut porter une plus grande attention aux caractéristiques d'échange des gaz (67). A l'origine, les doublures de plastique avaient été mises à l'essai pour créer une atmosphère modifiée à l'intérieur de l'emballage. Comme les niveaux de gaz carbonique peuvent parfois être dommageables, ce procédé est presque exclusivement utilisé pour les guignes, qui supportent des teneurs élevées en gaz carbonique et de faible teneur en oxygène. 
Eaves (38) a développé le procédé de l'insertion de sachets de chaux dans les doublures des caisses scellées pour neutraliser le gaz carbonique, mais cette technique n'est pas très répandue. Cependant, la pomme Golden Delicious et les poires Bartlett et Anjou sont couramment emballées dans des caisses doublées de polyéthylène perforé pour prévenir les pertes d'eau.

À la sortie de l'entrepôt, il faut absolument ouvrir d'un bout à l'autre les doublures scellées des caisses de cerises et autres produits. Lorsqu'elles arrivent à leur processus de maturation, les poires respirent intensément; pour cette raison, les doublures perforées des caisses sont éventrées à leur sortie de l'entrepôt frigorifique. Les doublures en polyéthylène, à multiples perforations minuscules, balancent de façon adéquate les échanges d'humidité et de gaz respiratoire entre le fruit et l'atmosphère de l'entrepôt frigorifique; ils ne conviennent cependant pas pour l'entreposage en atmosphère contrôlée (AC). Lorsque ces doublures servent pour l'entreposage en $\mathrm{AC}$ des fruits emballés, des trous additionnels sont nécessaires, particulièrement pour les poires, afin d'empêcher la teneur en gaz carbonique de dépasser le seuil critique, qui peut être aussi bas que $2 \%$.

\section{MESURES D'HYGIÈNE DANS LES ENTREPÔTS}

Les microorganismes à l'origine des moisissures et pourritures sont parfois une source d'ennui dans les entrepôts. Ils s'attaquent aux contenants et aux autres structures en bois et ils dégagent une odeur nauséabonde qui peut altérer le goût des produits entreposés. Il est difficile de s'en débarrasser complètement mais des mesures d'hygiène peuvent en limiter l'expansion, par exemple retirer au fur et à mesure les produits avariés des caisses partiellement atteintes. Le moyen le plus efficace de tenir l'entrepôt propre, c'est de le nettoyer à fond dès qu'il est vide et d'attendre plusieurs jours avant de le remplir à nouveau. Utiliser à cette fin un agent tel une solution à $1 \%$ de phosphate trisodique, puis pulvériser une solution d'hypochlorite de calcium ou de sodium contenant $0,8 \%$ de chlore (49). L'application d'une peinture fongicide assure une protection additionnelle après le nettoyage (81). L'élément fongicide a un effet rémanent. Dans les entrepôts de pommes de terre, un composé quaternaire d'ammonium est couramment utilisé pour pulvériser les surfaces intérieures. Avant le lavage ou la pulvérisation, il faut recouvrir toutes les installations électriques, de même que toute structure métallique si l'on emploie des substances corrosives. Le maintien d'une bonne ventilation et d'une température élevée dans les entrepôts non utilisés aide à réduire la croissance des moisissures.

Ni l'ozone, ni la lumière ultra-violette ne restreignent efficacement la croissance des microorganismes, pas plus qu'ils n'améliorent les 
conditions d'entreposage. Des concentrations, même faibles, d'ozone sont délétères et peuvent endommager certains produits à des concentrations aussi basses que $0,5 \mathrm{ppm}$.

Les filtres à air au charbon activé empêchent les odeurs de se développer dans les chambres d'entreposage mixte pouvant renfermer des fruits, des légumes, des oeufs et des produits laitiers.

\section{ENTREPOSAGE MIXTE}

Bien que certains produits exigent le même degré de température et d'humidité, il n'est pas toujours désirable de les entreposer ensemble dans la même pièce. Des restrictions s'imposent très fréquemment, du fait que certains produits dégagent des substances volatiles susceptibles de nuire à d'autres produits. Les pommes, les poires, les pêches, les prunes, les abricots et les tomates dégagent de l'éthylène qui, même à faible concentration, peut provoquer la germination des pommes de terre, des carottes et des oignons, causer du blanchiment, du jaunissement ou des désordres aux légumes feuillus tels que le chou, la laitue, le céleri et le chou de Bruxelles, ou encore donner un goût amer aux carottes. Ces deux groupes de produits ne doivent donc pas être entreposés dans la même pièce, ni dans le même bâtiment, à moins de prévoir des mesures spéciales de ventilation. Les pommes de terre donnent parfois une saveur de terre aux fruits, surtout à des températures élevées. Règle générale, les produits laitiers ne sont pas entreposés avec les fruits et les légumes.

\section{ENTREPOSAGE EN ATMOSPHÈ RE CONTRÔLÉE}

L'entreposage en atmosphère contrôlée $(\mathrm{AC})$ est le nom donné à la technique qui permet de maintenir à des taux constants la composition gazeuse de l'atmosphère de l'entrepôt aussi bien que sa température. L'air est composé de $78 \%$ d'azote, de $21 \%$ d'oxygène, de $0,03 \%$ de gaz carbonique et de quantités minimes de plusieurs autres gaz n'ayant aucune importance physiologique. En AC, la teneur en oxygène peut être abaissée jusqu'à $1 \%$ et celle du gaz carbonique portée à $5 \%$ ou plus selon les besoins particuliers du produit entreposé. Les teneurs en oxygène excédant $5 \%$ ne retardent guère la sénescence; une teneur de $2 \%$ en oxygène semble un minimum relativement universel pour l'AC classique. Dans les entrepôts où un bon contrôle des gaz est assuré, un niveau d'oxygène de $2,5 \%$ semble acceptable. Toutefois, des teneurs très faibles en oxygène, de 1,0 à $1,5 \%$, améliorent la qualité du produit stocké, mais ces teneurs doivent être utilisées avec précaution, soit dans les seuls entrepôts où il est possible de contrôler la teneur de l'oxygène avec une précision de 
$\pm 0,1 \%$. Un échantillonneur et un régulateur automatisés d'oxygène sont recommandés pour le contrôle de l'oxygène à de très faibles teneurs. Un pourcentage accru de l'accumulation du gaz carbonique dans l'atmosphère de l'entrepôt $\mathrm{AC}$ est un facteur important de succès lorsque les teneurs en oxygène dépassent $2 \%$. La tolérance au gaz carbonique peut cependant être limitative pour certains produits; cette tolérance varie selon la saison de croissance au champ, la teneur en oxygène de l'atmosphère en entrepôt et d'autres facteurs indéterminés. La concentration en gaz carbonique donnée au tableau 1 est quelquefois inférieure au niveau optimal mais peut être employée à peu près sans danger pour le produit. Tableau 1. Conditions d'entreposage en atmosphère contrôlée
de certains cultivars de pommes et de poires

Cultivars

Gaz carbonique

$(\%)$
Oxygène

$(\%)$

Température

$\left({ }^{\circ} \mathrm{C}\right)$

McIntosh*

Delicious*

Empire

Golden Delicious*

Idared

Rome Beauty

Northern Spy

Stayman Winesap

Spartan*

Newtown

Jonathan

Baldwin

Macoun

Bartlett

Bosc*

d'Anjou*

Clapps Favorite $5,0^{\dagger}$

$1,5-2,0$

$0,5-1,0$

$2,0-3,0$

$0,5-1,0$

$2,0-3,0$

2,0

5,0

2,0

3,0

$3,0-5,0$

$2,0-3,0$

5,0

$1,5-2,0$

$0,5-1,0$

$1,5-2,0$

$0,0-1,0$
2,5

2,5

2,5

2,5

2,5

2,5

2,5

2,5

2,5

2,5

2,5

2,5

2,5

2,5

2,5

2,5

2,0
2,0 à $3,5 \dagger$

$-0,5$ à 0,0

1,0 à 1,5

$-0,5$ à 0,0

0,0

0,0

0,0

$-0,5$

$-0,5$ à 0,0

2,0

0,0

0,0

3,5

$-1,0$ à 0

$-1,0$ à 0

$-1,0$ à 0

0,0

* La qualité du fruit peut être préservée davantage en entreposant ces cultivars dans $0-2 \%$ de $\mathrm{CO}_{2}+1,0-1 \%$ de $\mathrm{O}_{2}$ ou aux températures suggérées. Toutefois, ces recommandations ne sont que proposées et ne devraient pas être suivies sans essais préliminaires.

†En Colombie-Britannique, on recommande $2 \%$ de gaz carbonique au cours du premier mois; on a constaté qu'une température de $1,5^{\circ}-2,5^{\circ} \mathrm{C}$ est plus appropriée en Colombie-Britannique. 


\section{UTILISATION DE L'AC}

L'AC est utilisée surtout pour les pommes, même si cette technique peut également servir pour d'autres fruits (poires, guignes) et quelques légumes (chou). L'avantage de cette méthode comparée à l'entreposage frigorifique apparaît de plus en plus à mesure que se prolonge la période de conservation. Les divers cultivars de pommes ne bénéficient pas tous également de l'AC. Cependant, l'AC peut atténuer la plupart des désordres physiologiques tels l'échaudure, le coeur brun, la tache de la Jonathan et le blettissement de la chair; l'AC ralentit aussi la pourriture. Par exemple, la tache de la Jonathan peut être prévenue par une concentration de gaz carbonique aussi faible que $0,5 \%$ (36). L'AC permet de conserver l'acidité de tous les cultivars de pommes, ce qui améliore la qualité des cultivars à faible teneur en acide après entreposage prolongé $(127,155)$. Mais l'AC n'est pas aussi favorable à tous les cultivars de pommes. Par exemple, un entreposage $\mathrm{AC}$ prolongé peut détruire partiellement ou même modifier la saveur particulière de certains cultivars et ne pas ralentir le ramollissement comme espéré (99). C'est le cas des cultivars Winesap, Délicieuse et Golden Delicious (Délicieuse jaune) qui sont entreposés avec succès qu'à des températures d'environ $-0,5^{\circ} \mathrm{C}$.

Diverses recherches récentes ont permis d'améliorer les techniques d'entreposage sous $\mathrm{AC}$ et d'obtenir des pommes de meilleure qualité après entreposage. Les exploitants d'entrepôt d'AC, désireux d'améliorer la rétention de la qualité du fruit entreposé et de prolonger la saison de vente, ont acquis de nouveaux équipements plus raffinés. Ainsi, ils réalisent de l'entreposage en AC très pauvre en oxygène ( $1,0-1,5 \%$; ou pauvre en éthylène; ils baissent rapidement l'oxygène (à la fermeture de l'entrepôt); ils utilisent l'atmosphère modifiée avec enrobage comestible des fruits et l'entreposage en AC programmée.

\section{AC TRÈS PAUVRE EN OXYGÈNE}

L'entreposage en milieu très pauvre en oxygène se fait dans des chambres d'AC étanches à l'air (essai de 20 minutes, figure 3), au moyen d'épurateurs de gaz carbonique et par un réglage de l'oxygène. La technique est simple : la teneur en oxygène de l'entrepôt est réduite de $2-3 \%$ à $1,0-1,5 \%$. En termes physiologiques, une teneur de $1,0 \%$ en oxygène est inférieure au seuil requis pour un ramollissement rapide des fruits, et n'altère ni la texture du fruit ni les acides titrables des cultivars McIntosh, Cortland, Golden Delicious, Spartan et Red Delicious $(88,96,100,126)$. Les McIntosh semblent les plus vulnérables aux faibles teneurs en oxygène, mais les dommages peuvent être évités ou minimisés par la sélection de lots 
de fruits préclimactériques à forte teneur en calcium et en phosphore. L'entreposage en atmosphère très pauvre en oxygène est utilisé commercialement depuis 1981 dans le sud de l'Ontario et s'avère de plus en plus rentable d'une année à l'autre. Les principaux avantages de la commercialisation de cette technique sont : une meilleure rétention de la fermeté du fruit et de ses acides titrables; une réduction de 5 à $10 \%$ des meurtrissures lors du tri et de l'empaquetage chez les pommes traditionnellement molles (McIntosh et Golden Delicious); et la possibilité d'approvisionner le marché tout au long de l'année pour les entreposeurs disposant de réserves suffisantes. Les inconvénients de l'AC très pauvre en oxygène sont: les risques de détérioration et de pertes liés à la faible teneur en oxygène; le court écart de temps où le

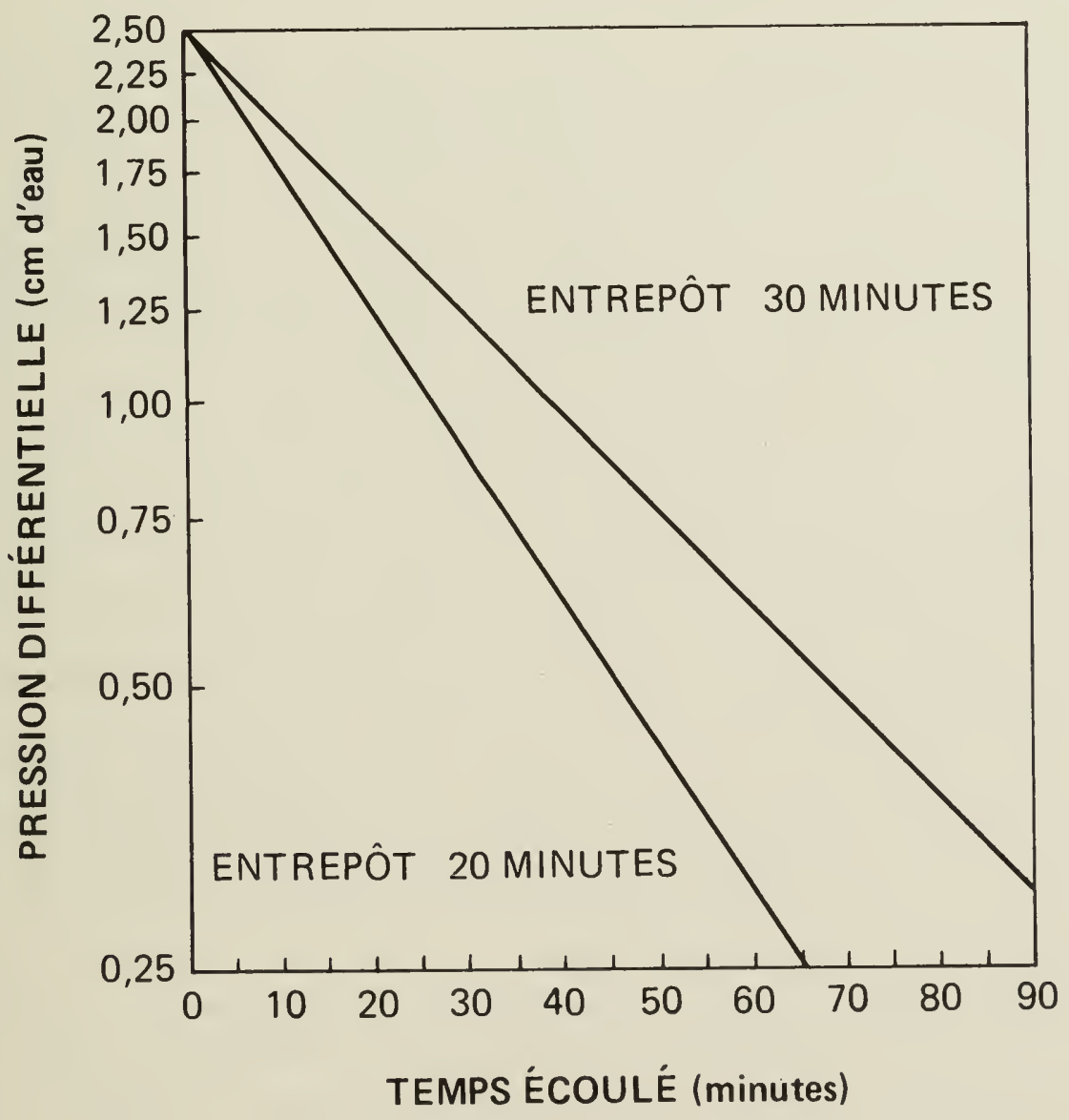

Figure 3. Chute de la pression en fonction du temps lors de la vérification de l'étanchéité d'une chambre à atmosphère contrôlée (11) 
fruit a la maturité requise pour être cueilli; la nécessité de cueillir des fruits préclimactériques et donc pas suffisamment mûrs pour une qualité optimale; et les pertes de saveur caractéristiques de l'entreposage prolongé. En dernière analyse, l'entreposage AC pauvre en oxygène est profitable que si les risques d'avarie ne dépassent pas $10 \%$ du produit total entreposé. Un conditionneur qui expérimente l'entreposage en $\mathrm{AC}$ pauvre en oxygène pour la première fois devrait consulter les autorités locales pour obtenir des conseils pertinents à cette région. Des essais à petite échelle plutôt qu'à échelle commerciale devraient être menés pendant plusieurs années pour permettre à l'entreposeur d'évaluer quels sont ses risques d'avarie en milieu très pauvre en oxygène. L'utilisation d'un échantillonneur et d'un contrôleur automatisés d'oxygène pour régler la teneur de l'atmosphère d'entreposage en oxygène à $\pm 0,1 \%$ près est souhaitable.

\section{AC PAUVRE EN ÉTHYLÈNE}

L'éthylène $\left(\mathrm{C}_{2} \mathrm{H}_{4}\right)$ est un gaz qui agit à la façon d'une hormone de mûrissement. Ce gaz est généré et dégagé par le fruit et son action est autocatalytique. L'AC pauvre en éthylène est utilisée pour les McIntosh; elle reprend la composition gazeuse de l'AC classique (5,0\% $\mathrm{CO}_{2}+2,5-3 \% \mathrm{O}_{2}, 3{ }^{\circ} \mathrm{C}$ ) mais nécessite la sélection d'un fruit préclimactérique qui est refroidi immédiatement, et une diminution de l'oxygène dans les 3 à 5 jours qui suivent le début de la récolte du fruit. Les pommes McIntosh doivent recevoir au milieu de l'été une application de daminozide à $1000 \mathrm{ppm}$, puis être cueillies à l'état préclimactérique (indice d'amidon 2-4) (52, 150, 177); ensuite, elles sont refroidies et scellées dans les 5 jours qui suivent la récolte; la teneur atmosphérique du $\mathrm{C}_{2} \mathrm{H}_{4}$ doit être maintenue au-dessous de $1 \mathrm{ppm}$ pour préserver la fermeté du fruit et conserver ses acides titrables (107). Par cette méthode, la texture de la McIntosh augmente de 4 à 18 Newtons (N) (1 à $4 \mathrm{lb}-\mathrm{f})$ avec une amélioration moyenne de la fermeté de 4 à $11 \mathrm{~N}$ (1 à 2,5 lb-f). Ce traitement d'entreposage s'avérera profitable pour l'entreposeur à condition de pouvoir disposer d'un lessiveur d'éthylène commercial économique et efficace. Plusieurs lessiveurs intéressants sont expérimentés actuellement dans divers centres de recherche.

Jusqu'ici, une meilleure qualité de la McIntosh a pu être maintenue en ayant recours à une $\mathrm{AC}$ pauvre en éthylène, dans de petits entrepôts expérimentaux ou semi-commerciaux. Toutefois, l'élimination du $\mathrm{C}_{2} \mathrm{H}_{4}$ des entrepôts commerciaux de 200 ou $400 \mathrm{t}$ est difficile à cause du très grand volume d'espace libre, de l'importante production potentielle du $\mathrm{C}_{2} \mathrm{H}_{4}$ par les fruits et du besoin de maintenir le $\mathrm{C}_{2} \mathrm{H}_{4}$ en bas de $1 \mathrm{ppm}$ dans l'atmosphère. Ces contraintes physiques nécessitent la mise au point d'un lessiveur de $\mathrm{C}_{2} \mathrm{H}_{4}$ très efficace. 
Deux méthodes pour éliminer le $\mathrm{C}_{2} \mathrm{H}_{4}$ sont employées actuellement: l'élimination chimique par oxydation du $\mathrm{C}_{2} \mathrm{H}_{4}$ à l'aide de permanganate de potassium sur un vecteur inerte; et la combustion catalytique du $\mathrm{C}_{2} \mathrm{H}_{4}$ sur un catalyseur à température élevée $\left(200-680^{\circ} \mathrm{C}\right)$. L'élimination du $\mathrm{C}_{2} \mathrm{H}_{4}$ par combustion catalytique est très efficace et des moyens sont à l'étude pour réduire la charge de chaleur que cette technique impose au système de réfrigération. Des recommandations devraient être faites d'ici peu.

\section{AC RAPIDE}

L'AC rapide désigne un ensemble de procédures qui consistent à réduire au minimum les étapes de chargement d'une chambre $\mathrm{AC}$, de la récolte au champ à la mise en régime gazeux. Ceci inclut la cueillette des fruits, le remplissage et la fermeture de la chambre AC, le refroidissement du produit et la réduction de l'oxygène à $3 \%$. Des travaux récents sur la Golden Delicious ont comparé l'AC rapide fait en moins de 7 jours aux $\mathrm{AC}$ classiques, où la respiration des fruits abaisse l'oxygène aux conditions voulues en 21 jours environ à partir de la fermeture de la chambre $(88,89,90)$. Une meilleure rétention de la fermeté du fruit de 4 à $11 \mathrm{~N}(1$ à $2,5 \mathrm{lb}-\mathrm{f})$ et une augmentation des acides titrables de 2 à $3 \%$ ont été notées en réduisant rapidement la teneur en oxygène à 2 ou $3 \%$ par purge à l'azote ou par combustion catalytique. Chez la McIntosh, une chute rapide de l'oxygène de l'entrepôt en 1 jour au lieu de 10 à $0{ }^{\circ} \mathrm{C}\left(3^{\circ} \mathrm{C}\right.$ pendant la réduction de l'oxygène) n'améliore pas constamment la texture et la rétention des acides titrables. La provenance du lot de fruits et la saison de croissance influencent grandement les résultats (181, données non publiées). Toutefois, des temps d'abaissement de la teneur en oxygène excédant 10 jours après la récolte donnent des McIntosh plus molles contenant moins d'acides titrables et d'une qualité inférieure, en plus de réduire la durée potentielle d'entreposage. Il faut insister sur le fait que l'intervalle maximal de 10 jours entre la récolte et le moment où la teneur en oxygène dans l'entrepôt est réduite à $3 \%$ inclut aussi le temps de récolte, d'entreposage, de refroidissement du produit jusqu'à moins de $5{ }^{\circ} \mathrm{C}$ ou moins, et de fermeture des portes. En résumé, pour obtenir une mise en régime gazeux typique d'AC rapide, il faut refroidir tous les fruits immédiatement après leur récolte, les charger et les sceller dans l'entrepôt aussitôt que possible, puis réduire la teneur en oxygène soit par purge à l'azote ou par combustion catalytique. 


\section{ATMOSPHËRE MODIFIÉE}

En entreposage sous atmosphère modifiée (AM), la composition de l'atmosphère diffère de celle de l'air mais elle n'est pas contrôlée à des niveaux précis. L'AM peut être réalisée à l'aide d'une pellicule en plastique qui enveloppe les contenants de produits destinés à l'expédition (voir section pellicule en plastique) ou à la taille du fruit par enrobage. Dans les deux cas, la composition gazeuse est établie par la seule respiration du produit.

Dans plusieurs régions du Canada où la pomme est cultivée, certains entreposeurs indépendants disposent d'un approvisionnement ou d'un capital insuffisant pour construire leur propre entrepôt à $\mathrm{AC}$. Dans ces circonstances, il est possible de substituer l'entreposage sous AC, à l'AM car un enrobage comestible peut être appliqué sur les fruits gardés au froid. Cet enrobage est apposé par immersion ou par vaporisation et il agit tel une barrière à la surface du fruit pour empêcher en partie l'oxygène d'entrer dans le fruit et le gaz carbonique d'en sortir. En choisissant un enrobage approprié au produit à entreposer, il est possible de simuler diverses conditions AC. Toutefois, comme l'effet atmosphérique final dépend du taux respiratoire de chaque fruit et de sa perméabilité épidermique, on observe de grandes variations de compositions gazeuses d'un fruit à l'autre en AM comparativement à l'AC traditionnelle. Des recherches sont actuellement en cours pour corriger les effets variables de l'enrobage et pour déterminer son potentiel d'application commerciale. Des enrobages semi-perméables de pommes et de poires dans des conditions de laboratoire montrent toutefois une rétention importante et constante de la fermeté du fruit et des acides titrables dans les entrepôts frigorifiques.

\section{AC PROGRAMMÉE}

La McIntosh, la Spartan et la Golden Delicious sont résistantes aux avaries causées par le manque d'oxygène au début de la saison d'entreposage et peuvent tolérer $1 \%$ d'oxygène ou moins pendant un temps considérable. Toutefois, un lot particulier peut souffrir du manque d'oxygène s'il est exposé pendant toute la saison d'entreposage. De plus, il a été montré que l'exposition des pommes à $1,0 \%$ d'oxygène pendant 40 jours ou plus peut induire dans le fruit des changements qui retardent le ramollissement même après que le fruit a été retiré du milieu pauvre en oxygène (fig. 4). L'entreposage en AC programmée offre ces avantages et comporte au moins deux régimes d'atmosphère distincts au cours de la saison d'entreposage. Des données préliminaires indiquent qu'une exposition initiale des pommes McIntosh à $1,5 \%$ de $\mathrm{CO}_{2}+1,0 \%$ de $\mathrm{O}_{2}$ pendant 2,5 mois, 
puis à $5 \%$ de $\mathrm{CO}_{2}+2,5-3 \%$ de $\mathrm{O}_{2}$ pendant 5 autres mois donne un fruit d'une qualité comparable à celle des pommes entreposées dans $1,5 \%$ de $\mathrm{CO}_{2}+1,0 \%$ de $\mathrm{O}_{2}$ pendant une période d'entreposage totale de 7,5 mois. Avec cette technique, une exposition de courte durée peut donner un fruit d'une texture semblable à celle d'une exposition prolongée dans une atmosphère très pauvre en oxygène, mais avec l'avantage que les risques d'avaries causées par le manque d'oxygène et les pertes de saveur caractéristiques de l'AC pauvre en oxygène sont réduits.

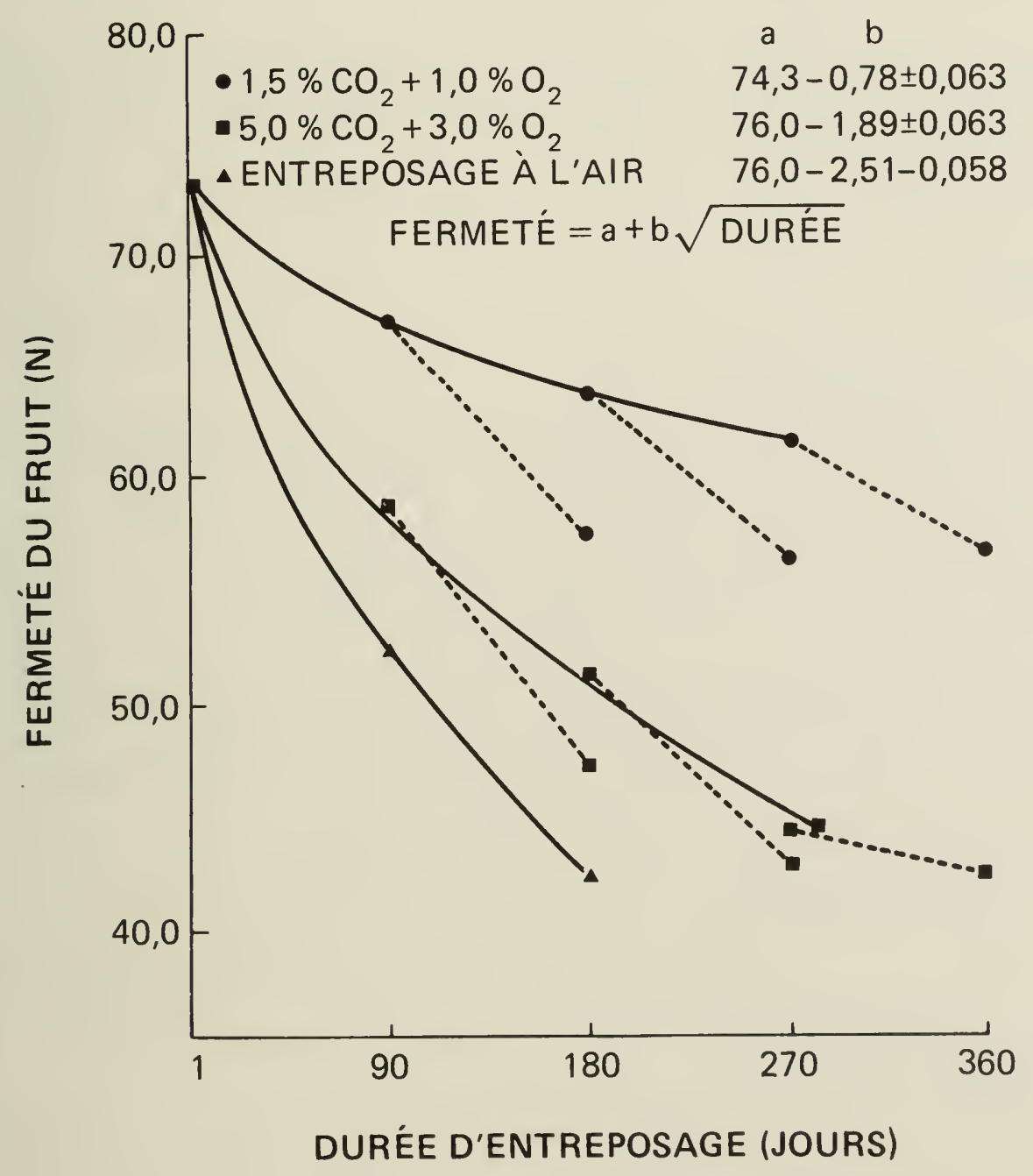

Figure 4. Perte de fermeté des pommes McIntosh entreposées initialement dans des atmosphères contrôlées et à l'air et perte subséquente de fermeté durant l'entreposage additionnel à l'air (...). (Tiré de : Lidster et al., 1984). Can. Inst. Food. Sci. Technol. J. 17:086-091). 
Les travaux récents de recherche sur l'AC fournissent une variété de choix pour améliorer la qualité finale du produit et allonger la saison commerciale de la pomme. 'Toutefois, chaque option nécessite une amélioration de régie des entrepôts et, dans certains cas, un investissement supplémentaire en capital. Nul doute que chacune des techniques discutées ci-dessus améliore le produit et est profitable; mais c'est sur une base économique que ce choix d'une technique doit être fait en tenant compte du prix du produit, de la concurrence sur le marché et des moyens de chaque entreposeur.

\section{CONDITIONS D'ENTREPOSAGE DES FRUITS}

Le tableau 2 ainsi que les pages suivantes contiennent des recommandations touchant l'entreposage de la plupart des fruits cultivés au Canada.

\section{ABRICOTS}

Température : $-1,0$ à $0,0^{\circ} \mathrm{C}$

Humidité relative : 85 à $95 \%$

La durée d'entreposage des abricots est courte; elle dépend du cultivar et de la maturité au moment de la récolte. Un fruit mou à maturité peut être entreposé au maximum deux semaines, tandis qu'un fruit ferme et bien coloré peut être entreposé de 2 à 4 semaines. Un entreposage prolongé entraîne des pertes de saveur, favorise la pourriture et empêche les abricots de mûrir. Les fruits les plus sensibles à ces avaries sont ceux qui ont été cueillis et entreposés alors qu'ils n'étaient pas assez mûrs. Un phénomène particulier aux abricots et aux pêches en entrepôt frigorifique est le développement d'une texture cotonneuse et sèche. Ce phénomène se produit surtout lorsque le fruit a été entreposé trop longtemps à basse température et principalement s'il n'était pas assez mûr. Cette texture cotonneuse peut être évitée, et la durée de l'entreposage au froid des abricots prolongée à cinq ou six semaines, par un réchauffement périodique du fruit ( 48 heures à $20^{\circ} \mathrm{C}$ toutes les 2 à 3 semaines d'entreposage) ou par un entreposage en $\mathrm{AC}$ ( 3 à $5 \%$ gaz carbonique plus 2 à $5{ }^{\circ} \mathrm{C}$ avec une température de -1 à $0{ }^{\circ} \mathrm{C} ; 31,102$ ). Pour obtenir de meilleurs résultats en entrepôt, il faut cueillir les abricots aussi mûrs que le permettent la manipulation et l'emballage. Pour éviter la moniliose causée par Monilinia spp., les abricots peuvent être enduits de bénomyl (Benlate), par immersion ou par vaporisation, aussitôt après la cueillette. 
Tableau 2. Durée, température et humidité relative d'entreposage recommandées, et point maximal de congélation des fruits frais

\begin{tabular}{|c|c|c|c|c|}
\hline & & & & $\begin{array}{l}\text { Point de } \\
\text { ongélation }\end{array}$ \\
\hline Fruits & $\begin{array}{c}\text { Température } \\
\left({ }^{\circ} \mathrm{C}\right)\end{array}$ & $\begin{array}{l}\text { Humidité } \\
\text { relative } \\
(\%)\end{array}$ & $\begin{array}{c}\text { Durée } \\
\text { approximative } \\
\text { dentreposage }\end{array}$ & $\underset{\left.\operatorname{maxi}^{\circ} \mathrm{C}\right)}{\max }$ \\
\hline
\end{tabular}

\begin{tabular}{|c|c|c|c|c|}
\hline Abricots & 0,0 & $85-95$ & 1 à 2 semaines & $-1,1$ \\
\hline Bleuets & 0,0 & $85-95$ & 2 à 4 semaines & $-0,8$ \\
\hline Canneberges & $2,0-4,5$ & $80-90$ & 2 mois & $-0,8$ \\
\hline $\begin{array}{l}\text { Cerises, sucrées } \\
\text { sûres }\end{array}$ & $\begin{array}{l}0,0 \\
0,0\end{array}$ & $\begin{array}{l}85-95 \\
85-95\end{array}$ & $\begin{array}{l}3 \text { à } 4 \text { semaines } \\
\text { quelques jours }\end{array}$ & $\begin{array}{l}-1,8 \\
-1,7\end{array}$ \\
\hline Fraises & 0,0 & $85-95$ & 5 à 10 jours & $-0,8$ \\
\hline Frambroises & 0,0 & $85-95$ & quelques jours & $-1,1$ \\
\hline \multirow{2}{*}{$\begin{array}{l}\text { Melons, } \\
\text { brodés (canta- } \\
\text { loups) } \\
\text { d'eau } \\
\text { (pastèques) } \\
\text { honeydew }\end{array}$} & $0,0-7,0$ & $85-90$ & 2 semaines & $-0,8$ \\
\hline & $\begin{array}{l}2,0-4,5 \\
7,0-10,0\end{array}$ & $\begin{array}{l}85-90 \\
85-90\end{array}$ & $\begin{array}{l}2 \text { à } 3 \text { semaines } \\
2 \text { à } 3 \text { semaines }\end{array}$ & $\begin{array}{l}-0,4 \\
-1,1\end{array}$ \\
\hline Mûres & 0,0 & $85-95$ & quelques jours & $-0,8$ \\
\hline Pêches & 0,0 & $85-95$ & 2 semaines & $-0,9$ \\
\hline \multirow{2}{*}{$\begin{array}{l}\text { Poires } \\
\text { Bartlett } \\
\text { cultivars d'auton } \\
\text { et d'hiver }\end{array}$} & mne & $85-95$ & 2 à 3 mois & $-1,6$ \\
\hline & $-1,0$ & $85-95$ & 3 à 5 mois & $-1,7$ \\
\hline Pommes & $-0,5 \dagger$ & $85-96$ & $\begin{array}{l}\text { selon le cultivar } \\
\text { et la méthode } \\
\text { d'entreposage }\end{array}$ & $-1,7$ \\
\hline $\begin{array}{l}\text { Prunes, (y compris } \\
\text { les pruneaux) }\end{array}$ & 0,0 & $85-95$ & $\begin{array}{l}\text { pruneaux } \\
4 \text { à } 6 \text { semaines } \\
\text { prunes, voir texte }\end{array}$ & $-1,3$ \\
\hline $\begin{array}{l}\text { Raisins } \\
\text { d'Amérique }\end{array}$ & 0,0 & $85-95$ & 1 mois & $-1,3$ \\
\hline
\end{tabular}

* Certains chiffres sont tirés de l'ouvrage de référence 128. Les points maximaux de congélation indiquent les limites inférieures de sécurité.

+Voir également le tableau 1. 
Tableau 3. Périodes d'entreposage normale et maximale de certains cultivars communs de pommes et sensibilité de ces fruits aux désordres d'entreposage

\begin{tabular}{|c|c|c|c|c|}
\hline \multirow[t]{2}{*}{ Cultivar } & \multicolumn{2}{|c|}{$\begin{array}{l}\text { Période } \\
\text { d'entreposage } \\
\text { (mois) }\end{array}$} & \multirow[t]{2}{*}{$\begin{array}{c}\text { Risque } \\
\text { d'échaudure }\end{array}$} & \multirow[t]{2}{*}{$\begin{array}{l}\text { Autres désordres } \\
\text { possibles }\end{array}$} \\
\hline & normale & $\max$ & & \\
\hline Gravenstein & $0-1$ & 3 & minime & $\begin{array}{l}\text { tache amère, tache } \\
\text { de la Jonathan }\end{array}$ \\
\hline Wealthy & $0-1$ & 3 & minime & $\begin{array}{l}\text { échaudure à chair } \\
\text { molle, tache de la } \\
\text { Jonathan }\end{array}$ \\
\hline Grimes Golden & $2-3$ & 4 & sérieux & $\begin{array}{l}\text { blettissement, tache } \\
\text { amère, ratatinage }\end{array}$ \\
\hline Jonathan & $2-3$ & 4 & minime & $\begin{array}{l}\text { tache de la } \\
\text { Jonathan, coeur } \\
\text { aqueux, échaudure } \\
\text { à chair molle, }\end{array}$ \\
\hline McIntosh & $2-4$ & $4-5$ & minime & $\begin{array}{l}\text { coeur brun, } \\
\text { blettissement }\end{array}$ \\
\hline Empire & $3-4$ & 5 & moyen & $\begin{array}{l}\text { blettissement, } \\
\text { désordres prégélifs }\end{array}$ \\
\hline $\begin{array}{l}\text { Cortland } \\
\text { Spartan } \\
\text { Rhode Island }\end{array}$ & $\begin{array}{c}3-4 \\
4\end{array}$ & $\begin{array}{l}5 \\
5\end{array}$ & $\begin{array}{l}\text { moyen } \\
\text { très minime }\end{array}$ & $\begin{array}{l}\text { blettissement } \\
\text { blettissement }\end{array}$ \\
\hline Greening & $3-4$ & 6 & grave & $\begin{array}{l}\text { tache amère, blet- } \\
\text { tissement interne }\end{array}$ \\
\hline Délicieuses & $3-4$ & 6 & $\begin{array}{l}\text { de minime } \\
\text { à moyen }\end{array}$ & $\begin{array}{l}\text { tache amère, coeur } \\
\text { aqueux, blettisse- } \\
\text { ment interne }\end{array}$ \\
\hline Stayman & $4-5$ & 5 & grave & coeur aqueux \\
\hline $\begin{array}{l}\text { York Imperial } \\
\text { Idared }\end{array}$ & $\begin{array}{l}4-5 \\
4-5\end{array}$ & $\begin{array}{c}5-6 \\
6\end{array}$ & grave & tache amère \\
\hline Northern Spy & $\begin{array}{l}4-5 \\
4-5\end{array}$ & 6 & minime & tache amère \\
\hline Rome Beauty & $4-5$ & $6-7$ & minime & $\begin{array}{l}\text { tache amère, coeur } \\
\text { brun, échaudure à } \\
\text { chair molle, blet- } \\
\text { tissement interne, } \\
\text { tache de la } \\
\text { Jonathan }\end{array}$ \\
\hline Newtown & $5-6$ & 8 & minime & $\begin{array}{l}\text { tache amère, blet- } \\
\text { tissement interne }\end{array}$ \\
\hline Winesap & $5-7$ & 8 & moyen & coeur aqueux \\
\hline
\end{tabular}




\section{BLEUETS}

Température : $0{ }^{\circ} \mathrm{C}$

Humidité relative : 85 à $95 \%$

La plupart des bleuets ne sont pas prérefroidis; ils sont plutôt triés et emballés immédiatement après la récolte, puis réfrigérés et expédiés à $10^{\circ} \mathrm{C}$. Les fruits qui sont manipulés de cette manière peuvent avoir une durée de 1 à 3 jours après la récolte, ce qui impose une expédition par voie aérienne pour les destinations éloignées. Les bleuets sont très sujets à être attaqués par Botrytis cinerea, Alternaria spp. et Gloeosporium spp., cela empêche habituellement de les garder en étalage ou en entrepôt commercial. Toutefois, les bleuets récoltés avec les pédoncules intacts, au rapport sucre-acide faible, enduits d'un agent de stérilisation en surface ou de fongicide, prérefroidis dans les premières heures après la récolte, et entreposés à $0^{\circ} \mathrm{C}$, ont une durée d'entreposage acceptable de 2 à 4 semaines $(8,29,74,76)$. L'entreposage $\mathrm{AC}$ [20\% de gaz carbonique et $15 \%$ d'oxygène (29)] peut prolonger légèrement la durée de conservation.

\section{CANNEBERGES}

Température : 2,0 à $5^{\circ} \mathrm{C}$

Humidité relative : 80 à $90 \%$

Le risque de pourriture, le ratatinement dû aux pertes d'eau et la détérioration physiologique, limitent la durée d'entreposage des canneberges. Les canneberges peuvent être gardées jusqu'à 2 mois dans un entrepôt ordinaire, refroidi par ventilation à l'air mais elles devraient se conserver jusqu'à 3 ou 4 mois dans un entrepôt frigorifique à une température de 2 à $5{ }^{\circ} \mathrm{C}$. L'entreposage à une température de 7 à $10^{\circ} \mathrm{C}$ pendant plusieurs semaines après la récolte améliore la couleur des canneberges, particulièrement lorsqu'elles ont été cueillies tôt. L'entreposage à une température de près de $0^{\circ} \mathrm{C}$ durant plus de 4 semaines environ peut occasionner du blettissement prégélif. Une cueillette mécanique ou à la main peu soignée, le transport, le triage mécanique et l'emballage peuvent causer des dommages mécaniques aux canneberges qui écourteront leur durée de conservation sur les étagères et accentueront les pertes par pourriture et meurtrissures $(57,115,135)$.

L'entreposage en atmosphère contrôlée ne s'est pas avéré efficace contre la détérioration des canneberges (5) mais l'exposition en atmosphère faite à $100 \%$ d'azote pendant 3 semaines peut réduire la pourriture (109). Les baies entassées dans des récipients étanches ou des entrepôts non aérés peuvent être endommagées par une accumulation de gaz carbonique et un manque d'oxygène. 


\section{CERISES}

Température : $-1,0$ à $0,0^{\circ} \mathrm{C}$

Humidité relative : 85 à $95 \%$

La durée limite d'entreposage des guignes est d'environ 3 semaines et celle des cerises sûres que de quelques jours. La durée d'entreposage des guignes dépend, dans une large mesure, de leur traitement après la cueillette. Parce que les cerises ont une surface relativement grande par rapport à leur volume, elles perdent facilement leur eau; ces pertes surviennent particulièrement si la température après la récolte est élevée. Par temps chaud et sec, les cerises peuvent perdre du poids à raison de $1 \%$ par heure tandis que les pédoncules peuvent perdre jusqu'à $4 \%$ par heure de leur poids (133). Pour éviter le noircissement excessif de la pelure, le brunissement du pédoncule et la détérioration de l'apparence du fruit, les cerises doivent être protégées contre le soleil sitôt cueillies, et conduites à l'entrepôt frigorifique dans les heures qui suivent.

L'entreposage frigorifique des cerises dans des caisses doublées d'un revêtement intérieur en polyéthylène de $38 \mu \mathrm{m}$ ( $1,5 \mathrm{mil})$ permet d'obtenir une atmosphère modifiée de 6 à $9 \%$ de gaz carbonique; cette pratique est efficace pour préserver l'apparence fraîche des fruits et prévenir leur détérioration lors d'entreposage prolongé. Les cerises supportent bien une concentration élevée de gaz carbonique et une concentration faible d'oxygène; il faut cependant éventrer les sacs en polyéthylène à la sortie des fruits de l'entrepôt. L'entreposage des guignes en atmosphère contenant $20 \%$ de gaz carbonique et une teneur normale en oxygène à une température de -1 à $0{ }^{\circ} \mathrm{C}$, limite la pourriture, le brunissement des pédoncules et la perte de fermeté, et peut prolonger la durée de conservation totale jusqu'à 5 ou 6 semaines (133). L'entreposage des cerises sous diverses atmosphères contrôlées n'est pas supérieur à l'entreposage dans les sacs en polyéthylène (154). Toutefois l'entreposage des guignes sous AC très pauvre en oxygène $\left(0 \% \mathrm{CO}_{2}+1,0\right.$ à $\left.2,0 \% 0_{2},-1,0^{\circ} \mathrm{C}\right)$ permet de conserver au fruit sa fermeté, ses acides titratables et l'apparence fraîche des pédoncules verts; ce type d'AC peut prolonger la durée de conservation jusqu'à 5 ou 6 semaines (30).

Les cerises se gâtent facilement lorsque leur durée potentielle de conservation en entrepôt est expirée. En les retirant de l'entrepôt frigorifique pour les placer dans un endroit plus chaud, elles pourrissent très rapidement. Le dichloran s'est révélé efficace contre la pourriture des cerises; il est utilisé régulièrement lorsque les guignes sont refroidies à l'eau glacée ou manipulées à l'état humide pendant le classement et l'emballage. Les cerises emballées à l'état humide doivent être refroidies promptement pour éviter le fendillement. Les guignes et les cerises sures doivent être vaporisées avec de l'iprodione un jour avant la récolte pour réduire la pourriture par la moniliose causée par Monilinia spp. pendant l'entreposage. 
Pour maximiser leur durée d'entreposage et de conservation sur les étagères, de même que leur résistance aux blessures mécaniques (101), les cultivars de cerises sucrées (Bing, Hedelfingen, Lambert, Sam, Ulster et Van) devraient être généralement cueillis lorsqu'ils ont atteint la coloration rouge foncé (comparateur de couleur des cerises : nos 6 à 33) (25). Les guignes cueillies pour la transformation devraient rester sur l'arbre jusqu'à ce qu'elles soient complètement noires (comparateur de couleur no 34). Ces derniers temps, les marchands préfèrent les cerises plus claires (comparateurs de couleur nos 3 à 6) pour la seule raison qu'ils veulent accéder tôt à ce marché lucratif. L'objectif de profits se fait au détriment du consommateur qui se voit offrir des fruits de qualité inférieure (48) (forte acidité et moins de solides solubles) et très vulnérables aux dommages mécaniques (101). Il devient alors difficile de maintenir un prix et une demande suffisante pour des fruits de haute qualité après la première cueillette. Des pédoncules d'un beau vert frais sont considérés sur le marché comme un indice de qualité pour les cerises. Le refroidissement rapide après la cueillette, l'emballage en sacs de polyéthylène ou l'application d'enrobages émulsifiables (95) empêchent la perte d'eau et aide à préserver l'apparence fraîche des fruits.

\section{FRAISES}

Température : $0{ }^{\circ} \mathrm{C}$

Humidité relative : 85 à $95 \%$

Les fraises fraîches peuvent être gardées 10 jours au plus à $0^{\circ} \mathrm{C}$ et à une humidité relative de 85 à $95 \%$. Les fraises placées en entrepôt perdent de leur saveur et de leur éclat (112) mais la durée d'entreposage commercial se termine habituellement dès l'apparition de la pourriture (Botrytis cinerea et Rhizopus). Si la température dépasse $5{ }^{\circ} \mathrm{C}$, la croissance de la moisissure Phytophthora s'accélère.

Le prérefroidissement (extraction rapide de la chaleur sensible) à $0{ }^{\circ} \mathrm{C}$ est essentiel dans les 2 premières heures qui suivent la récolte car, si le fruit est maintenu à $10^{\circ} \mathrm{C}$, sa durée d'entreposage est réduite d'un tiers par rapport à celle d'un fruit maintenu à $0^{\circ} \mathrm{C}$. Les fruits gardés à la température de 25 à $30^{\circ} \mathrm{C}$ à la cueillette sans prérefroidissement devraient être vendus le même jour. Le prérefroidissement des fraises se fait par ventilation forcée; un fort débit d'air froid passe au travers des contenants de fraises empilés dans un tunnel. Par la suite, les fraises doivent être transportées dans des véhicules réfrigérés pour une conservation optimale et de longue durée jusqu'au magasin.

La pourriture peut abréger considérablement la durée d'entreposage des fraises fraîches. Il est donc important de la prévenir. Pour réduire efficacement les pertes dues à la pourriture après la récolte, il 
faut appliquer du captan, du bénomyl, de l'iprodione, du thiram ou du thiophanate-méthyle au champ avant la récolte (54).

Les cultivars de fraise à texture typiquement molle sont plus sujets à la pourriture (113). La sélection de cultivars de fraise résistants à la pourriture (33) mais réunissant les caractéristiques souhaitées de qualité peut permettre de prolonger la durée maximale d'entreposage. L'exposition des fruits à des vapeurs d'acétaldéhyde de 1 à $4 \%$ pendant 20 à 30 minutes $(121,161)$, à de la glace sèche, à des concentrations de 20 à $30 \%$ de gaz carbonique (glace sèche dans un emballage en polyéthylène) (204) ou à des atmosphères contrôlées (5 à $15 \%$ de $\mathrm{CO}_{2}+1$ à $2 \%$ de $\left.\mathrm{O}_{2}, 3^{\circ} \mathrm{C}\right)(207)$ peut aussi réduire l'incidence de la pourriture et prolonger la durée commerciale de mise en marché.

L'irradiation aux rayons gamma, à raison de 2000 à $3000 \mathrm{~Gy}$, s'est révélée efficace pour prévenir la détérioration des fraises, un des rares produits qui ne souffrent pas de ce traitement (24). Il est probable cependant que la législation et le prix de revient de cette technique limitent l'utilisation commerciale de l'irradiation.

\section{FRAMBOISES}

Température : $0{ }^{\circ} \mathrm{C}$

Humidité relative : 85 à $95 \%$

Les framboises, les mûres noires, les mûres de Logan et les mûres des haies ne se prêtent pas à l'entreposage frigorifique à long terme; un prérefroidissement rapide leur est cependant bénéfique. Les framboises peuvent se garder au maximum de 5 à 7 jours à $0{ }^{\circ} \mathrm{C}$ avec une humidité relative de 85 à $95 \%$ à condition que la température du fruit ait été réduite à $0{ }^{\circ} \mathrm{C}$ dans les quelques heures qui ont suivi la cueillette. Les mûres des baies Young et Boysen ne peuvent se conserver plus de 2 à 4 jours sans perte importante (112).

Les pertes commerciales de framboises et la diminution de leur qualité sont dues principalement à la pourriture (Botrytis cinerea, Rhizopus et Cladosporium herbarum) et au ramollissement. Un refroidissement rapide après la récolte retarde la perte de baies mais une vaporisation au chlorure de calcium avant la récolte (43), la sélection des cultivars (33) et une exposition aux vapeurs d'acétaldéhyde (160) réduisent encore plus ces pertes dues à la pourriture et au ramollissement.

\section{MELONS}

Les trois principaux cultivars de melons vendues au Canada sont le cantaloup, le melon miel et le melon d'eau. Les deux premières sont des variétés botaniques du melon brodé. En général, les melons ne se conservent pas longtemps. Cependant, grâce au prérefroidissement, 
les melons sont mieux protégés au cours du transport et de la mise en vente. Ainsi, ils peuvent être entreposés temporairement lorsque le marché est saturé.

\section{Melon cantaloup}

Température : 0 à $7^{\circ} \mathrm{C}$

Humidité relative : 85 à $90 \%$

Normalement, le cantaloup se conserve en entrepôt près de 2 semaines à $0{ }^{\circ} \mathrm{C}$ bien que dans certaines conditions indéterminées, quelques cultivars se détériorent lorsque la température est inférieure à $7^{\circ} \mathrm{C}$. Le degré de maturité au champ est important à la fois pour l'entreposage et la valeur commerciale; il se détermine par la facilité avec laquelle la tige se détache et par la couleur non jaunie du fruit. Ces melons se conservent alors moins longtemps que ceux de moindre maturité mais ils sont d'une qualité supérieure (125). Les cantaloups mûrs se conservent sans danger de désordres prégélifs à de basses températures. Souvent, les melons sont prérefroidis en les plaçant dans de la glace. Des inspections fréquentes et minutieuses lors de l'entreposage et de la vente sont nécessaires afin de déceler les avaries dès leur apparition (162).

\section{Melon miel}

Température : 7 à $10^{\circ} \mathrm{C}$

Humidité relative : 85 à $90 \%$

Ce melon, qui est sujet aux désordres prégélifs, peut se conserver de 2 à 3 semaines, à une température de $7^{\circ} \mathrm{C}$. Ces désordres sont de la même nature que ceux subis par le cantaloup. Il est recommandé de ne pas se servir de glace pour prérefroidir les melons autres que le cantaloup (112).

\section{Melon d'eau}

Température : 2 à $4,5^{\circ} \mathrm{C}$

Humidité relative : 85 à $90 \%$

Le melon d'eau peut être entreposé de 2 à 3 semaines à une température comprise entre 2 et $5^{\circ} \mathrm{C}$. À une température de $0{ }^{\circ} \mathrm{C}$, il se couvre de petites taches résultant de désordres prégélifs et développe un mauvais goût. L'apparition de pourriture indique habituellement de ne pas prolonger l'entreposage (162). 


\section{PÊCHES}

Température : $0,0^{\circ} \mathrm{C}$

Humidité relative : 85 à $95 \%$

La durée d'entreposage des pêches est de 3 semaines au maximum; elle dépend du cultivar et du degré de maturité et d'infection fongique du fruit. Quand la pourriture ne limite pas la durée d'entreposage des pêches, l'apparition d'une texture sèche, pâteuse, quelquefois décrite avec justesse comme cotonneuse altère la qualité des fruits. Chez les cultivars tardifs, le temps frais au moment de la croissance et un degré de maturité insuffisant rendent les pêches cotonneuses après un séjour prolongé en entrepôt frigorifique (50). Ce désordre peut être partiellement corrigé par un réchauffement intermittent de 2 jours à $20^{\circ} \mathrm{C}$ ou à la température ambiante toutes les 2 ou 4 semaines (14). La susceptibilité à ce désordre est réduite en laissant mûrir les fruits des variétés sensibles durant 2 jours, à $21^{\circ} \mathrm{C}$, avant l'entreposage frigorifique. Les pêches cueillies assez mûres sont ordinairement considérées comme les meilleures; elles sont bonnes à manger après 6 ou 7 jours de conservation à $21^{\circ} \mathrm{C}$. Les fruits de maturité avancée peuvent être délicieux au goût mais avoir une texture médiocre, molle et parfois filandreuse qui les rend sujets aux meurtrissures. Les fruits qui mettent de 9 à 10 jours à mûrir sont souvent farineux et peu sucrés et leur saveur caractéristique est à peine perceptible. Une température de 18 à $24^{\circ} \mathrm{C}$ et une humidité relative de 50 à $65 \%$ favorisent considérablement la maturation des pêches. À une température de $27^{\circ} \mathrm{C}$ ou plus, la chair prend une coloration rougeâtre et la saveur en est altérée (186).

La durée de conservation en entrepôt frigorifique de quelques cultivars de pêche peut être prolongée par l'utilisation d'atmosphères contrôlées combinées à un réchauffement intermittent. D'après les premières études, une atmosphère composée de $5 \%$ de gaz carbonique et de $3 \%$ d'oxygène à $0^{\circ} \mathrm{C}$ convient à plusieurs cultivars de pêche $(15$, $112,194)$. Des études plus récentes (4) indiquent qu'une composition de $5 \%$ de gaz carbonique et $1 \%$ d'oxygène $\left(0^{\circ} \mathrm{C}\right)$ avec réchauffement intermittent à $20^{\circ} \mathrm{C}$ pendant 2 jours toutes les 4 semaines d'entreposage peut augmenter la durée d'entreposage jusqu'à 20 semaines.

Les pêches sont très sensibles aux pathogènes en entrepôt; ceux-ci entraînent en peu de temps des pertes graves. L'immersion ou l'aspersion au dichloran après la récolte réduit efficacement l'effet de Rhizopus tandis que le Bénomyl appliqué après la récolte est efficace contre la moniliose causée par Monilinia spp. Cette pourriture brune trouvée en entrepôt peut aussi être réduite par l'application d'iprodione un jour avant la cueillette. 


\section{POIRES}

Température : $-1,0^{\circ} \mathrm{C}$

Humidité relative : 85 à $95 \%$

En dépit de leur apparence ferme et résistante au moment de la cueillette, les poires sont des fruits délicats qui exigent des soins spéciaux après la récolte $(51,64)$. Quelques heures de trop dans le verger, un refroidissement lent ou une température légèrement trop élevée dans l'entrepôt peuvent abréger la durée d'entreposage des poires et susciter l'insatisfaction des acheteurs. L'entreposage des variétés Anjou et Bartlett à $-1{ }^{\circ} \mathrm{C}$ au lieu de $0{ }^{\circ} \mathrm{C}$ peut prolonger de $40 \%$ la durée de conservation $(151,152)$. L'idéal serait de refroidir les fruits à $-1{ }^{\circ} \mathrm{C}$ dans les 4 jours qui suivent la récolte lorsqu'un entreposage de longue durée est requis. Cet objectif d'un refroidissement aussi rapide à $-1{ }^{\circ} \mathrm{C}$ ne peut être atteint si l'entrepôt n'a pas l'espace ni les capacités de réfrigération suffisants. Certaines poires Bartlett, cueillies lorsqu'elles ont une forte teneur en amidon et une faible teneur en sucre, peuvent avoir un point de congélation aussi haut que $-2{ }^{\circ} \mathrm{C}$.

La fermeté des poires mesurée au pénétromètre donne un indice relativement fiable de leur degré de maturité (Tableau 4). La Bartlett, qui mûrit à la fin d'août lorsqu'il fait chaud, se maintient à un degré de maturité acceptable pas plus d'une semaine. A maturité avancée, la durée d'entreposage des poires est abrégée et l'apparition de désordres, tel le coeur brun, est favorisé. Les cultivars plus tardifs, telle l'Anjou à maturité plus lente et facile à se détacher de l'arbre, sont souvent récoltées encore vertes. Elles mûrissent alors de façon inégale et incomplète et restent moins juteuses. Il faut cueillir les poires lorsqu'elles sont encore vertes et dures avant qu'elles ne mûrissent sur l'arbre. Les tests de fermeté au pénétromètre constituent un moyen sûr de vérifier leur maturité.

Les nuits fraîches, où la température tombe à $7{ }^{\circ} \mathrm{C}$ ou moins à la fin de la saison de croissance, peuvent stimuler la production d'éthylène et causer le mûrissement prématuré des poires Bartlett sur l'arbre. Dans des conditions extrêmes, il arrive que les poires mûrissent et qu'elles commencent à se détériorer avant le temps normal prévu pour la récolte. Les fruits légèrement touchés ont une teinte rosée au calice (extrémité rosée) et sont sujets au blettissement durant leur maturation en entrepôt. Des recherches effectuées dans l'état d'Oregon ont démontré que cet effet néfaste des nuits froides avant la récolte peut être annulé par des pulvérisations daminozide ou d'acide gibbérellique $(63,201)$.

La plupart des cultivars de poires mûrissent plus uniformément après une période d'entreposage frigorifique de 2 ou 3 semaines. Certains cultivars pas tout à fait mûrs doivent même être traités à 
Tableau 4. Épreuve de maturité au pénétromètre de certains cultivars de poires et durée approximative d'entreposage

Épreuve du pénétromètre [à pointe de $8 \mathrm{~mm}$

Cultivar
Durée d'entreposage

à $-1,0^{\circ} \mathrm{C}$

(mois)

$\begin{array}{lccc}\text { Anjou } & 70-50 & (15,0-12,0) & 4-6 \\ \text { Bartlett } & 85-75 & (19,0-17,0) & 2-3 \\ \text { Beurre Bosc } & 60-55 & (14,0-12,0) & 3-3,5 \\ \text { Clapp's Favorite } & 70-60 & (16,0-13,5) & 2-3 \\ \text { Clarigeau } & 60-50 & (14,0-11,0) & 4-5 \\ \text { Comice } & 60-40 & (13,0-9,0) & 2-3 \\ \text { Doyenne Boussock } & 65-55 & (14,0-12,0) & 2 \\ \text { Flemish Beauty } & 60-50 & (13,0-11,0) & 2 \\ \text { Hardy } & 50-40 & (11,5-9,0) & 2-3 \\ \text { Kieffer } & 70-55 & (16,0-12,0) & 2-3 \\ \text { Red Bartlett } & 85-75 & (19,0-17,0) & 3-4 \\ \text { Winter Nelis } & 65-55 & (14,0-12,0) & 4-5\end{array}$

l'éthylène pour provoquer un mûrissement immédiatement à la récolte. La température idéale pour le mûrissement des poires est de $18^{\circ} \mathrm{C}$; certains cultivars, telles l'Anjou et la Winter Nelis, mûrissent toutefois lentement en entrepôt frigorifique (7). D'autres cultivars, telles la Bartlett, la Bosc et la Flemish Beauty, ne mûrissent pas en entrepôt frigorifique et, s'ils sont entreposés trop longtemps, ne mûrissent plus du tout même à leur retour à des températures favorables. Le jaunissement de la Bartlett en entrepôt indique que le fruit est à la veille de ne plus pouvoir mûrir. Ce jaunissement peut progresser avec la sénescence et produire un brunissement marqué de la pelure, à ne pas confondre avec l'échaudure de la poire Anjou bien 
que semblable. L'échaudure de la poire Anjou, qui ressemble davantage à l'échaudure de la pomme, peut être prévenue en appliquant après la cueillette du Stopscald ${ }^{\circledR}$ (éthoxyquine) par immersion ou en imprégnant de ce produit le papier d'emballage.

Le frottement des poires, au cours de l'emballage, du transport ou de la manutention, laissent de disgracieuses marques brunes sur la pelure dues au brunissement enzymatique des cellules endommagées. Le mûrissement rend le fruit plus sujet à ce genre d'accident; c'est pourquoi il faut emballer les poires après la cueillette ou tôt en cours d'entreposage frigorifique. Les fruits refroidis ne sont pas plus sensibles que les autres à ce désordre de la pelure; les retirer de l'entrepôt pour les réchauffer avant l'emballage ne fait que raccourcir la durée d'entreposage.

Les poires sont emballées dans des sacs en polyéthylène pour réduire les pertes d'eau des fruits et prévenir l'apparition de rides à l'extrémité du pédoncule durant un entreposage prolongé. Des sacs de polyéthylène de $38 \mu \mathrm{m}$ criblés de perforations minuscules sont utilisés pour entreposer les poires. Ils sont éventrés à la sortie des fruits de l'entrepôt frigorifique pour les faire mûrir. L'utilisation de sacs protecteurs scellés, en vue de créer une atmosphère modifiée, n'a pas donné satisfaction parce qu'un taux excessif de gaz carbonique endommage souvent les fruits. La tolérance des poires au gaz carbonique varie selon la saison, le degré de maturité, les pratiques d'entreposage et la concentration d'oxygène $(64,117,195)$. Les poires se conservent bien en atmosphère contrôlée lorsque la concentration du gaz carbonique est inférieure à $2 \%$. Les pertes dues à la pourriture lors de l'emballage des poires dans des sacs en polyéthylène peuvent être minimisées par un traitement au thiabendazole (TBZ) avant l'entreposage. Le Stopscald ${ }^{\circledR}$ et du TBZ peuvent être combinés pour prévenir l'échaudure et la moniliose des poires d'Anjou.

\section{POMMES}

Température : $-0,5$ à $0{ }^{\circ} \mathrm{C}$ pour la plupart des cultivars Humidité relative : 85 à $96 \%$

La capacité des entrepôts de pommes dépasse celle des entrepôts de n'importe quel autre fruit ou légume et l'on dispose d'une documentation considérable sur la construction des entrepôts, la manipulation et l'entreposage des pommes $(11,49,93,112,141,144,182,183)$. Le tableau 3 donne les périodes d'entreposage normale et maximale de certains cultivars communs de pomme. La durée d'entreposage, la qualité et la sensibilité de ces produits aux maladies et aux désordres physiologiques peuvent cependant être modifiées par les conditions climatiques de la saison, le type de sol et les pratiques culturales. L'entreposeur doit savoir comment le cultivar se comporte dans sa 
région et ce à quoi s'attendre des différents lots cultivés dans des conditions différentes de sol et de culture. S'il possède ces données, il pourra acheminer ses meilleurs lots vers l'AC et les autres en entrepôt frigorifique ordinaire ou encore, au besoin, dans un endroit d'accès facile pour inspection et écoulement rapide sur le marché. Prélever de temps à autre de petits échantillons de fruits dans les divers lots du verger et les laisser mûrir afin de vérifier leur état, est une mesure de surveillance souhaitable.

La mesure de la fermeté de la chair des pommes à l'aide d'un pénétromètre constitue une façon objective d'évaluer la condition des fruits (62). Divers cultivars de pommes ont la chair plus ou moins ferme au moment de la récolte et ramollissent à un rythme qui varie selon le cultivar. Un degré de maturité avancé au moment de la récolte, un retard à mettre les fruits en entrepôt ou à les refroidir rapidement, peut être détecté par les tests de fermeté car le ramollissement qui suit est accéléré.

\section{Degré de maturité}

Le degré de maturité au moment de la récolte influe beaucoup sur la durée possible de consérvation en entrepôt. Les pommes cueillies trop vertes n'ont pas la saveur et la texture caractéristiques des fruits mûris à point : elles se rident et sont sujettes à l'échaudure, au coeur brun et à la tache amère. Cueillies trop mûres, elles sont plus exposées à devenir farineuses, plus sensibles aux pathogènes et au blettissement dû au coeur aqueux à la récolte ou à la sénescence hâtive en entrepôt $(39,40)$.

Il n'y a pas de méthode absolument sure pour apprécier le degré de maturité des pommes, mais un certain nombre d'indices permettent une évaluation satisfaisante du degré de maturité à la récolte, lorsque employés par des personnes expérimentées. Parfois, les pommes ne sont pas cueillies au moment précis où elles ont atteint la maturité voulue, à cause du mauvais temps, de la pénurie de main-d'oeuvre ou parce que le pomiculteur décide d'attendre que les pommes développent plus de couleur.

Les indices de maturité concernent la couleur de la pelure, de la chair et des pépins, la teneur des tissus en amidon, la teneur interne en éthylène, la facilité avec laquelle le fruit se détache de l'arbre, la fréquence du coeur aqueux et le nombre de jours écoulés depuis la floraison $(23,25,87,97,145,150)$. Les tests de fermeté au pénétromètre constituent une meilleure mesure de la maturité des poires que des pommes (tableau 4). Des essais d'entreposage et une expérience de plusieurs années sont nécessaires pour reconnaître lequel de ces indices est le plus sûr pour un cultivar et des conditions de culture données d'un fruit tel que les pommes ou les poires. 


\section{Conditions d'entreposage}

Il est très important de transporter les fruits rapidement dans un entrepôt frigorifique et de les refroidir convenablement le plus tôt possible après la cueillette. Le détachement du fruit de l'arbre accentue son intensité respiratoire et son mûrissement, particulièrement par temps chaud. Tout délai pour refroidir les pommes après la récolte peut abréger la durée d'entreposage, en accélérer le mûrissement et le ramollissement, et augmenter les risques d'échaudure, de détérioration et de pourriture. La McIntosh ramollit jusqu'à 20 fois plus rapidement à une température de $21^{\circ} \mathrm{C}$ qu'à une température de $0{ }^{\circ} \mathrm{C}$. Au cours d'un entreposage prolongé, des températures légèrement élevées peuvent aussi avoir un effet nocif tangible sur la conservation des fruits. La plupart des cultivars se prêtent à un entreposage à des températures juste au-dessus de leur point de congélation, surtout si la température est maintenue uniforme et est étroitement contrôlée. Des expériences ont montré une amélioration de 20 à $25 \%$ de rétention de qualité des pommes entreposées à $-1,0^{\circ} \mathrm{C}$ au lieu de $0{ }^{\circ} \mathrm{C}$ (143). Selon les conditions de croissance, un petit nombre de cultivars, telles la Jonathan, la Northwest Greening, la Grimes Golden, la Cox Orange et la Winter Banana, peuvent être atteintes d'échaudure à chair molle et parfois de blettissement, à des températures inférieures à 1 ou $2{ }^{\circ} \mathrm{C}$ (39). Le coeur brun de la McIntosh et le brunissement de la pulpe des Newtown sont des désordres prégélifs causés par des températures trop basses. L'entreposage de la McIntosh entre -1 et $0{ }^{\circ} \mathrm{C}$ durant 3 à 4 mois ou plus, développe le coeur brun. L'entreposage en atmosphère contrôlée entre 2 et $4{ }^{\circ} \mathrm{C}$ s'est révélé très efficace pour prévenir le coeur brun de la McIntosh, sans en accélérer le mûrissement. Les Newtown cultivées au cours des étés frais de Watsonville en Californie ou des étés frais de la ColombieBritannique, doivent être conservées à des températures de plus de $2,0^{\circ} \mathrm{C}$, si l'on veut éviter le brunissement de la pulpe.

\section{Désordres d'entreposage}

Nous étudierons brièvement ci-après certains des désordres énumérés au tableau 3 qui peuvent être évités ou atténués par une bonne régie d'entreposage; les ouvrages de référence mentionnés (39, $42,49,60,140$ et 159) fournissent des renseignements plus détaillés à ce sujet.

Échaudure. Tous les cultivars de pommes sont sujets à l'échaudure dans certaines conditions. Cependant, certains cultivars, tels que la Spartan, la Golden Delicious, la Newtown et la McIntosh, en sont rarement atteints pendant un entreposage de durée normale. La 
fréquence des échaudures, chez les cultivars plus sensibles, diffère selon les saisons, les pratiques culturales et les méthodes de régie. Une température élevée avant et pendant la récolte, un degré insuffisant de maturité, une forte nutrition azotée au champ, le retard à entreposer les fruits, une température élevée dans l'entrepôt, une période d'entreposage prolongée, ont tous tendance à aggraver l'échaudure $(39,63)$. Il arrive parfois que le paraffinage des fruits et l'entreposage dans des caisses doublées de polyéthylène aggravent l'échaudure, tandis que l'entreposage $\mathrm{AC}$ classique et l'AC très pauvre en oxygène en diminue les risques $(88,99,134)$.

Les causes mentionnées ci-dessus désignent au pomiculteur et à l'entreposeur les moyens de régie dont ils disposent pour réduire l'échaudure. Toutefois, pour certains cultivars très sujets au désordre, il est conseillé de traiter les fruits avec un inhibiteur dans les quatre ou cinq semaines qui suivent la récolte et, de préférence, immédiatement après la cueillette et avant l'entreposage frigorifique. Deux inhibiteurs d'échaudure efficaces sont autorisés pour les pommes (68, 157,179 ), bien que leur usage continu soit remis en question. Ce sont l'éthoxyquine, produit vendu par Monsanto sous le nom commercial de Stopscald ${ }^{\circledR}$, et la diphénylamine, communément appelée DPA. La DPA est ordinairement considérée comme l'inhibiteur le plus efficace, mais les deux sont beaucoup plus efficaces que le papier huilé. Il ne faut pas utiliser la DPA sur les pommes Golden Delicious ni sur les poires Anjou; la DPA peut aussi endommager d'autres variétés à l'occasion. L'utilisation du Stopscald ${ }^{\circledR}$ comporte peu de contreindications; des avaries sont constatées seulement lorsque les fruits séjournent directement dans la solution qui repose dans le fond concave des contenants dépourvus d'orifice de drainage appropriés. La meilleure manière d'appliquer le Stopscald ${ }^{\circledR}$ consiste à immerger complètement les fruits dans un bassin rempli de ce produit, ou en en faisant circuler un fort volume dans un récipient drainé. Une fois séchés après l'application du Stopscald ${ }^{\circledR}$, les fruits peuvent être lavés ou paraffinés sans diminuer l'efficacité de l'inhibiteur (157). Le Stopscald ${ }^{\circledR}$ peut aussi être appliqué par pulvérisation ou au pinceau au moment de l'emballage. Bien que cette méthode constitue une excellente protection contre l'échaudure, elle n'est pas souvent employée, car elle favorise les dermatites de contact chez les travailleurs sensibles aux produits chimiques.

Coeur brun. Le coeur brun est un désordre d'entreposage fréquent chez la McIntosh partout où elle est cultivée, conservée à une température trop basse en entrepôt ou trop longtemps $(39,148)$. Ce désordre est aggravé par un degré insuffisant de maturité et un excès d'azote (42); il apparaît généralement dans la chair centrale de la McIntosh après 3 ou 4 mois d'entreposage à une température de -1 à $0{ }^{\circ} \mathrm{C}$ et il augmente davantage durant les 5 ou 6 jours de séjour à $21^{\circ} \mathrm{C}$ 
après entreposage. L'irradiation ou les rayons gamma (140) peuvent réduire le coeur brun et l'échaudure de la McIntosh, mais la seule méthode pratiquée dans le commerce est celle de l'entreposage AC, qui permet une température plus élevée sans mûrissement excessif. Dans la vallée de l'Okanagan, en Colombie-Britannique, les pommes McIntosh sont entreposées sous $\mathrm{AC}$ à une température de 1,5 à $2,0^{\circ} \mathrm{C}$, température minimale pour la prévention du coeur brun (155). Dans les autres régions où la McIntosh est cultivée, il semble que la température doit se situer à $3{ }^{\circ} \mathrm{C}$ ou plus dans les chambres $\mathrm{AC}$ pour éviter ce désordre.

Blettissement. À l'exception de la Jonathan qui est parfois altérée par de basses températures, les pertes importantes causées par le blettissement résultent de la sénescence avancée du fruit. Les tissus affectés de blettissement sont mous, secs et d'un brun diffus. Règle générale, le blettissement se retrouve chez les fruits de forte taille, dont la sénescence est excessive et accélérée par une manipulation à la récolte ou un entreposage qui laissent à désirer; le blettissement s'associe à une composition minérale de la chair du fruit excessive en azote et carencée en calcium avec ou non de fortes teneurs en magnésium. Chez certains cultivars, tels que la Golden Delicious, la Spartan et la McIntosh, le blettissement peut résulter de meurtrissures. Pour d'autres cultivars, comme la Delicious et la Winesap, le blettissement survient en entrepôt, là où le coeur aqueux était présent à la récolte. Même si l'entreposage $\mathrm{AC}$ retarde le blettissement et la sénescence, il ne solutionne pas les problèmes causés initialement par de mauvaises pratiques culturales et une manipulation négligée. Le blettissement de la Spartan dû à une carence en calcium peut être prévenu en pulvérisant sur le feuillage du pommier du chlorure de calcium ou en y trempant les pommes à la récolte. Le pomiculteur averti peut minimiser les pertes causées par le coeur aqueux en s'y prenant à temps pour récolter. Les Délicieuses légèrement atteintes de coeur aqueux peuvent être séparées des pommes saines en les plongeant dans une solution d'alcool de poids spécifique approprié (156). Dans les cas plus ou moins bénins, le coeur aqueux se résorbe en entrepôt frigorifique sans laisser beaucoup de séquelles, particulièrement si le désordre n'atteint pas sévèrement aucune partie de la pomme. La coutume de garder les pommes à la température du verger, après la récolte, pour faire disparaître le coeur aqueux plus rapidement, est une pratique néfaste qui accélère le mûrissement, occasionne un début de blettissement et empêche le tri efficace des pommes saines par l'alcool.

Pourriture. Les pertes causées par la pourriture, communément par le Penicillium, mais en certains cas par l'anthracnose d'entrepôt (Gloeosporium) ou par le Botrytis, sont dues aux méthodes de culture 
et de manipulation. Même si les pommes ont été protégées par la pulvérisation des pommiers au champ, elles peuvent être infectées de Penicillium par la suite lors de manipulations brutales susceptibles de causer des meurtrissures et le bris de la pelure. L'utilisation accrue de récipients d'immersion basculants augmente encore les risques d'infection des fruits endommagés. La chenille du pommier, retrouvée partout en verger, est une source d'infection de l'anthracnose d'entrepôt (Gloeosporium); l'infection commence dans le verger et se développe lentement dans le fruit durant l'entreposage frigorifique (44). Elle n'est pas inhibée par les atmosphères très pauvres en oxygène. Une température humide, au moment de la cueillette, et un entreposage prolongé à un degré d'humidité élevé, favorisent l'évolution de cette maladie. Le thiabendazole et le bénomyl sont des produits efficaces contre la pourriture, homologués pour application sur les pommes et les poires après la récolte.Ces produits chimiques, appliqués par immersion ou par vaporisation sur les fruits après la récolte, ont permis de lutter efficacement contre le Penicillium, le Botrytis et le Gloeosporium. Lorsque des mesures de protection contre l'échaudure s'imposent et que l'emploi d'un fongicide est jugé à propos, un mélange de thiabendazole et de Stopscald ${ }^{\circledR}$ peut être appliqué.

\section{PRUNES}

Température : $0^{\circ} \mathrm{C}$

Humidité relative : 85 à $95 \%$

Le degré de maturité des prunes au moment de la récolte influence beaucoup la qualité du fruit. La teneur en extraits solubles, mesurée au réfractomètre est le meilleur indice de maturité des prunes. Avec une teneur de 17 à $18 \%$ en solubles solides, les prunes mûrissent en 7 jours environ à $18^{\circ} \mathrm{C}$; après un entreposage de 1 mois à $0{ }^{\circ} \mathrm{C}$, elles mûrissent en 5 jours à $18^{\circ} \mathrm{C}(47,56)$. La couleur est aussi un indice utile de maturité; les prunes prêtes à cueillir ont une chair de couleur ambre moyennement foncée. Toutefois, les tests de fermeté de la chair sont moins consistants car les résultats varient trop d'une année à l'autre $(47,56)$.

La prune hâtive Triflora (variété japonnaise) est sujette au blettissement, surtout pendant l'entreposage à des températures variant entre 0 et $4,5^{\circ} \mathrm{C}$. L'entreposage à une température inférieure à $4,5^{\circ} \mathrm{C}$ est donc problématique; mais, même à des températures plus élevées, la durée de conservation en entrepôt est relativement courte. D'autres variétés s'entreposent à $0{ }^{\circ} \mathrm{C}$ et se conservent de 2 à 3 semaines sinon plus; tout dépend de la variété et du degré de maturité au moment de la récolte.

À part la pourriture, les principales causes de perte des prunes en entrepôt sont le brunissement interne et le blettissement. Ces 
désordres ne sont pas visibles extérieurement, de sorte qu'il faut procéder à de fréquents examens internes en cours d'entreposage pour les découvrir et écouler les lots sensibles le plus tôt possible $(112,137)$.

\section{RAISINS}

Température : $0,0^{\circ} \mathrm{C}$

Humidité relative : 85 à $95 \%$

Le raisin récolté au Canada est surtout du type Labrusca ou américain; il se conserve beaucoup moins longtemps que le raisin de type Vinifera ou européen. En général, le raisin de type américain est expédié directement pour la consommation ou la transformation. Il se conserve jusqu'à 4 semaines si la température est rigoureusement maintenue à $0{ }^{\circ} \mathrm{C}$. Les variétés hybrides, comme le Sheridan, peuvent se conserver jusqu'à 2 mois. La fumigation à l'anhydride sulfureux peut endommager le raisin de type américain, mais non celui de type européen. Le manque de soins à la récolte fait fendiller le raisin et l'insuffisance d'humidité entraîne le dessèchement des tiges $(22,70)$.

Des grappes de Vinifera peuvent être entreposées jusqu'à 4 à 6 mois lorsqu'elles sont emballées sans être serrées et enfermées dans des enveloppes en polyéthylène avec un générateur de $\mathrm{SO}_{2}$ biétagé à une température de 0 à $1{ }^{\circ} \mathrm{C}(71)$. Les enveloppes en polyéthylène de $38 \mu \mathrm{m}$ empêchent la dessication des tiges et du fruit mais l'humidité élevée favorise la pourriture. Le générateur de $\mathrm{SO}_{2}$ biétagé retarde la pourriture pendant l'entreposage à long terme. Le générateur biétagé est formé d'un sachet de $3 \mathrm{~g}$ de métabisulfate de potassium sous papier, et d'un sachet de $3 \mathrm{~g}$ de métabisulfite de potassium sous polyéthylène de $38 \mu \mathrm{m}$ scellé; le tout est enfermé dans une autre enveloppe de polyéthylène avec $10 \mathrm{~kg}$ de fruits. Son usage a pour but de retarder la pourriture pendant l'entreposage à long terme (123).

\section{CONDITIONS D'ENTREPOSAGE DES LÉGUMES}

On trouvera, au tableau 5 et dans les pages qui suivent, des recommandations sur l'entreposage de la plupart des légumes cultivés au Canada. 
Tableau 5. Durée, température et humidité relative d'entreposage recommandées, et point maximal de congélation des légumes frais $(119,206)$

\begin{tabular}{|c|c|c|c|c|}
\hline Légumes & $\begin{array}{c}\text { Température } \\
\left({ }^{\circ} \mathrm{C}\right)\end{array}$ & $\begin{array}{c}\text { Humidité } \\
\text { relative } \\
(\%)\end{array}$ & $\begin{array}{l}\text { Durée approxi- } \\
\text { mative de la } \\
\text { période } \\
\text { d'entreposage }\end{array}$ & $\begin{array}{c}\text { Point } \\
\text { maximal } \\
\text { de } \\
\text { congélation } \\
\left({ }^{\circ} \mathrm{C}\right)\end{array}$ \\
\hline
\end{tabular}

\begin{tabular}{|c|c|c|c|c|}
\hline Ail séché & 0 & $70-75$ & 6 à 8 mois & $-0,8$ \\
\hline Asperges & 0 & $95-100$ & 3 semaines & $-0,6$ \\
\hline Aubergines & $7,0-10,0$ & $85-90$ & 10 jours & $-0,8$ \\
\hline \multicolumn{5}{|l|}{ Betteraves } \\
\hline en bottes & 0 & $95-100$ & 10 à 14 jours & $-0,4$ \\
\hline parées & 0 & $95-100$ & 1 à 3 mois & $-0,9$ \\
\hline \multicolumn{5}{|l|}{ Carottes, } \\
\hline $\begin{array}{l}\text { en bottes } \\
\text { parées }\end{array}$ & $0,0-1,0$ & $95-100$ & 2 semaines & \\
\hline $\begin{array}{l}\text { parees } \\
\text { Céleri }\end{array}$ & $\begin{array}{c}0,0-1,0 \\
0\end{array}$ & $\begin{array}{l}95-100 \\
95-100\end{array}$ & $\begin{array}{l}4 \text { à } 9 \text { mois } \\
3 \text { mois }\end{array}$ & $\begin{array}{l}-1,4 \\
-0,3\end{array}$ \\
\hline $\begin{array}{c}\text { Champignons } \\
\text { de couche }\end{array}$ & 0 & $85-90$ & 5 jours & $-0,3$ \\
\hline $\begin{array}{l}\text { Choux brocoli } \\
\quad \text { (italiens ou bra }\end{array}$ & $\begin{array}{c}0 \\
\text { anchus) }\end{array}$ & $90-97$ & 1 à 3 semaines & $-0,6$ \\
\hline \multicolumn{5}{|l|}{ Choux de } \\
\hline Bruxelles & $-0,5-0,0$ & $95-97$ & 1 à 5 mois & $-0,8$ \\
\hline Choux-fleurs & 0 & $95-100$ & 0,5 à 4 semaines & $-0,8$ \\
\hline Choux hâtifs & 0 & $95-100$ & 3 à 4 semaines & $-0,9$ \\
\hline tardifs & 0 & $95-100$ & 3 à 7 mois & $-0,2$ \\
\hline Choux-raves & 0 & $95-100$ & 2 à 4 semaines & $-1,0$ \\
\hline Citrouilles & $7,0-10,0$ & $70-75$ & 2 à 3 mois & $-0,8$ \\
\hline Concombre & $7,0-10,0$ & $95-100$ & 10 à 14 jours & $-0,5$ \\
\hline \multicolumn{5}{|l|}{ Courges de } \\
\hline printemps & $7,0-10,0$ & $70-75$ & 2 semaines & $-0,5$ \\
\hline d'hiver & $7,0-10,0$ & $70-75$ & 6 mois & -0 \\
\hline zucchini & 5,0 & 95 & 1 à 2 semaines & 0 \\
\hline \multicolumn{5}{|l|}{ Endives ou } \\
\hline scaroles & 0 & $95-100$ & 2 à 3 semaines & $-0,3$ \\
\hline Epinards & 0 & $95-100$ & 10 à 14 jours & -0 , \\
\hline $\begin{array}{l}\text { Haricots, } \\
\text { de Lima (avec }\end{array}$ & se) 0 & $90-95$ & 2 semaines & $-0,6$ \\
\hline $\begin{array}{l}\text { cosse, sans coss } \\
\text { vert ou jaune }\end{array}$ & se) & $90-9$ & 8 à 10 jours & \\
\hline Laitue pommée & 0 & $95-100$ & 2 à 3 semaines & \\
\hline Maïs sucré & 0 & $90-100$ & 8 jours & -0 \\
\hline
\end{tabular}


Tableau 5. Durée, température et humidité relative d'entreposage recommandées, et point maximal de congélation des légumes frais $(119,206)$ ( $f i n)$

\begin{tabular}{cccc} 
Légumes & $\begin{array}{c}\text { Humidité } \\
\text { Température } \\
\text { relative } \\
(\%)\end{array}$ & $\begin{array}{c}\text { Durée approxi- } \\
\text { mative de la } \\
\text { période } \\
\text { d'entreposage }\end{array}$ & $\begin{array}{c}\text { Point } \\
\text { maximal } \\
\text { de } \\
\text { congélation } \\
\left({ }^{\circ} \mathrm{C}\right)\end{array}$ \\
\hline
\end{tabular}

Oignons à repiquer

Oignons séchés

Oignons verts

0

0

0

Panais

Patates douces

Petits pois

Poireaux verts

Poivrons

Pommes de terre récoltes hâtives récoltes

Radis, tardives de printemps en bottes d'hiver

Raifort

Rhubarbe

Rutabagas ou navets

Salsifis

Tomates, mûres vertes tournantes

0

$$
\begin{gathered}
13,0-16,0 \\
0
\end{gathered}
$$$$
-1,0-0,0
$$$$
7,0-10,0
$$

voir texte

voir texte

65-75

50-70

95-100

5 à 7 mois

5 à 9 mois

2 semaines

95-100

2 à 4 mois

$$
-0,3
$$

85-90

95-100

4 à 6 mois

1 à 2 semaines

$-1,1$

95-100

1 à 3 mois

85-90

8 à 10 jours

$-1,2$

$-0,7$

$-0,7$

85-90

1 à 3 semaines

$-0,9$

85-90

voir texte

95-100

95-100

2 semaines

2 à 4 mois

10 à 12 mois

2 à 3 semaines

$-0,4$

$-0,7$

$-1,8$

95-100

$-0,3$

95-100

6 mois

2 à 4 mois

2 à 5 jours

$-1,1$

$-0,9$

$-0,5$

2 à 6 semaines $-0,8$

\section{AIL}

Température : $0{ }^{\circ} \mathrm{C}$

Humidité relative : 70 à $75 \%$

L'ail se conserve aux mêmes température et humidité que les oignons. Il doit être en bon état avant d'être entreposé. S'il est bien sec, il peut se garder de 6 à 8 mois, à $0^{\circ} \mathrm{C}$. Dans un entrepôt ordinaire, 
refroidi à l'air, l'ail se conserve de 3 à 4 mois et même davantage, selon la température, pourvu que le milieu soit frais, sec et bien aéré. L'ail s'entrepose ordinairement dans des filets à mailles lâches empilés sur deux rangées bien espacées afin d'assurer une circulation d'air optimale (112).

\section{ASPERGES}

\section{Température : $0{ }^{\circ} \mathrm{C}$}

Humidité relative : 95 à $100 \%$

Les asperges refroidies à $0{ }^{\circ} \mathrm{C}$ immédiatement après la récolte peuvent se conserver 3 semaines à cette température et à une humidité très élevée. Étant donné que les turions d'asperge se dessèchent rapidement, la base des tiges est placée dans l'eau ou déposée sur de la mousse humide, des serviettes mouillées entourées de papier paraffiné ou d'autres sources d'humidité. À une température supérieure à $0{ }^{\circ} \mathrm{C}$, elles ont tendance à croître, à se flétrir à la pointe et à devenir ligneuses et dures. Habituellement, les asperges sont vendues immédiatement après la récolte, évitant ainsi les difficultés d'entreposage; leur entreposage n'est fait qu'à titre temporaire avant le transit et la vente. S'il doit s'écouler un long intervalle entre la récolte et la mise en marché, il faut les écouler sitôt arrivées à destination. En pareils cas, le prérefroidissement par ventilation forcée ou immersion dans de l'eau glacée (20 à 30 minutes entre 0 et $5{ }^{\circ} \mathrm{C}$ ) avant l'expédition est très important. Les asperges en entrepôt sont sujettes à deux types de pourriture, la pourriture bactérienne molle et la moisissure grise; toutefois, il est possible de lutter avec efficacité contre ces avaries en évitant les meurtrissures et en maintenant la température aux environs de $0{ }^{\circ} \mathrm{C}(86,102,176)$.

\section{AUBERGINES}

\section{Température : 7 à $10^{\circ} \mathrm{C}$}

Humidité relative : 85 à $90 \%$

Il est difficile de garder les aubergines en entrepôt plus d'une dizaine de jours. La température d'entreposage idéale se situe près de $10^{\circ} \mathrm{C}$. A une température de $4{ }^{\circ} \mathrm{C}$ ou moins, des désordres prégélifs surviennent produisant de légers picots superficiels ou de la rouille près du pédoncule; ceux-ci apparaissent au bout de 4 à 8 jours. Les picots parfois se regroupent ou même se fusionnent pour former des dépressions après quelque temps (164). 


\section{BETTERAVES}

Température : $0{ }^{\circ} \mathrm{C}$

Humidité relative : 95 à $100 \%$

Les betteraves se vendent soit avec leurs fanes, soit parées. Les "betteraves en bottes» (avec leurs feuilles) sont surtout destinées au commerce de détail. Quant au «betteraves parées", elles sont surtout destinées à la transformation et, en quantité limitée, au commerce de détail. Les betteraves vendues en bottes sont, la plupart du temps, récoltées avant leur pleine maturité, alors qu'elles ont de 4 à $7,5 \mathrm{~cm}$ de diamètre. Elles ne se conservent pas en entrepôt pendant de longues périodes, bien qu'elles puissent y séjourner de 10 à 14 jours à $0^{\circ} \mathrm{C}$ et à une humidité relative élevée. Pour prévenir le flétrissement des fanes et d'autres avaries, il convient d'éviter l'entassement. Les fanes sont parfois légèrement taillées afin de donner aux betteraves une meilleure apparence.Rafraîchir les betteraves avec de la glace, avant l'expédition, contribue à leur donner un aspect frais et à prolonger leur durée de conservation.

Les betteraves parées sont récoltées à maturité à l'automne, avant le gel. L'excès de terre qui les recouvre est enlevé et les fanes sont coupées près de la couronne. Les betteraves endommagées ou mal formées sont rejetées dès la récolte. Leur forme irrégulière suggère une texture coriace et ligneuse, et celles qui sont endommagées se dessèchent et sont le site d'infection pendant l'entreposage. Les betteraves ratatinent très facilement mais, en milieu très humide, elles se conservent de 1 à 3 mois, à $0^{\circ} \mathrm{C}$. Les caveaux et les entrepôts frigorifiques donnent de bons résultats; la mise en barils aérés ou en caisses à claire-voie est préférable à l'entreposage en vrac $(144,163)$. Les betteraves ne se conservent pas plus longtemps en atmosphère contrôlée (203).

\section{BROCOLI}

Température : $0{ }^{\circ} \mathrm{C}$

Humidité relative : 90 à $97 \%$

La période d'entreposage du brocoli, dans des conditions de réfrigération propices, est d'environ une semaine, après quoi il y a chute des fleurets et décoloration de la tête. Même pour une si courte période, le brocoli doit être gardé constamment sous réfrigération durant le transport et à l'étalage. Pour prévenir sa détérioration et la perte de vitamine $C$, il est nécessaire de le rafraîchir continuellement avec de la glace broyée ou de la glace liquide (consistant en $60 \%$ de glace broyée et de $40 \%$ d'eau) ou de le conserver à une température constante de $0{ }^{\circ} \mathrm{C}$. Les principales causes de détérioration sont la tache bactérienne, la pourriture bactérienne molle, la moisissure 
grise, ainsi que la pourriture aqueuse molle (162). En atmosphère contrôlée, la durée d'entreposage du brocoli peut être prolongée de 1 à 2 semaines par rapport à l'entreposage au froid $(91,105,106)$. Le brocoli tolère des atmosphères pauvres en oxygène et riches en gaz carbonique; il ne montre des symptômes d'avarie que si la teneur en oxygène tombe au-dessous de $0,5 \%$ et que celle du gaz carbonique dépasse $20 \%$. Dans une AC optimale $\left(10 \% \mathrm{CO}_{2}+1 \% \mathrm{O}_{2}, 3\right.$ à $\left.5{ }^{\circ} \mathrm{C}\right)$, la perte de chlorophylle et la sénescence des fleurets ainsi que le durcissement du brocoli sont retardés.

\section{CAROTTES}

\section{Température : 0 à $1{ }^{\circ} \mathrm{C}$}

Humidité relative : 95 à $100 \%$

Les carottes destinées à un long entreposage se récoltent mûres dès que les fanes ont pris une légère coloration brune. A défaut de chargement en vrac et d'entreposage immédiat, il est recommandé de récolter par temps frais et nuageux afin d'empêcher les racines de se dessécher entre l'arrachage et l'entreposage. Les carottes se conservent à une humidité relative de $95 \%$ ou plus, afin de diminuer les pertes d'eau, le brunissement du périderme et même le ratatinage. Pendant la récolte, les fanes sont rompues près de la couronne ou même de la racine; les carottes trop grosses, endommagées, déformées et plissées au collet sont rejetées au champ ou lors du préclassage avant entreposage. Il faut prendre soin d'éviter les dommages par abrasion pendant la récolte, le nettoyage et le transport à l'entrepôt. Des particules grossières de sol, les papiers rugueux des convoyeurs ou des brosses de nettoyage dures peuvent abîmer les cellules épidermiques et provoquer ainsi une éraflure superficielle blanche opaque plus visible aux faibles humidités relatives. Les carottes mûries à point peuvent être empilées jusqu'à $3 \mathrm{~m}$ de hauteur dans des caisses à claire-voie, et en vrac jusqu'à $4 \mathrm{~m}$, pourvu que l'aération (de préférence par ventilation forcée) soit suffisante dans l'entrepôt. Dans le cas d'entreposage en vrac sans contenant, les carottes devraient être lavées, refroidie à l'eau glacée et traitées au fongicide avant l'entreposage. La plupart des cultivars se conservent de 4 à 5 mois à une température de $0{ }^{\circ} \mathrm{C}$. Une aération suffisante permet d'éviter le goût amer que cause la présence d'éthylène provenant de certains fruits, dont les pommes et les poires, et des résidus de gaz d'échappement. Il ne faut pas entreposer dans le même endroit les fruits et les carottes. Pour prévenir le dessèchement et le flétrissement, les carottes requièrent une humidité relative élevée. En entrepôt domestique, elles peuvent être gardées en quantités restreintes dans de la mousse humide, de la sciure de bois, du papier journal, du sable ou toute autre matière qui permet de conserver 
l'humidité (141). A échelle commerciale, l'entrepôt à double paroi et le Filacell ${ }^{\circledR}$ assure un bon maintien de l'humidité, mais génère quelques inconvénients, dont un lent refroidissement initial et la difficulté de maintenir une température de $0{ }^{\circ} \mathrm{C}$.

Les jeunes carottes, qui n'ont pas atteint leur pleine maturité et qui sont destinées à la consommation immédiate ou à un court entreposage, se récoltent lorsqu'elles ont moins de $4 \mathrm{~cm}$ de diamètre. Parfois, elles se vendent en paquets avec leurs fanes mais ces dernières jaunissent facilement et soutirent rapidement l'eau des racines. C'est pourquoi même les jeunes carottes se vendent habituellement sans leurs fanes, emballées dans des sacs transparents pour le détail ou dans des cageots ouverts pour l'expédition de long parcours. Il faut les prérefroidir à l'eau glacée à une température de 4 à $7{ }^{\circ} \mathrm{C}$ ou plus bas, le plus tôt possible après la récolte et avant l'emballage pour l'expédition. Lorsque expédiées en cageots ouverts, les carottes peuvent être couvertes de glace rapée ou de glace liquide (60\% de glace concassée dans $40 \%$ d'eau) afin de conserver leur fraîcheur. Les jeunes carottes peuvent se conserver plusieurs jours et jusqu'à 2 semaines, suivant leur degré de maturité et les conditions d'entreposage.

Les carottes en entrepôt peuvent être endommagées lorsqu'elles sont exposées à des températures trop basses, bien qu'elles supportent un gel léger $\left(-1^{\circ} \mathrm{C}\right)$. Elles peuvent également se dessécher, être atteintes de pourriture molle aqueuse ou de pourriture molle bactérienne vers la fin de la période d'entreposage. L'élimination des racines endommagées lors de la récolte, une aération suffisante, ainsi que des inspections fréquentes au cours de l'entreposage, contribuent à prévenir ces avaries (176). Pour éviter la pourriture en entrepôt causée par un certain nombre de pathogènes, les carottes peuvent être trempées ou aspergées de bénomyl après la récolte. Cette étape peut faire suite au préclassage et au prérefroidissement à l'eau glacée lors d'entreposage en vrac.

Des carottes ont été entreposées jusqu'à 15 mois dans une atmosphère modifiée ( $\mathrm{AM}$ ) autogène contenant $3 \%$ de gaz carbonique plus $17 \%$ d'oxygène $\left(1{ }^{\circ} \mathrm{C}, \mathrm{HR} 98 \%\right)$, après emballage dans du polyéthylène de $20 \mu \mathrm{m}$ d'épaisseur (139) suite à un prérefroidissement à l'eau glacée. Cependant, la plupart des essais d'entreposage de carottes en atmosphère contrôlée ne sont pas prometteurs. L'incidence de la pourriture augmente dans des atmosphères contenant plus de $5 \%$ de gaz carbonique ou moins de $10 \%$ d'oxygène. Toutefois, une légère suppression de la formation des repousses ou des racines (197) et une meilleure rétention de la carotène (13) ont été notées en $\mathrm{AC}$ à 0 ou $1{ }^{\circ} \mathrm{C}$. 


\section{CÉLERI}

Température : $0{ }^{\circ} \mathrm{C}$

Humidité relative : 95 à $100 \%$

$\mathrm{Si}$ le céleri est refroidi rapidement dès la récolte et conservé à une température de $0{ }^{\circ} \mathrm{C}$ et à une humidité relative élevée, il est possible de le garder en entrepôt pendant près de 3 mois. Étant donné que le céleri est sujet à faner facilement, il est essentiel de le refroidir rapidement après la récolte et de le garder en lieu humide. L'immersion dans de l'eau glacée ou toute autre forme de prérefroidissement avant ou après la mise en cageots, donnent des résultats satisfaisants (146). Le prérefroidissement sous vide est également efficace à condition que le produit soit mouillé pour éviter les pertes d'eau. Lors de l'expédition, il est particulièrement avantageux de recouvrir le céleri de glace concassée ou de glace liquide (60\% glace uncassée et $40 \%$ eau).

Le froid peut causer des dommages au céleri à des températures atteignant si peu que $-0,3{ }^{\circ} \mathrm{C}(92)$. Il est donc nécessaire de maintenir au-dessus de $0{ }^{\circ} \mathrm{C}$ la température de l'entrepôt mais pas plus de $1{ }^{\circ} \mathrm{C}$ pour ne pas favoriser la pourriture. Des thermomètres précis doivent donc être employés. En raison de la nature feuillue de ce produit et de son taux élevé de respiration, le remplissage des cageots doit se faire à la verticale pour assurer une température uniforme et la libre circulation de l'air autour des pieds placés debouts. Il est recommandé de tailler le céleri à la même hauteur que le rebord supérieur du cageot.

Certaines maladies et désordres attribuables à l'entreposage, comme la pourriture molle, les carences de minéraux et la pourriture des racines, prennent origine au champ. Pour prévenir la propagation de ces avaries, il est utile de bien connaître les conditions de culture du céleri et de procéder à des inspections avant la mise en entrepôt. Une surveillance assidue en cours d'entreposage s'impose (176).

Des humidités relatives élevées (98 à $100 \% \mathrm{RH}$ ) dans des entrepôts à doubles parois ou d'autres systèmes d'entreposage à haute humidité, retardent beaucoup la perte de qualité en entrepôt (92). L'entreposage du céleri dans des enveloppes perforées ou scellées de polyéthylène de $38 \mu \mathrm{m}$, à l'intérieur de cageots placés à $0{ }^{\circ} \mathrm{C}$ améliore la qualité du céleri et la rétention en eau. L'emploi d'enveloppes scellées, entraînant une concentration de gaz carbonique de 2 à $3 \%$, n'a aucun effet nocif sur le céleri; au contraire, sa couleur verte y est mieux préservée (131). L'entreposage en $\mathrm{AC}$ contenant $5 \%$ de gaz carbonique et $3 \%$ d'oxygène retarde le développement de la pourriture et améliore la rétention de la chlorophylle dans le céleri $(120,199)$. Toutefois, l'AC prolonge la durée de conservation du céleri que de 2 à 3 semaines comparé à l'entreposage optimal à l'air très humide à $0^{\circ} \mathrm{C}$. 


\section{CHAMPIGNONS DE COUCHE}

Température : $0^{\circ} \mathrm{C}$

Humidité relative : 85 à $90 \%$

Les champignons frais ne se conservent pas longtemps et, par conséquent, ne sont entreposés que pendant de courtes périodes. La détérioration est caractérisée par un brunissement en surface et par la rupture de l'anneau. Les champignons frais cueillis peuvent se conserver en parfait état pendant 5 jours à $0{ }^{\circ} \mathrm{C}$, pendant 2 jours à $4{ }^{\circ} \mathrm{C}$ et pendant 1 jour seulement à $10^{\circ} \mathrm{C}$. Lorsque mis en vente à des températures plus élevées, il faut les écouler dès le jour de leur sortie de l'entrepôt; à $0^{\circ} \mathrm{C}$, ils ne se gardent pas plus de 3 ou 4 jours sur les comptoirs de vente, et pas plus de 2 jours à $4^{\circ} \mathrm{C}$. Pendant les périodes de transport et d'étalage, les champignons doivent être gardés continuellement sous réfrigération (112).

La rupture de l'anneau ainsi que la détérioration des champignons peuvent être empêchées dans des $\mathrm{AC}$ de $5 \%$ de $\mathrm{CO}_{2}$ et de $0,1 \%$ de $\mathrm{O}_{2}$ $\left(0^{\circ} \mathrm{C}\right)$ ou de $50 \%$ de $\mathrm{CO}_{2}$ et de 10 à $20 \%$ de $\mathrm{O}_{2}$ (187). Toutefois il faut bien s'assurer que la charge microbienne après entreposage est sécuritaire avant toute mise en vente.

\section{CHOUX}

Température : $0{ }^{\circ} \mathrm{C}$

Humidité relative : 95 à $100 \%$

Les choux hâtifs, récoltés habituellement en été avant d'avoir atteints leur pleine maturité, se conservent en entrepôt de 3 à 4 semaines à $0^{\circ} \mathrm{C}$ et à une humidité relative élevée. Étant donné qu'ils sont généralement récoltés en vue de la vente immédiate, il n'est pas avantageux, sur le plan économique, de les entreposer longtemps.

Les cultivars de chou d'hiver présentent toutefois une durée de conservation accrue, variant de 3 à 7 mois selon le cultivar, lorsqu'ils sont gardés à $0{ }^{\circ} \mathrm{C}$ et à une humidité relative élevée (tableau 6). En présence d'humidité élevée, la circulation de l'air doit être uniforme et suffisante en tous points de l'entrepôt pour éviter la condensation d'eau sur les choux aux sites les plus froids, ce qui favorise la croissance des moisissures. Le chou d'hiver est récolté à l'automne à sa pleine maturité. Cette maturité est déterminée par la teneur en sucres solides, la compacité et le poids des pommes variant entre 2 et $3 \mathrm{~kg}$, leur densité située entre 0,72 et $0,80 \mathrm{~g} \cdot \mathrm{cm}^{-3}$, et la couleur bleuâtre du feuillage due à l'abondance des cires. Récoltés trop tôt, les choux perdent beaucoup de poids et fanent en entrepôt; récoltés trop tard, les pommes sont blanchies par le gel au champ et risquent de présenter des dommages internes d'engelure non visibles de 
Tableau 6. Durée de conservation de divers cultivars de choux d'hiver à ${ }^{\circ} \mathrm{C}^{*}$

Moins de 3 mois

3 à 5 mois

5 à 6 mois

plus de 7 mois

Danish Ballhead

Eastern Ballhead

Hitoma

Hybrid F

Penn State

Ballhead

Rio Verde

Sanibel
Excel

Quick-Green

Storage

Custodian

Evergreen

Ballhead

Safekeeper

Superslaw

Winterkeeper
Green Winter

Storage Green

Ultra Green
April Green

Bartolo

Decema Extra

Hidena

Houston

Evergreen

$F_{1}$ Mercury

Polinius

Slawdena

*Ajouter 1 à 2 mois de plus pour l'AC [Tiré de Bérard and Vigier (17)].

l'extérieur. A la récolte, le chou est coupé de son pied et les feuilles externes endommagées ou trop ouvertes sont retirées. De deux à trois feuilles semi-adhérentes à la pomme sont conservées pour la protéger durant l'entreposage. Trop de feuillage nuit à la circulation de l'air. A la sortie de l'entrepôt, le parage des feuilles externes du chou est généralement requis pour la mise en marché. Le chou se conserve bien en cageots peu profond ou en pallets, à condition de ne pas excéder une hauteur de $1,5 \mathrm{~m}$, de ne pas surcharger les contenants, et d'assurer une bonne aération jusqu'au centre de la masse, parfois par air forcé. Le gel du chou en entrepôt doit être évité; bien que montrant peu de symptômes externes, le chou développe de l'engelure interne à aussi peu que $-0,8{ }^{\circ} \mathrm{C}$. Les principaux désordres d'entreposage du chou sont le flétrissement, la griselure du limbe, la bigarrure nervale, la moucheture noire, les principales moisissures notées sont le Botrytis cinerea, le Sclerotinia et l'Alternaria; et la pourriture la plus répandue est l'Erwinia carotovora $(17,18,122,162)$. Le chou peut être entreposé en $\mathrm{AC}$ à $5 \%$ de gaz carbonique et $2,5 \%$ d'oxygène à entre 0 
et $1{ }^{\circ} \mathrm{C}$ jusqu'à 10 mois. L'AC préserve la couleur verte du chou, en maintient la saveur et en retarde la sénescence (79). Cependant, l'usage de brûleurs catalytiques pour générer l'AC donne un goût désagréable au chou (55), à cause de la présence d'un résidu de combustion gazeux dans l'atmosphère autre que l'éthylène. L'AC contrôle complètement ou en partie la griselure du limbe, la bigarrure nervale et la moucheture noire $(17,18)$, mais certaines années, l'AC peut aggraver l'incidence de la médiane noire et de la tache nécrotique et accroître la susceptibilité aux désordres internes $(19,20,80)$.

Le chou ne doit pas être entreposé avec des produits horticoles générant de l'éthylène, telle la pomme. Une accumulation aussi faible que $1 \mathrm{ppm}$ de ce gaz dans un entrepôt provoque le jaunissement et l'abscission des feuilles de la tige centrale du chou. En AC cependant, l'effet nocif de l'éthylène est neutralisé par les hautes teneurs en $\mathrm{CO}_{2}$.

\section{CHOUX DE BRUXELLES}

Température : $-0,5$ à $0{ }^{\circ} \mathrm{C}$

Humidité relative : 95 à $97 \%$

Les choux de Bruxelles ne se conservent pas très longtemps, et moins longtemps isolés que fixés sur la tige récoltée. Détachés dès la récolte, ils peuvent supporter un entreposage de 3 à 4 semaines à une température de $-0,5^{\circ} \mathrm{C}$ à $0^{\circ} \mathrm{C}$ et une humidité relative élevée pour éviter le flétrissement. Afin de prévenir le jaunissement et la formation de moisissures, il faut les conserver dans de petits contenants. Ils sont sujets aux mêmes avaries que le chou et le meilleur moyen de prévenir ces dernières consiste à entreposer les choux de Bruxelles à basse température, dans un milieu bien aéré $(162,184)$.

En $\mathrm{AC}$ ( 4 à $6 \%$ de $\mathrm{CO}_{2}+1,5$ à $3 \%$ de $\mathrm{O}_{2}$ ), les choux de Bruxelles conservent mieux leur chlorophylle et sont moins sujets à la pourriture que dans un entrepôt ordinaire (105). Dans une AC idéale, les choux de Bruxelles peuvent être conservés de 1 à 3 mois.

\section{CHOU-FLEUR}

Température : $0{ }^{\circ} \mathrm{C}$

Humidité relative : 95 à $100 \%$

Le chou-fleur n'est pas habituellement gardé en entrepôt. Cependant, au besoin, il peut être conservé à une humidité relative élevée pendant près de 2 semaines à $0{ }^{\circ} \mathrm{C}$ ou pendant 1 semaine à $4{ }^{\circ} \mathrm{C}$, à condition qu'il soit entreposé en bon état et immédiatement après la récolte. Le chou-fleur est habituellement paré et mis en cageots après la récolte. Il doit être placé la tête en bas afin d'éviter tout dommage causé par l'eau, la terre ou tout autre corps étranger retenu sur 
l'inflorescence. L'emballage individuel dans du cellophane permet cependant de présenter les têtes vers le haut. En entrepôt, le chou-fleur se flétrit ou pourrit parfois; ses fleurs blanches continuent à mûrir et à brunir ou à s'étioler, s'écartant ainsi les unes des autres (162). La pourriture due à des infections d'Alternaria spp. ou de Pseudomonas maculicola se manifeste sous forme de petites taches brunes ou noires qui s'élargissent pour former de grandes lésions noires. La conservation à basse température empêche ces avaries. C'est pourquoi le prérefroidissement rapide à l'aide de glace concassée, de glace liquide ou de neige est si avantageux avant l'expédition vers les marchés (112).

Des expériences faites en Angleterre ont démontré que l'AC peut prolonger de 2 semaines la période d'entreposage du chou-fleur. Les conditions suggérées sont les suivantes : $10 \%$ de gaz carbonique, $11 \%$ d'oxygène et $79 \%$ d'azote et une température de 0 à $1{ }^{\circ} \mathrm{C}$. Un entreposage maximal de 8 semaines du chou-fleur peut aussi être fait en presence de 2 à $5 \%$ de gaz carbonique et de 2 à $5 \%$ d'oxygène, à une température de 0 à $1^{\circ} \mathrm{C}(82,210)$. Toutefois, les différences de durée et de qualité entre l'entreposage en $\mathrm{AC}$ et l'entreposage frigorifique semblent minimes.

\section{CHOU-RAVE}

Température : $0{ }^{\circ} \mathrm{C}$

Humidité relative : 95 à $100 \%$

Le chou-rave se conserve de 2 à 4 semaines entreposé a $0{ }^{\circ} \mathrm{C}$ et à une humidité relative de 95 à $100 \%$.

\section{CITROUILLES ET COURGES}

Température : 7 à $10^{\circ} \mathrm{C}$

Humidité relative : 70 à $75 \%$

Le potiron, appelé communément citrouille, est une espèce de grosse courge ronde et jaune. La durée d'entreposage des citrouilles et des courges varie selon le genre et le cultivar. Dans tous les cas, ces légumes doivent être manipulés avec soin, car la moindre meurtrissure prédispose à la pourriture en entrepôt. Un préconditionnement de 2 semaines à une température de 26 à $30^{\circ} \mathrm{C}$ dans un local chauffé à l'aide de poêles ou d'autres sources de chaleur, favorise la cicatrisation des meurtrissures légères. Afin de prolonger au maximum la durée d'entreposage, il faut laisser mûrir complètement les courges avant de les récolter et enlever complètement la tige au moment de la récolte afin d'éviter toute avarie de manutention.

Après ce préconditionnement, la température de l'entrepôt est abaissée entre 6 et $10^{\circ} \mathrm{C}$ et l'humidité relative maintenue entre 70 et 
$75 \%$. Les cultivars Table Cream et Butternut se conservent 2 mois; les courges Turban et Buttercup, 3 mois; la courge Delica et d'autres variétés japonaises, 4 à 5 mois; la Hubbard (courge à pelure rugueuse et dure), 6 mois. Afin d'assurer une conservation maximale, il faut placer les courges sur des claies, sur une seule couche et sans qu'elles se touchent. Les citrouilles ne se gardent pas en entrepôt aussi bien que les autres espèces de courges; leur durée de conservation est au plus de quelques semaines. Le zucchini, une courge d'été, extrêmement populaire, se vend tel que récolté sans préconditionnement. Sa pelure tendre exige une manipulation soignée et sa protection contre la dessication. La courge d'été (Cucurbita pepo) se récolte avant sa pleine maturité. Sa période d'entreposage à une température de $0{ }^{\circ} \mathrm{C}$ et à une humidité relative de 85 à $90 \%$ n'excède pas 2 semaines $(112$, 171).

\section{CONCOMBRES}

Température : 7 à $10^{\circ} \mathrm{C}$

Humidité relative : 95 à $100 \%$

Les concombres ne se conservent que de 10 à 15 jours entre 7 et $10^{\circ} \mathrm{C}$, à une humidité relative élevée. Ils sont sensibles aux désordres prégélifs; à une température inférieure à $7{ }^{\circ} \mathrm{C}$, le froid produit des picots et des taches aqueuses foncées qui favorisent l'implantation de pourritures, surtout si la température s'élève par la suite. Ces désordres prégélifs peuvent se produire en l'espace de 2 jours à $0{ }^{\circ} \mathrm{C}$. Le jaunissement rapide du concombre est dù à l'opposé à des températures dépassant $10^{\circ} \mathrm{C}$. La présence d'éthylène dégagé par des produits tels les tomates, les pommes et les pêches, accélère le jaunissement du concombre. Il est donc important de refroidir rapidement les concombres entre 7 et $10{ }^{\circ} \mathrm{C}$ et de maintenir cette température stable pendant l'entreposage et le transport. L'utilisation des cageots favorisant une bonne circulation d'air est recommandée. Parfois, les concombres sont enduits de paraffine afin de prévenir leur déshydratation immédiate (69).

L'entreposage des concombres de serre en $\mathrm{AC}$ contenant de 0 à $10 \%$ de gaz carbonique et de 3 à $5 \%$ d'oxygène $\left(10\right.$ à $\left.13^{\circ} \mathrm{C}\right)$ peut prolonger la durée commerciale utile de 1 à 2 semaines par rapport à l'entreposage au froid $(6,120)$. En AC, une durée totale d'entreposage de 45 jours est possible en retirant l'éthylène de l'entrepôt.

\section{ENDIVES OU SCAROLES}

Température : $0{ }^{\circ} \mathrm{C}$

Humidité relative : 95 à $100 \%$ 
L'endive ou la scarole sont des légumes feuillus qui ne se prêtent pas à un entreposage commercial prolongé. Même à la température idéale de $0{ }^{\circ} \mathrm{C}$, ces espèces ne sauraient se garder plus de 2 à 3 semaines. Les conditions d'entreposage de l'endive sont pratiquement les mêmes que celles de la laitue. Comme pour cette dernière, l'emploi de glace broyée prolonge la durée de conservation. Il faut maintenir l'humidité relative entre 90 et $100 \%$ pour prévenir le flétrissement. Un certain déjaunissement souhaitable se produit habituellement au cours de l'entreposage (112). Toutefois, en vieillissant, l'endive montre du brunissement à la base des feuilles du chicot.

\section{ÉPINARDS}

Température : $0{ }^{\circ} \mathrm{C}$

Humidité relative : 95 à $100 \%$

Les épinards se conservent généralement que pendant de courtes périodes, soit 10 à 14 jours après avoir été coupés. Un prérefroidissement rapide à l'aide de glace concassée ou de glace liquide prolonge quelque peu la durée de conservation $(112,163)$.

\section{HARICOTS DE LIMA}

Température : 0 à $4,5^{\circ} \mathrm{C}$ en cosses; $0^{\circ} \mathrm{C}$ écossés Humidité relative : 90 à $95 \%$

Les haricots de Lima entreposés en cosses se conservent 2 semaines environ à $0^{\circ} \mathrm{C}$ ou 10 jours à $4,5^{\circ} \mathrm{C}$. Une bonne aération est aussi importante pour cette espèce que pour les haricots jaunes, les deux étant sujets aux mêmes formes de pourriture. Souvent, les haricots de Lima sont entreposés déjà écossés; en ce cas, s'ils sont frais, ils se conserveront environ 2 semaines à $0{ }^{\circ} \mathrm{C}$ ou 4 jours à $4,5^{\circ} \mathrm{C}$. Entreposés trop longtemps, les haricots écossés deviennent collants et perdent leur couleur $(102,176)$.

\section{HARICOTS VERTS OU JAUNES}

Température : 7 à $10^{\circ} \mathrm{C}$

Humidité relative : 90 à $95 \%$

Refroidis immédiatement après la récolte et maintenus à une température de $7^{\circ} \mathrm{C}$, les haricots jaunes se conservent de 8 à 10 jours. Il faut cependant éviter le contact avec la glace. À une température de $4,5^{\circ} \mathrm{C}$ ou moins, ils sont sujets à des désordres prégélifs qui se manifestent par des picots en entrepôt et des taches roussâtres après l'entreposage. Une bonne circulation d'air est importante en tout temps. Si la circulation d'air est insuffisante, l'humidité s'accumule 
au centre de la masse et accélère la pourriture et d'autres dommages. Les haricots jaunes conservés trop longtemps sont surtout sujets à la pourriture molle aqueuse, à la pourriture molle visqueuse, à la moisissure chevelue (Rhizopus), à la moisissure grise et à l'anthracnose $(102,176)$. L'entreposage en $\mathrm{AC}$ des haricots verts en présence de 0 à $10 \%$ de gaz carbonique plus 2 à $6 \%$ d'oxygène $\left(7^{\circ} \mathrm{C}\right)$ peut prolonger de 3 jours la durée après la récolte du légume par rapport à l'entreposage à l'air à la même température, mais cette courte durée ne justifie pas son usage (59).

\section{LAITUE}

Température : $0{ }^{\circ} \mathrm{C}$

\section{Humidité relative : 95 à $100 \%$}

Bien qu'il existe plusieurs espèces de laitue, la variété commerciale la plus populaire est la laitue pommée. La laitue n'est pas un produit qui se prête à un entreposage prolongé, mais elle peut supporter un entreposage de 2 à 3 semaines, voire un peu plus, à condition d'abaisser sa température rapidement à $0{ }^{\circ} \mathrm{C}$, de la garder à ce niveau, et de maintenir l'humidité à un niveau très élevé. Il faut surveiller la température et la maintenir à $0{ }^{\circ} \mathrm{C}$ sans risque de gel car la laitue gèle à des températures de $-0,2^{\circ} \mathrm{C}$ seulement (112). L'emballage de la laitue dans des sacs individuels de polyéthylène perforés ou dans des cageots doublés permet de réduire la déshydratation au cours de l'entreposage et du transport.

Immédiatement après la récolte, il est conseillé de parer la laitue, de la prérefroidir sous vide ou à l'eau glacée, et de l'entreposer dans de la glace pour qu'elle garde sa fraîcheur. Il faut rejeter toute laitue avariée, en particulier celle qui est atteinte de brûlure de la pointe. Cette anomalie entraîne de la pourriture visqueuse en entrepôt (163).

Le refroidissement sous vide a révolutionné le procédé de manutention de la laitue dans les régions maraîchères spécialisées. De grandes quantités de laitues, empaquetées en boîte ou en cageots et de préférence mouillées, sont déposées dans une chambre où l'on fait le vide. L'évaporation de l'eau à l'intérieur et autour de la laitue a pour effet de produire un refroidissement rapide. De cette façon, les contenants demeurent secs. Il est préférable d'utiliser des contenants en fibres pour l'expédition et la mise en marché. Ils sont plus solides et résistent mieux à la pourriture $(9,10)$.

La laitue ne doit pas être entreposée avec des fruits, tels les pommes, les poires, les pêches ou les melons, qui dégagent de l'éthylène. De faibles concentrations de ce gaz (1 ppm) provoquent le jaunissement et la formation de taches rousses. Une atmosphère pauvre en oxygène évite la formation de taches rousses, mais une concentration de gaz carbonique de $4 \%$ et des basses températures 
peuvent provoquer des taches brunes (BNS) chez certains cultivars $(26,104)$. La laitue saine s'entrepose bien jusqu'à 75 jours en $\mathrm{AC}$ $\left(2,5 \%\right.$ de gaz carbonique et $2,5 \%$ d'oxygène à $\left.2{ }^{\circ} \mathrm{C}\right)(175)$.

\section{MAÏS SUCRÉ}

Température : $0{ }^{\circ} \mathrm{C}$

Humidité relative : 90 à $100 \%$

Dans des conditions optimales de refroidissement et d'entreposage, le maïs sucré se conserve 8 jours au maximum. Il faut le récolter au stade laiteux (c'est-à-dire lorsque le jus du grain est liquide et blanc) et le refroidir le plus rapidement possible. Le prérefroidissement à l'eau glacée est le plus efficace; il se fait par arrosage ou par immersion à des températures voisines de $0{ }^{\circ} \mathrm{C}(83,185)$. Le prérefroidissement sous vide ou à l'air forcé peut fonctionner que si le maïs est humide. Le but principal du prérefroidissement est de conserver la succulence du maïs. Cette qualité se perd facilement lors de la transformation normale des sucres en amidon. Comme ces réactions s'effectuent beaucoup plus rapidement à haute température (près de six fois plus vite à $20^{\circ} \mathrm{C}$ qu'à $0{ }^{\circ} \mathrm{C}$ ), il est indispensable de refroidir le maïs aussi rapidement que possible (35).

Avant d'être expédié sur le marché, le maïs doit être prérefroidi à $0{ }^{\circ} \mathrm{C}$ au cours des 6 heures qui suivent la récolte et recouvert abondamment de glace; il faut veiller à ce que la glace soit en contact avec le plus d'épis possibles. En maintenant une bonne circulation d'air à l'intérieur des amoncellements de maïs, l'effet isolant de l'enveloppe et l'épi, qui retiennent la chaleur de la respiration, est amoindrie. À cette fin, la méthode la plus efficace consiste à emballer le maïs dans des cageots d'une capacité de 5 douzaines chacun, lesquels sont d'ailleurs les plus courants (174).

Pour des renseignements additionnels concernant le maïs sucré, consulter l'ouvrage de référence 77 .

\section{OIGNONS}

Les oignons se conservent en entrepôt sous trois formes : les petits oignons verts (en botte), les oignons à repiquer (petits oignons séchés) et les oignons secs (gros oignons séchés). On entrepose surtout les gros oignons secs.

\section{Oignons verts}

Température : $0{ }^{\circ} \mathrm{C}$

Humidité relative : 95 à $100 \%$ 
La durée d'entreposage de ces oignons est courte. Soumis à un prérefroidissement rapide à l'eau glacée, dans de la glace broyée ou de la glace liquide, les oignons verts peuvent conserver leur fraîcheur jusqu'à 2 semaines.

\section{Oignons à repiquer}

\section{Température : $0{ }^{\circ} \mathrm{C}$}

\section{Humidité relative : 65 à $75 \%$}

Habituellement, les oignons à repiquer sont gardés en entrepôt ordinaire et refroidis à l'air. À cause de leur petite taille, ils sont étalés dans des caissettes à claire-voie qui assurent une bonne circulation de l'air. Dès qu'ils sont empilés, ils ont tendance à se tasser, ce qui empêche l'aération. À part cela, leur entreposage demande les mêmes soins que les oignons séchés.

\section{Oignons séchés}

Température : $0{ }^{\circ} \mathrm{C}$

\section{Humidité relative : 50 à $70 \%$}

L'oignon est une plante bisannuelle : la première année, il produit un bulbe; la deuxième année, des fleurs et des graines. L'entreposage a pour but de prévenir toute forme de germination, même interne, du bulbe. Au début de l'entreposage, l'oignon est en dormance, mais après 3 à 6 mois, il entre dans une période critique de réveil vernal au cours de laquelle se manifestent des symptômes internes et externes de croissance. L'entreposage en milieu très humide stimule la croissance des racines, tandis que la moindre élévation de température, à ce moment-là, accélère la croissance des pousses. Même le développement interne du coeur diminue la qualité de l'oignon et oblige tôt ou tard à mettre fin à l'entreposage. C'est pourquoi la période d'entreposage des oignons séchés est d'environ 5 mois selon le cultivar, les conditions de température et certains autres facteurs (209).

Cependant, les oignons traités au champ ou avant entreposage avec des inhibiteurs de germination, tels que l'hydrazide maléique ou l'irradiation aux rayons gamma, peuvent demeurer indéfiniment à l'état latent $(78,124)$. C'est ainsi que leur durée d'entreposage est prolongée de 8 à 10 mois selon l'efficacité du traitement, le cultivar des oignons, la présence de maladies et le procédé de séchage des bulbes. (Important : consulter les règlements en vigueur dans votre région, au sujet des traitements contre la germination, avant de les appliquer).

Les oignons sont arrachés au moment où $50 \%$ au moins des fanes se sont affaissées au sol. Iis sont alors déposés sur place pour un premier séchage des fanes. L'aspect cassant de la pelure externe et la fanaison 
jusqu'au collet indiquent que le séchage est suffisant. A ce moment, les oignons sont récoltés et transportés à l'entrepôt pour une seconde période de séchage. Les oignons sont empilés dans des boîtes sur une hauteur maximale de 4,5 m, à travers lesquelles de l'air forcé circule. Les deux premiers jours, de l'air à la température de l'extérieur y circule, à raison de $1,5 \mathrm{~m}^{3}$ d'air par minute et par mètre cube d'oignons. Puis, pendant les 8 à 10 jours suivants, de l'air chauffé entre 24 et $30^{\circ} \mathrm{C}$ (à la source de chaleur) y passe à une humidité relative de $60 \%$; enfin, de l'air frais de l'extérieur y circule pour refroidir les oignons avant de les entreposer à $0^{\circ} \mathrm{C}$. Lorsque la pourriture du collet due au Botrytis allili pose un problème, les oignons sont traités en élevant la température de la pièce à $45{ }^{\circ} \mathrm{C}$ pendant plus de 5 ou 6 jours et en les maintenant pendant un jour à cette température, après quoi ils sont refroidis à la température définitive de l'entrepôt pendant 2 à 3 jours. Pour un entrepôt de $700 \mathrm{t}$, cette technique nécessite trois réchauffeurs au mazout de $160000 \mathrm{kcal} / \mathrm{h}$ avec un débit approximatif d'air de 20000 à $40000 \mathrm{~m} 3 / \mathrm{h}$ à travers le produit (138). Près de $5 \%$ du poids des oignons doit être éliminé par évaporation. La fin du séchage est notée lorsque le collet est totalement fermé et que la pelure est cuivrée et fine sur plus d'une assise. Les oignons trop séchés perdent leur pelure externe. Un excès d'humidité ou des températures élevées provoquent la formation de taches sur la pelure. La condensation d'eau à la surface des bulbes peut aussi avoir le même effet; cela se produit lors de journées chaudes où l'air extérieur humide et chaud entre en contact avec les oignons gardés à une température plus basse et que le point de rosée de l'air extérieur ainsi refroidi est atteint.

Les oignons sont classés selon leur forme et leur couleur, la variété la plus en demande sur le marché étant l'oignon jaune rond. Au Canada, les cultivars les plus populaires sont Abco, Canada Maple, Capable, Copra, l'Exporter, Progress, Rocket et Taurus. L'aspect de chaque variété varie considérablement suivant la technique de préconditionnement. Le séchage à l'air, dans un bâtiment, produit des bulbes de couleur et de qualité très uniformes. Un séchage à point laisse la pelure intacte et luisante $(35,78,209)$.

\section{PANAIS}

Température : $0^{\circ} \mathrm{C}$

Humidité relative : 95 à $100 \%$

Les panais requièrent ordinairement les mêmes soins que les carottes et se conservent de 2 à 4 mois, à $0{ }^{\circ} \mathrm{C}$ et à une humidité relative élevée. Ils sont parés au moment de la récolte à l'automne. Ils peuvent être entassés en vrac, mais le plus souvent ils sont placés dans des palettes de bois, des caisses ou autres sortes de contenants. 
L'utilisation de sacs en polyéthylène perforé pour doubler les contenants, empêche les pertes d'humidité. Les principaux problèmes que posent l'entreposage des panais, sont le brunissement de surface et le ratatinage. Le brunissement de surface provient de dommages mécaniques qui brisent les cellules épidermiques. Pour éviter cette avarie, il faut récolter et en emballer les racines en évitant de les frotter inutilement.

\section{PATATES DOUCES}

Température : 13,0 à $16,0^{\circ} \mathrm{C}$ Humidité relative : 85 à $90 \%$

Les patates douces demandent de longues périodes de temps chaud pour leur croissance et aussi une température élevée pendant l'entreposage. Des températures d'entreposage inférieures à $10^{\circ} \mathrm{C}$ provoquent la formation de désordres prégélifs sous forme de petites taches, surtout si les tubercules sont mal séchés. Ainsi atteintes, les patates douces pourrissent plus vite et se décolorent avant ou après la cuisson.

Les patates doivent être récoltées à maturité et exemptes d'avaries. Elles se conserveront mieux en entrepôt si elles ont été préconditionnées pendant 10 jours à $30^{\circ} \mathrm{C}$ et à une humidité relative de plus de $90 \%$. Il est généralement nécessaire de chauffer ou d'humidifier l'air pour ce traitement. Après le préconditionnement, la température est abaissée (entre 13 et $16^{\circ} \mathrm{C}$ ) et l'humidité relative est maintenue entre 85 et $90 \%$. Dans ces conditions, les patates douces peuvent se conserver de 4 à 6 mois (112).

\section{PETITS POIS VERTS}

Température : $0^{\circ} \mathrm{C}$

Humidité relative : 95 à $100 \%$

Tout comme le maïs, les petits pois verts se détériorent à la suite des réactions normales de conversion des sucres en amidon. Dans la mesure du possible, les pois non écossés doivent être prérefroidis immédiatement après la récolte, par immersion dans de l'eau glacée, ou par dépôt de glace râpée ou liquide dans les contenants. $\AA 0^{\circ} \mathrm{C}$, ils se conservent de 1 à 2 semaines. À $4{ }^{\circ} \mathrm{C}$, la période d'entreposage est d'environ 3 ou 4 jours. Les établissements de transformation gardent parfois les pois verts écossés en entrepôt. La durée de conservation en est alors considérablement raccourcie mais il est possible de la prolonger en refroidissant rapidement les pois, en les lavant pour éliminer le jus superficiel (112), puis en les gardant à $0{ }^{\circ} \mathrm{C}$. 
Température : -1 à $0,0^{\circ} \mathrm{C}$

Humidité relative : 95 à $100 \%$

Les poireaux sont entreposés debout dans des cageots, puis gardés dans les mêmes conditions que le céleri. Avec une manutention soignée, ils peuvent se conserver en entrepôt de 1 à 3 mois. Il est suggéré de les emballer dans des sacs de plastique scellés (112), puisque des études indiquent que les poireaux peuvent tolérer une concentration maximale de gaz carbonique de $16 \%$. Cette pratique retarde le jaunissement et la pourriture. Les poireaux peuvent être entreposés jusqu'à 6 mois dans une atmosphère de $5 \%$ de gaz carbonique et de $1 \%$ d'oxygène $\left(0{ }^{\circ} \mathrm{C}, \mathrm{HR} 98\right.$ à $\left.100 \%\right)$ tandis qu'à l'air, dans les mêmes conditions frigorifiques, ils se conservent au plus 12 semaines.

\section{POIVRONS}

Température : 7 à $10^{\circ} \mathrm{C}$ Humidité relative : 85 à $90 \%$

Les poivrons se conservent de 8 à 10 jours en entrepôt à une température comprise entre 7 et $10^{\circ} \mathrm{C}$. A des températures plus élevées, ils rougissent et se gâtent rapidement. Aux basses températures de 0 à $2{ }^{\circ} \mathrm{C}$, ils développent des désordres prégélifs sous la forme de picots où s'installe facilement la pourriture; celle-ci cause des dommages graves et malodorants lors du retour des poivrons à la température ambiante (164). L'emballage dans des sacs de polyéthylène perforés et le paraffinage prolongent la période d'entreposage et de mise en marché des poivrons (69).

\section{POMMES DE TERRE HÂTIVES}

Température : voir ci-après

Humidité relative : 85 à $90 \%$

Ces pommes de terre se récoltent avant maturité. Elles sont destinées à la consommation immédiate et ne peuvent se conserver longtemps. Toutefois, elles peuvent se garder plusieurs semaines si elles sont parfaitement saines. Lorsque destinées à la consommation immédiate, les pommes de terre hâtives peuvent être entreposées à $10^{\circ} \mathrm{C}$, mais si elles sont destinées à la transformation, particulièrement pour en faire des croustilles, il est préférable de les entreposer à des températures comprises entre 15 et $21^{\circ} \mathrm{C}$. Quelle que soit la température, l'humidité relative doit toujours être de 85 à $90 \%$ (112). 


\section{POMMES DE TERRE TARDIVES}

Température : voir ci-après

Humidité relative : 85 à $90 \%$

La majeure partie de la récolte de pommes de terre se fait à maturité complète. La maturité des pommes de terre et le risque de dommages pouvant survenir au champ à cause du gel déterminent le moment de la récolte. La maturité est difficile à définir, mais l'important est de laisser mûrir les pommes de terre jusqu'à ce que leur teneur en matière sèche atteigne un maximum (densité élevée) et que la pelure s'épaississe. Ces conditions se produisent environ 2 semaines après le dessèchement des fanes. Habituellement, les fanes sont détruites par des procédés mécaniques, des produits chimiques ou en coupant l'eau d'irrigation. La destruction des fanes à l'aide de produits chimiques est recommandée lorsqu'il y a danger de brûlures tardives (128).

Les pommes de terre doivent être manipulées avec soin car les tubercules se meurtrissent et craquent facilement. Ces blessures peuvent entraîner du ratatinage et ouvrir la porte aux maladies en entrepôt. Les pommes de terre, ainsi avariées et infectées par la maladie, ne doivent pas être entreposées avec les autres.

Il est extrêmement important de préconditionner les pommes de terre avant de les entreposer définitivement. Le séchage a pour but de raffermir et de durcir la pelure, ce qui réduit la perte d'eau et de poids de la charge, augmente la résistance aux maladies et favorise la cicatrisation des meurtrissures mineures. Les deux processus physiologiques en jeu sont la subérisation et la formation d'un périderme. Le premier processus dure 2 jours environ à $20^{\circ} \mathrm{C}$, tandis que le deuxième est beaucoup plus lent (189). Pour ces deux processus, la température et l'humidité relative doivent être élevées. La cicatrisation cesse pratiquement à des températures de $8{ }^{\circ} \mathrm{C}$ ou moins. Entre 13 et $16^{\circ} \mathrm{C}$ et à une humidité relative très élevée $(95 \%)$, un préconditionnement de 10 à 14 jours est requis (128). Toutefois, s'il y a présence de brûlures tardives, la période de préconditionnement devra être abrégée pour éviter l'évolution de la maladie.

La température influence grandement la physiologie de la pomme de terre. Après le préconditionnement, la température idéale d'entreposage varie selon l'usage auquel les pommes de terre sont destinées, la durée de l'entreposage et le traitement préalable fait contre la germination. Des températures de $4{ }^{\circ} \mathrm{C}$ et plus favorisent la germination, tandis que des températures inférieures à $10^{\circ} \mathrm{C}$ provoquent l'accumulation de sucres et celles inférieures à $2{ }^{\circ} \mathrm{C}$ peuvent causer des dommage prégélifs (166). Ces facteurs justifient les recommandations suivantes:

Pomme de terre de semence : 2 à $3,5^{\circ} \mathrm{C}$; période d'entreposage de 7 à 8 mois ou plus. 
Pomme de terre de table : 7 à $10^{\circ} \mathrm{C}$ pour un entreposage de courte durée ou jusqu'à l'émergence des germes. Ces températures valent également pour une longue période d'entreposage si les turbercules ont été traités contre la germination; dans le cas contraire, la température doit être abaissée à $4^{\circ} \mathrm{C}$. Selon le cultivar, les pommes de terre de table peuvent être gardées en entrepôt durant 4 à 9 mois.

Tubercules destinés à la préparation de croustilles: Il est préférable de traiter ces tubercules contre la germination et de les conserver à $10^{\circ} \mathrm{C}$. Entreposés à $4{ }^{\circ} \mathrm{C}$, les tubercules donnent des croustilles brunes. Cette perte de qualité peut être prévenue par un procédé coûteux de reconditionnement lors de la transformation.

Tubercules destinés à la préparation de frites: Ces tubercules se gardent à des températures de 4 à $10^{\circ} \mathrm{C}$ car ici le brunissement n'a pas autant d'importance que dans le cas des croustilles. Ces pommes de terre sont maintenues à une humidité relative élevée ( 85 à $90 \%)$ en tout temps, surtout lorsque la température est de $7^{\circ} \mathrm{C}$ ou plus, et que les tubercules sont sujets à ratatiner. En présence de température de l'ordre de $10{ }^{\circ} \mathrm{C}$, les inhibiteurs de germination jouent un rôle important dans l'entreposage car ils permettent d'éviter la formation des sucres et la nécessité de recourir à un reconditionnement. L'hydrazide maléique (forme aminée), appliquée aux fanes 2 semaines après la pleine floraison, à raison de $3 \mathrm{~L}$ dans 880 à $1320 \mathrm{~L}$ d'eau par hectare, s'est révélée très efficace (128). L'ispropyle- $N$-(3-chlorophényl) carbonate (CIPC) donne aussi des résultats satisfaisants durant l'entreposage, si toutes les coupures et meurtrissures des tubercules sont cicatrisées avant son application (27). Le traitement aux rayons gamma ( $85 \mathrm{~Gy}$ ) du cobalt 60 s'est révélé efficace (130). Ce traitement peut toutefois faire augmenter la teneur en sucres (28), mais de façon temporaire (32). Un procédé, jugé très efficace en Grande-Bretagne et ailleurs, consiste à utiliser de l'alcool nonylique (3,5,5-triméthyle-hexane-1-ol) en l'appliquant directement sur les pommes de terre entreposées par évaporation dans le système de ventilation, à raison de $1 \mathrm{~mL} / \mathrm{m}^{3}$ d'air avec un débit de $1,5 \mathrm{~m} 3 / \mathrm{min}$ la tonne de pommes de terre (28). (Important : consulter les règlements en vigueur dans la région avant d'employer un produit chimique quelconque).

Les pommes de terre sont conservées en majeure partie dans des entrepôts ventilés à l'air froid ou réfrigérés. L'uniformité de la température et de la répartition de l'air dans l'entrepôt est essentielle à la bonne conservation des pommes de terre. La condensation d'eau sur les zones froides des murs et du plafond de l'entrepôt ou à l'intérieur de la masse de tubercules est nocive. Si les pommes de terre sont entreposées dans des compartiments, elles ne doivent pas être empilées sur une hauteur de plus de $4,5 \mathrm{~m}$, et le dessus de la pile 
doit être au même niveau. Un tas en pointe favorise la condensation d'eau. Aujourd'hui, les sacs, les boîtes et autres contenants font place aux palettes ou à l'entreposage en vrac, ce qui permet une manutention plus économique.

Les pommes de terre doivent être entreposées dans l'obscurité car la lumière favorise la formation de solanine, un composé toxique au goût amer. La présence de solanine est soupçonnée quand les tubercules sont verts car la lumière entraîne aussi la formation de chlorophylle.

Les murs des entrepôts doivent être suffisamment isolés et le système de ventilation bien régler pour éviter les basses températures et surtout le gel en hiver. Par contre, l'apport d'air humide plus chaud que les pommes de terre peut causer de la condensation. L'aération doit être suffisante pour empêcher l'accumulation de gaz carbonique; la présence excédentaire de ce gaz élève la teneur en sucres (72) et, dans les cas graves, cause la formation du coeur noir (163 165).

Les entreprises de transformation de pommes de terre, en particulier les fabricants de croustilles, sont très exigeantes quant à la qualité des tubercules entreposés. Ces transformateurs vérifient très soigneusement la teneur en matière sèche, la teneur en sucres réducteurs et la texture des tubercules. Le choix de cultivars appropriés et de bonnes techniques de manutention et d'entreposage sont les principaux facteurs qui déterminent la qualité des pommes de terre de transformation. Lorsqu'il y a accumulation de sucres réducteurs, les tubercules doivent être reconditionnés à des températures comprises entre 15 et $21^{\circ} \mathrm{C}$ pendant une semaine ou plus, afin de permettre la transformation des sucres en amidon ou en d'autres composés n'altérant pas la qualité de cuisson. Toutefois, cette technique se révèle souvent inefficace pour des raisons encore mal identifiées. Le lavage des croustilles crues et leur trempage dans l'eau s'est révélé efficace à cet égard (192). Les cultivars qui se prêtent le mieux à la transformation sont l'Atlantic, la Kennebec, la Norchip et la Superior, même s'ils ne répondent pas toujours comme souhaité aux procédés de reconditionnement. Pour de plus amples renseignements sur les pommes de terre, consulter les ouvrages de référence 16,75 et 143 .

Lougheed (110) a trouvé que l'entreposage des pommes de terre dans une atmosphère contenant $15 \%$ de gaz carbonique $\left(10^{\circ} \mathrm{C}\right)$ inhibe la germination et que l'entreposage des pommes de terre dans 2 à $5 \%$ d'oxygène semble être prometteuse pour l'entreposage à long terme des pommes de terre destinées à la fabrication des croustilles. L'entreposage en AC n'est pas recommandé pour les pommes de terre car l'amélioration de la qualité apportée, comparée à l'entreposage ventilé ou frigorifique, n'est pas suffisante pour en justifier l'investissement supplémentaire. 


\section{RADIS}

Température : $0{ }^{\circ} \mathrm{C}$

\section{Humidité relative : 95 à $100 \%$}

Les radis de printemps se vendent généralement en bottes et avec leurs feuilles. Ils perdent ainsi rapidement leur turgidité. Aussi, maintenant la tendance est à la vente des radis de printemps déjà parés et emballés dans des sacs de plastique. Ils se conservent en entrepôt environ 2 semaines à $0^{\circ} \mathrm{C}$ et à une humidité relative élevée. Les radis prérefroidis à l'eau glacée après la récolte ou par l'addition de glace durant l'expédition gardent leur aspect de fraîcheur et se vendent mieux. Les radis d'hiver, plus gros, se conservent en bon état de 2 à 4 mois dans les conditions d'entreposage recommandées pour les radis de printemps (112).

\section{RAIFORT}

Température : -1 à $0{ }^{\circ} \mathrm{C}$

Humidité relative : 90 à $95 \%$

Le raifort se conserve bien de 10 à 12 mois, à $0{ }^{\circ} \mathrm{C}$ et à une humidité relative de 90 à $95 \%$. Il est préférable de récolter les racines après qu'elles ont été saisies par le froid, car elles se conservent mieux que les racines récoltées en pleine croissance. Des inspections fréquentes de la qualité des lots sont recommandées (112).

\section{RHUBARBE}

Température : $0{ }^{\circ} \mathrm{C}$

Humidité relative : 95 à $100 \%$

Les tiges de rhubarbe, fraîches et en bon état, peuvent se conserver en entrepôt de 2 à 3 semaines. Il faut placer les bottes dans des cageots, lesquels sont empilés de façon à assurer une bonne circulation d'air de tout côté, sinon il y a danger d'échauffement et de moisissure (112).

\section{RUTABAGAS OU NAVETS}

Température : $0{ }^{\circ} \mathrm{C}$

Humidité relative : 95 à $100 \%$

La variété Laurentienne est la plus communément cultivée; elle se prête bien à l'entreposage à long terme en vue de ventes tardives. Elle peut se conserver jusqu'à 6 mois à $0{ }^{\circ} \mathrm{C}$ et à une humidité relative de 95 à $100 \%$. On a trop tendance à négliger les précautions à prendre lors de la manutention de ce légume à la récolte. Pourtant, en y 
apportant le soin voulu, les meurtrissures et la pourriture qui s'y infiltrent peuvent être réduites durant l'entreposage. Le traitement à l'hydrazide maléique prévient efficacement les repousses au collet lorsque les conditions d'entreposage ne sont pas idéales. (Important: consulter les règlements en vigueur dans la région avant d'utiliser un produit chimique quelconque). Le rutabaga est généralement entreposé en vrac mais il est préférable de le conserver dans des palettes pour favoriser une expédition sélective des lots.

Ce légume se prête bien au paraffinage qui en améliore l'aspect et prévient les pertes d'humidité. Le paraffinage à la sortie de l'entrepôt a considérablement contribué à établir la renommée internationale du rutabaga canadien $(53,84,129)$.

\section{SALSIFIS}

Température : $0{ }^{\circ} \mathrm{C}$

Humidité relative : 95 à $100 \%$

Le salsifis exige les mêmes soins que les carottes parées. Un gel superficiel ne l'endommage pas mais il exige une manipulation rigoureusement soignée. Le salsifis se conserve de 2 à 4 mois dans les conditions mentionnées plus haut (112).

\section{TOMATES}

Température : mûres, $10,0^{\circ} \mathrm{C}$; mûrissantes, 13,0 à $16,0^{\circ} \mathrm{C}$ Humidité relative : 85 à $90 \%$

Les tomates se récoltent ordinairement vertes-palissantes ou partiellement colorées. Le but de l'entreposage consiste à régler le processus de maturation. Des températures inférieures à $10^{\circ} \mathrm{C}$ dans les champs ou en entrepôt peuvent entraîner des désordres prégélifs. En bas de $10^{\circ} \mathrm{C}$, le rougissement du fruit est réduit et les risques de coloration inégale s'accentuent; des picots, du blettissement et l'affaissement des tissus surviennent, alors que le fruit reste sans saveur $(196,208)$. L'influence de la température est complexe. Parfois, l'exposition momentanée à de basses températures ne semble causer aucun dommage.

Une température de $13{ }^{\circ} \mathrm{C}$ est recommandée pour une maturation lente. À cette température, la plupart des cultivars se conservent bien de 2 à 6 semaines et se colorent très lentement. A $15{ }^{\circ} \mathrm{C}$, le processus de coloration évolue rapidement (166). En maintenant la température à $18{ }^{\circ} \mathrm{C}$, une coloration rapide sans ramollissement notable est obtenue. Des températures égales ou supérieures à $21{ }^{\circ} \mathrm{C}$ favorisent une maturation rapide de même que des changements de couleur, de texture et de saveur notoires. 
Lorsque les tomates sont bien mûres, la période d'entreposage peut être prolongée en abaissant la température à $10^{\circ} \mathrm{C}$. Des expériences ont démontré que les tomates mûres se conservent assez bien à des températures variant entre 0 et $4{ }^{\circ} \mathrm{C}$ mais qu'elles se ramollissent parfois quelque peu à $2^{\circ} \mathrm{C}$. Par conséquent, les tomates mûres ne devraient pas être gardées en entrepôt plus de quelques jours (61, 173).

L'usage d'éthylène gazeux en concentration infime fait accélérer la maturation et la coloration des tomates. Le mûrissement des tomates est ainsi accéléré par une exposition à 300 à 400 ppm d'éthylène à $20^{\circ} \mathrm{C}$. Cette pratique, pas toujours concluante, se substitue à l'application d'agents chimiques de mûrissement au champ. Les ouvrages de référence 112 et 163 donnent de plus amples renseignements sur les tomates. Des applications sur le terrain de bénomyl accélèrent le mûrissement probablement en stimulant la production d'éthylène (188).

Selon le cultivar employé, l'AC contribue plus ou moins sensiblement au maintien de la qualité et prolonge la durée d'entreposage de la tomate (108). Une atmosphère de $2,5 \%$ de gaz carbonique et de $2,5 \%$ d'oxygène à $13{ }^{\circ} \mathrm{C}$, assure un contrôle optimal des moisissures : Phoma destructera, Alternaria alternata, Botrytis cinerea et $F$ usarium spp., alors qu'une atmosphère de $5,0 \%$ de gaz carbonique et 2,5\% d'oxygène est dite optimale au Québec et en Nouvelle-Écosse (41). L'usage commercial du principe d'une $\mathrm{AC}$ riche en gaz carbonique et basse en oxygène semble limité au cas où un poids connu de tomates est emballé dans une membrane à perméabilité différentielle et où le produit génère sa propre atmosphère $(3)$.

\section{CONCEPTION ET CONSTRUCTION DES ENTREPOTS FRIGORIFIQUES}

\section{CONSIDÉRATIONS GÉNÉRALES}

Lors de la construction d'un grand entrepôt frigorifique, il est bon d'obtenir des plans et des devis détaillées pour le bâtiment et le matériel. Ainsi les entrepreneurs ont des chances égales lors de la présentation des soumissions et les propriétaires ont des garanties de construction conformes aux normes. Les renseignements qui suivent ne sont pas suffisants pour les entrepreneurs, bien que de quelque utilité pour la préparation de plans et devis d'entrepôts. Ils sont plutôt destinés à servir de guide pour ceux qui construisent de petits entrepôts sans recourir aux services de spécialistes.

Il existe un certain nombre de publications relatives à la construction d'entrepôts réfrigérés $(1,58,63,132,141,168,169)$. Le 
Service des plans du Canada a également préparé des plans d'entrepôt à fruits et légumes. Les ministères provinciaux de l'Agriculture et des organismes-conseils locaux peuvent fournir un catalogue de ces plans. Notre but, ici, n'est pas d'étudier en détail la construction des entrepôts frigorifiques, mais d'insister sur certains facteurs reconnus comme importants sur les plans technique et économique. Il faut concevoir l'entrepôt en fonction d'une manutention mécanique de produits en vrac ou sur palettes. Cela signifie que le bâtiment doit comporter un plancher en béton de niveau, sans poteaux de soutien, et présenter une hauteur libre qui soit fonction de la hauteur des produits entreposés. Il faut définir la méthode d'entreposage lors de l'établissement des plans définissant la taille et la forme de l'entrepôt.

Dans les entrepôts où la palettisation est utilisée, les rangées de produits doivent être parallèles à la direction de la circulation de l'air et espacées de 12 à $15 \mathrm{~cm}$ les unes des autres. Toutefois, des études récentes (12) ont remis en question ce besoin d'espacement.entre les rangées pourvu que la circulation d'air soit suffisante. Il faut laisser un espace d'au moins $25 \mathrm{~cm}$ entre les pallettes et le mur. Cet espace est nécessaire pour le retour de l'air circulant vers les ventilateurs et pour éviter le gradient de température noté près des murs de l'entrepôt en réponse aux conditions extérieures. Les conduites d'air ou les serpentins de ventilateur devraient être installés non pas à l'extérieur mais au-dessus de l'allée de chargement. Celle-ci est généralement située au centre dans les grands entrepôts ou le long d'un des murs dans les petits entrepôts.

Il faut laisser un espace de 0,5 à $1 \mathrm{~m}$ ou plus entre le sommet des produits emmagasinés et le plafond, pour permettre à l'air de circuler vers les murs extérieurs sans être gêné par les solives du plafond. La vitesse de l'air sortant du ventilateur ou d'une conduite d'aération doit être suffisante pour assurer une circulation uniforme dans les points les plus éloignés de l'entrepôt; sinon la réfrigération est inadéquate et les températures peu uniformes favorisent la condensation ou le gel localisé.

\section{CONDITIONS D'ISOLATION}

Les définitions suivantes de certains termes techniques faciliteront la compréhension du texte.

Chaleur d'infiltration. Les définitions de chaleur sensible et de chaleur de respiration données dans la première partie de cette publication portent sur l'aspect réfrigération des produits. La chaleur d'infiltration est une autre source de chaleur contre laquelle il faut lutter dans les entrepôts. Cette source de chaleur se déplace d'un point chaud vers un point froid, à une vitesse de transmission d'autant 
plus rapide que la différence de température entre les points est grande et que la résistance thermique au transfert de la chaleur est faible. Dans un entrepôt réfrigéré, l'isolant et les autres matériaux employés dans la construction opposent une certaine résistance au transfert de la chaleur. Dans un entrepôt bien isolé, la charge de réfrigération imposée par la chaleur d'infiltration est faible comparativement à la charge que provoque la chaleur sensible au chargement des produits. Les ampoules et les moteurs électriques, les chariots élévateurs, les travailleurs et les infiltrations d'air chaud par les portes ou autres fentes constituent autant de sources de chaleur. Les définitions suivantes relatives à la chaleur peuvent être utiles :

Capacité calorifique. La quantité de chaleur requise pour élever de $1{ }^{\circ} \mathrm{C}$ la température de $1 \mathrm{~kg}$ d'eau est appelée capacité calorifique et elle est équivalente à $4,2 \mathrm{~kJ}$ (kilojoules).

Charge frigorifique. La charge frigorifique est la capacité de réfrigération requise par unité de temps pour exploiter un entrepôt avec succès en période de pointe. Elle détermine la taille du système de réfrigération à acheter et la puissance nécessaire qu'il doit avoir. La charge frigorifique est habituellement exprimée en kilojoules par heure (watts). $1 \mathrm{~W}$ (watt) équivaut à $3,6 \mathrm{~kJ} / \mathrm{h}$.

Chaleur spécifique. La chaleur spécifique est le nombre de kilojoules qu'il faut ajouter ou retirer à $1 \mathrm{~kg}$ d'une substance pour modifier sa température de $1{ }^{\circ} \mathrm{C}$. Une valeur de 3,8 est acceptable pour la plupart des fruits et des végétaux dont la chaleur spécifique exacte n’est pas connue.

Valeur $R$ de résistance thermique. La résistance au passage de la chaleur offerte par différents matériaux de construction a été mesurée. Elle est exprimée en valeur de R. Cette résistance mesure le nombre de kilojoules à l'heure qui traversent $1 \mathrm{~m}^{2}$ de matériau d'une épaisseur de $1 \mathrm{~cm}$, lorsque la différence de température est de $1{ }^{\circ} \mathrm{C}$. Par exemple, la valeur de $\mathrm{R}$ de la fibre de verre est de 0,064 environ, celle du béton de 0,002 et celle du bois de 0,024 à 0,051 . Plus la valeur de $\mathrm{R}$ est grande, meilleure est l'isolation.

Valeur moyenne $R$ de résistance thermique. La résistance moyenne au transfert de la chaleur d'une paroi isolée peut être calculée en utilisant les valeurs connues de $\mathrm{R}$ de l'isolant et des éléments structuraux de la paroi, et en les multipliant par l'épaisseur respective de chaque matériel puis en faisant la somme des résultats. Ceci prévaut tant pour le plancher, les murs que les plafonds. Dans le calcul de la résistance thermique, il faut ajouter les valeurs de $R$ des films d'air en surface qui sont données dans le tableau 7 (11). Le 
facteur exprimant la conductivité thermique totale d'une structure composée, comme un plancher, un mur ou un plafond, est l'inverse de la valeur $R(1 / R)$ et représente la chaleur $(\mathrm{kJ})$ traversant $1 \mathrm{~m} 2 / \mathrm{h}$ pour chaque degré $\left({ }^{\circ} \mathrm{C}\right)$ d'écart de température entre les côtés chaud et froid.

Tableau 7. Résistance thermique de quelques matériaux de construction isolants

Valeur R1 $\left(\mathrm{m}^{2} \cdot{ }^{\circ} \mathrm{C} \cdot \mathrm{h} / \mathrm{kJ}\right)$

\section{Isolants :}

Fibre de verre en matelas 2

Fibre de verre en vrac

Fibre de verre en panneau

Verre cellulaire (Foamglas)

Polystyrène extrudé

Polystyrène en panneau mouluré3

Polyuréthane en panneau

Mousse de polyuréthane appliquée sur place

Polyisocyanurate en panneau

$0,064 / \mathrm{cm}$

$0,049 / \mathrm{cm}$

$0,077 / \mathrm{cm}$

$0,055 / \mathrm{cm}$

$0,096 / \mathrm{cm}$

$0,080 / \mathrm{cm}$

$0,120 / \mathrm{cm}$

$0,120 / \mathrm{cm}$

$0,136 / \mathrm{cm}$

\section{Matériaux de construction :}

Contre-plaqué de sapin

Revêtement de fibres en panneau

Panneau d'agglomérés (Aspenite ${ }^{\circledR}$ )

Placoplâtre

Béton coulé

Bloc de béton $(20 \mathrm{~cm})$

Bloc de béton $(30 \mathrm{~cm})$

Verre, vitrage simple

$0,024 / \mathrm{cm}$

$0,051 / \mathrm{cm}$

$0,036 / \mathrm{cm}$

$0,017 / \mathrm{cm}$

$0,002 / \mathrm{cm}$

0,054

0,063

0,005

\section{Enduits ignifuges pour mousses :}

Plâtre de perlite et gypse $(1,25 \mathrm{~cm})$

Plâtre de gypse et vermiculite $(1,25 \mathrm{~cm})$

$0,013 / \mathrm{cm}$

$0,012 / \mathrm{cm}$

Cellulose retardant la propagation des flammes $(2,5 \mathrm{~cm})$

$0,077 / \mathrm{cm}$

\section{Films et espaces d'air}

Film d'air, à l'extérieur en été ou à l'intérieur dans une pièce chauffée

Film d'air, à l'extérieur en hiver ou à l'intérieur dans un entrepôt froid

0,012

Espace d'air de $2,5 \mathrm{~cm}$ ou plus (valeur moyenne)

0,008

0,035

${ }^{1}$ Facteurs de conversion: 1 watt $(\mathrm{W})=3,6 \mathrm{~kJ} / \mathrm{h} ;{ }^{\circ} \mathrm{K}={ }^{\circ} \mathrm{C}+273$.

2 Sans pare-vapeur, valeur moyenne pour plusieurs types.

3 Masse volumique : $0,024 \mathrm{~g} / \mathrm{cm}^{3}$. 
Meilleure est l'isolation (valeur R élevée), moins il y a de chaleur qui s'infiltre. Cependant, en raison du prix actuel des matériaux, il vient un point où un supplément d'isolation ne se justifie plus. Pour une température d'entreposage de -1 à $0{ }^{\circ} \mathrm{C}$, les valeurs de $\mathrm{R}$ pour le plancher, les murs et le plafond devraient être approximativement de $0,49,0,95$ et $1,6\left(\mathrm{~m}^{2} \cdot{ }^{\circ} \mathrm{C} \cdot \mathrm{h} / \mathrm{kJ}\right)$ respectivement $(2)$.

Planchers. Des études effectuées dans l'État de Washington (163) montrent que l'isolation d'un plancher d'entrepôt réfrigéré constitué d'une dalle n'est pas rentable lorsque la nappe phréatique est à plus de $3,6 \mathrm{~m}$. Toutefois, avec le prix de l'énergie approchant 2 à 3 cents le joule, une isolation minimale de $\mathrm{R}-0,49 \mathrm{~m} 2 .{ }^{\circ} \mathrm{C} \cdot \mathrm{h} / \mathrm{kJ}$ est recommandée pour le plancher (2). Il est cependant important d'isoler les murs de fondation jusqu'à $60 \mathrm{~cm}$ environ au-dessous du niveau du sol en allant vers la semelle, avec $5 \mathrm{~cm}$ d'isolant rigide tel que la mousse de polystyrène ou l'uréthane. Cette isolation évite des pertes de chaleur excessives tout le long du périmètre.

Pare-vapeur. Les matériaux isolants sont moins efficaces lorsqu'ils sont humides. Un pare-vapeur posé du côté chaud de l'isolant (jamais des deux côtés) empêche la condensation de la vapeur d'eau sur l'isolant et l'accumulation de vapeur d'eau due à la condensation. Le polyéthylène en feuilles de 100 à $120 \mu \mathrm{m}$ d'épaisseur est un pare-vapeur efficace; il est souvent employé dans les bâtiments à structure de bois, où il est posé sous le revêtement extérieur. L'aluminium en feuille constitue également un excellent pare-vapeur mais il ne doit pas être appliqué directement sur du béton, ni sur le sol parce que les sels basiques exsudés par ces matériaux le détruiront.

\section{CHARGES DE RÉFRIGÉRATION}

Avec les renseignements qui précèdent et en appliquant les données suivantes, il est possible de calculer la charge de réfrigération d'un entrepôt de fruits et de légumes.

\section{Besoin de froid pour les produits}

La plus importante source chaude dont il faille tenir compte est la chaleur sensible du produit chaud. Il est essentiel de bien estimer les quantités de produits à réfrigérer par jour au cours des périodes de pointe. Le calcul de la chaleur sensible se fait de la manière suivante:

La chaleur sensible du produit en kilojoules égale le poids du produit multiplié par la chaleur spécifique multipliée par l'abaissement de température prévu. De plus, il faut tenir compte de la chaleur sensible des contenants. Supposons, par exemple, qu'il faille refroidir 
des pommes de $21^{\circ} \mathrm{C}$ à $0{ }^{\circ} \mathrm{C}$ et que ces pommes sont entreposées en vrac dans des caisses de $385 \mathrm{~kg}$. Ainsi, pour 40 caisses-palettes manutentionnées par jour, la chaleur sensible, exprimée en kilojoules, sera de 15400 (poids réel des fruits, exprimé en kilogrammes) $\times 3,8$ (chaleur spécifique des pommes exprimée en kilojoules) $\times 21$ (abaissement de température requis en ${ }^{\circ} \mathrm{C}$ ) $=1228920 \mathrm{~kJ} /$ jour ou $51210 \mathrm{~kJ} / \mathrm{h}$. Puisqu'il faut $1 \mathrm{~W}$ pour absorber $3,6 \mathrm{~kJ}$ de chaleur par heure, il faudra disposer d'une capacité de réfrigération de $14225 \mathrm{~W}$ pour refroidir les fruits qui se trouvent dans les 40 caisses-palettes.

La quantité de chaleur provenant des caisses-palettes se calcule au moyen d'une formule analogue à celle utilisée pour les fruits : poids (environ $1800 \mathrm{~kg}$ pour 40 caisses-palettes vides) $\times$ chaleur spécifique (environ 2,5 pour les caisses-palettes) $\times$ abaissement de température requis $\left(21^{\circ} \mathrm{C}\right.$ dans ce cas). Le résultat donne environ $94500 \mathrm{~kJ} /$ jour qui exigent environ $1100 \mathrm{~W}$ de réfrigération pour 40 caisses-palettes dans cet exemple (voir figure 5).

\section{Chaleur de respiration}

La chaleur de respiration, ou chaleur métabolique, est libérée par tous les produits vivants; elle varie selon le cultivar, la maturité, la température et la nature même du produit. En raison du nombre de facteurs qui agissent sur la respiration, on ne peut donner de valeurs précises pour prévoir la chaleur de respiration mais les chiffres du tableau 8 sont suffisamment justes pour faire un calcul approximatif de cette source de chaleur. Ces chiffres montrent les grandes différences de chaleur de respiration selon les divers types de produits et selon la température.

La chaleur de respiration de certains types de produits maintenus à $0{ }^{\circ} \mathrm{C}$, peut être de peu d'importance; mais lorsque le produit est chaud, il faut en tenir compte. Plus le refroidissement est lent, plus la chaleur totale de respiration est importante. Par exemple, si l'on doit refroidir des pommes de $21^{\circ} \mathrm{C}$ à $0^{\circ} \mathrm{C}$ en 7 jours et que l'on introduise tous les jours des fruits chauds dans l'entrepôt, la chaleur de respiration comprend la chaleur de respiration cumulée des fruits se situant à des températures comprises entre $21^{\circ} \mathrm{C}$ et $0^{\circ} \mathrm{C}$. Le premier jour d'entreposage, la chaleur de respiration sera relativement faible, puisque'lle est produite par les seuls fruits entreposés en une journée. Mais au huitième jour, la chaleur de respiration approche un maximum qui demeurera constant pendant toute la durée de la mise en entrepôt. Le tableau 9 résulte d'une compilation de mesures de chaleur de respiration pour la réfrigération typique d'un entrepôt à fruits. Il montre comment la chaleur de respiration diminue à mesure que les fruits sont refroidis et comment la chaleur totale de respiration, au huitième jour, cumule la somme des chaleurs de 
respiration de tous les lots de fruits chargés chaque jour. En additionnant les valeurs de la ligne du bas, nous obtenons un total d'environ $17800 \mathrm{~kJ} / \mathrm{t}$ de fruits. Au cours de la période de chargement, cette valeur est d'abord égale à la chaleur de respiration de base, puis augmente graduellement à mesure que l'entreposage se poursuit. Par exemple, vers la fin de la période de mise en entrepôt, la chaleur de respiration sera de $17800 \mathrm{~kJ} / \mathrm{t}$ de fruits entreposée par jour plus environ $900 \mathrm{~kJ} /$ jour pour chaque tonne de fruits déjà refroidis à $0{ }^{\circ} \mathrm{C}$.

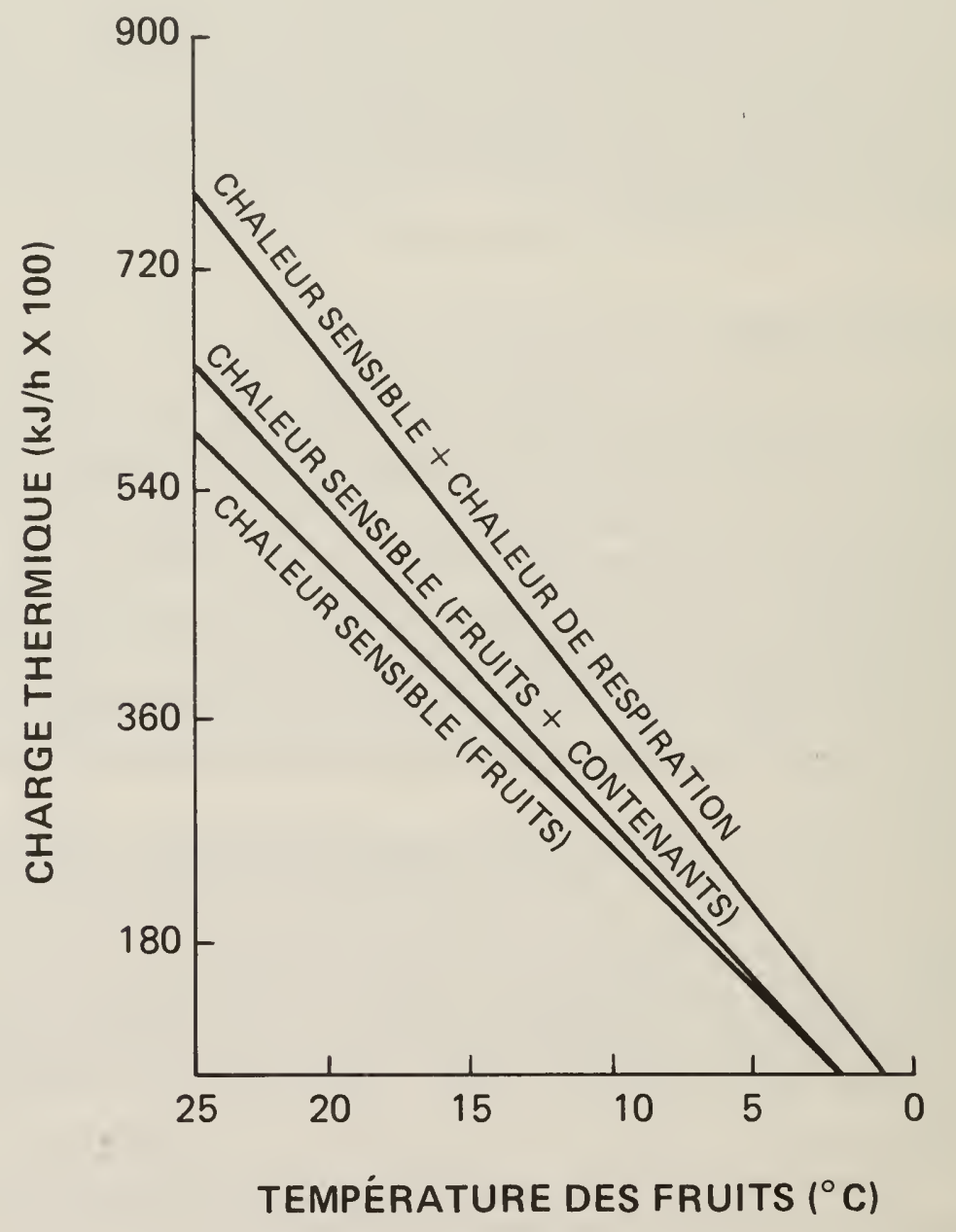

Figure 5. Charge thermique de 40 caisses-pallettes de pommes par jour, mises en entrepôt à des températures comprises entre 0 et $25^{\circ} \mathrm{C}$, et refroidies à $0^{\circ} \mathrm{C}$ en 7 jours. Le volume des caisses-palettes $(1,1 \times 1,2 \times 0,6 \mathrm{~m})$ peut contenir un poids net de fruits de $385 \mathrm{~kg}$. Si l'on remplace les caisses-palettes par des caisses ordinaires, la chaleur sensible des contenants doit être multipliée par 2. 
Tableau 8. Chaleur approximative de respiration de certains fruits et légumes frais entreposés aux températures indiquées*

Chaleur de respiration $(\mathrm{kJ} / \mathrm{t}$ par $24 \mathrm{~h}) \dagger$

Produit

$\begin{array}{lll}0,0{ }^{\circ} \mathrm{C} & 4,5^{\circ} \mathrm{C} \quad 15,5^{\circ} \mathrm{C} \quad 21,0{ }^{\circ} \mathrm{C}\end{array}$

Asperges

Betteraves, parées

Bleuets (myrtilles)

Canneberges

Carottes, parées

Céleri

Cerises

Champignons

Chou

Chou brocoli

Chou de Bruxelles

Chou-fleur

Concombres

Épinards

Fraises

Haricots

verts, jaunes

de Lima

Laitue pommée

Laitue à couper

Maiis sucré

Melons, cantaloups

Oignons

Oranges

Patates douces

Pêches

Petits pois

Poires

Poivrons

Pommes

Pommes de terre hâtives

Pommes de terre tardives

Prunes

Raisins d'Amérique

Rutabaga (chou-navet)

Tomates mûres

Tomates mûrissantes
14000

3100

2300

800

3500

1900

1200

8100

1200

5100

5100

4200

1900

5200

4400

7000

3300

2700

5200

10500

1500

600

900

2800

1500

9800

1000

3100

900

900

800

800

700

2200

1200

700
20900

4800

4100

1200

5100

2800

2900

17400

2400

19800

10500

5200

2900

12800

7000

11600

5800

3100

7400

15100

2300

900

1700

4000

2300

17400

1900

5500

1700

3000

1400

1700

1400

2600

1500

1300
46500

8400

9300

2600

9400

9500

7600

53500

7000

58100

23300

11600

7000

44200

23300

46500

29100

9300

16300

44200

9900

2800

4900

7300

10500

48800

11600

9900

7000

5800

2800

3300

4100

5800

6500

7200
58100

10500

11600

3700

14000

11900

9900

73200

11600

79100

32600

14500

9300

53500

30200

58100

40700

14000

20900

74400

14000

4200

6400

8700

19800

69800

14000

12800

9300

7600

3500

4400

8400

6400

9300

9300

* Chiffres tirés d'études sur la respiration et d'autres sources, par exemple 1, 107, 114.

†Btu par ton par jour $\times 1,16=$ kilojoule par tonne par jour. 
Tableau 9. Chaleur de respiration cumulée de pommes réfrigérées à raison d'une tonne par jour

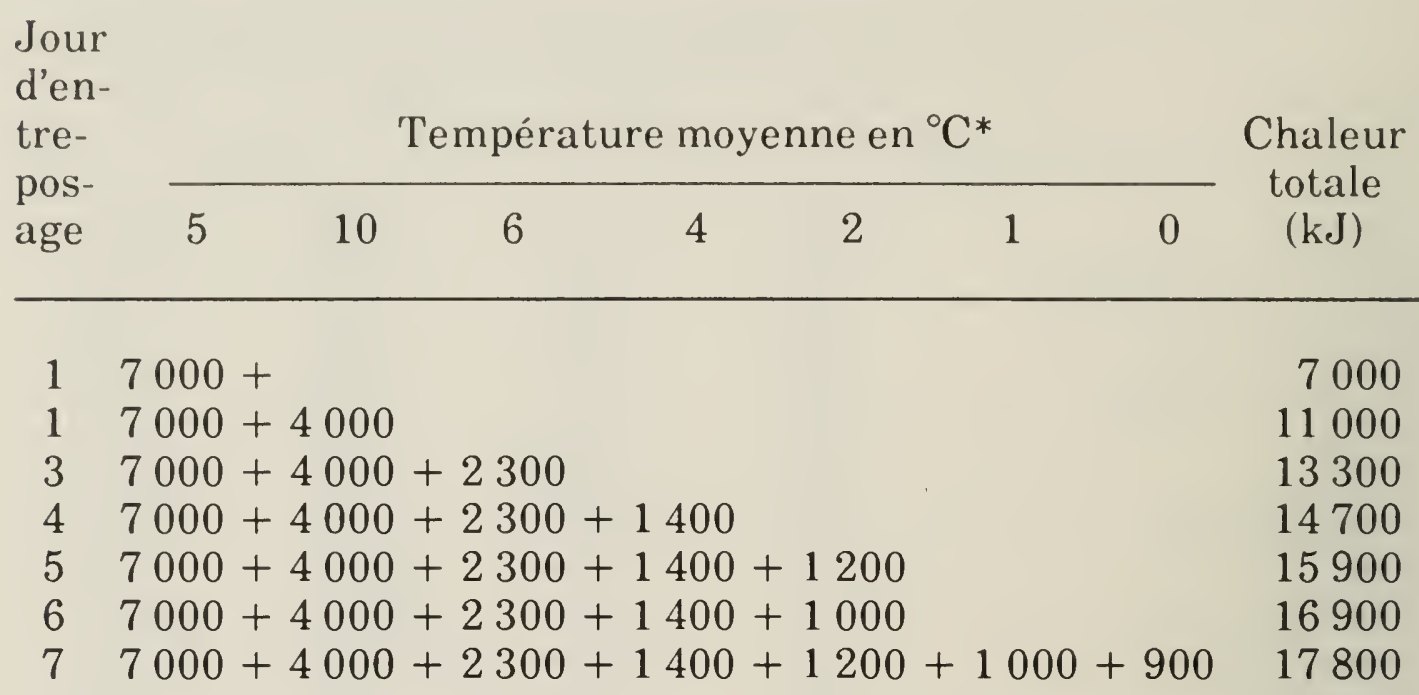

* Température moyenne approximative, jour après jour, de fruits refroidis de 21 à $0{ }^{\circ} \mathrm{C}$.

\section{Chaleur d'infiltration}

La chaleur entrant dans un entrepôt par transmission à travers les matériaux de construction se calcule comme suit :

La chaleur d'infiltration en kilojoules par heure égale la surface extérieure en mètres carrés multipliée par le coefficient de conductibilité thermique $(1 / R)$ multiplié par la différence de température $\left({ }^{\circ} \mathrm{C}\right)$ entre l'intérieur et l'extérieur. Il est d'usage d'adopter la température extérieure moyenne de la période d'entreposage la plus chaude et d'allouer de 5 à $9{ }^{\circ} \mathrm{C}$ de plus pour le toit ou le plafond que pour les murs. Pour un plancher isolé sur son périmètre seulement, une charge thermique d'environ $34,1 \mathrm{~kJ} / \mathrm{m}^{2}$ peut être admise. Pour un plancher isolé, une valeur de $1 / R$, analogue à celle qui a été retenue pour les murs et le plafond sur un sol de 10 à $13^{\circ} \mathrm{C}$, est utilisée. Si les planchers ne sont pas isolés, il est souhaitable de commencer à réfrigérer au moins une semaine avant de commencer l'entreposage. La transmission de chaleur par le plancher dépasse très largement $34,1 \mathrm{~kJ} / \mathrm{m}^{2}$ au début et devient progressivement moins importante, à mesure que le sol s'assèche et devient lui-même isolant. 
- Les lampes électriques produisent de la chaleur en fonction de leur wattage nominal.

- Les moteurs électriques dissipent habituellement $2686 \mathrm{~kJ} / \mathrm{h}$.

- Les chariots élévateurs produisent environ $36900 \mathrm{~kJ} / \mathrm{h}$.

- Les infiltrations d'air par les portes et les issues non isolées peuvent contenir une grande quantité de chaleur. Chaque mètre cube d'air pénétrant dans l'entrepôt introduit environ $60 \mathrm{~kJ}$ à $27^{\circ} \mathrm{C}$; $45 \mathrm{~kJ}$ à $21^{\circ} \mathrm{C}$ et $32 \mathrm{~kJ}$ à $16^{\circ} \mathrm{C}$. D'après l'ASHRAE (1), dans des conditions normales, le volume d'air peut être renouvelé complètement trois fois en 24 heures dans un entrepôt de $700 \mathrm{~m}^{3}$ et deux fois dans un entrepôt de $1400 \mathrm{~m}^{3}$.

Pour mieux comprendre la méthode de calcul des charges de réfrigération, prenons l'exemple d'un entrepôt dont la surface de plancher est de $164 \mathrm{~m}^{2}$ et la surface des murs est de $280 \mathrm{~m}^{2}$. Supposons que le plancher est une dalle de béton isolée seulement à la périphérie. Le volume total est d'environ $880 \mathrm{~m}^{3}$ et l'entrepôt contient $185000 \mathrm{~kg}$ de fruits dans 480 caisses-palettes. L'entrepôt est chargé à raison de 40 caisses-palettes par jour à $21^{\circ} \mathrm{C}$, pendant une période de 12 jours. La valeur de $R$ des murs est de 0,95 et celle du plafond de 1,6.

Le tableau 10 illustre la quantité totale de chaleur à éliminer à chaque heure, pour obtenir les besoins de réfrigération. Cependant, si l'entrepôt n'est pas en exploitation continue (s'il y a par exemple des interruptions pour le dégivrage), il faut tenir compte de la chaleur à extraire pendant le dégivrage. Supposons que l'on consacre $2 \mathrm{~h}$ par jour au dégivrage, la charge horaire totale doit alors être corrigée par un facteur $24 / 22$, comme suit : $104200 \times 24 / 22=113700 \mathrm{~kJ} / \mathrm{h}$. Il faut donc un compresseur d'environ $114000 \mathrm{~kJ} / \mathrm{h}$ pour cet entrepôt, avec une capacité correspondante pour les serpentins évaporateurs. La capacité du compresseur doit être fonction d'une pression d'aspiration correspondant à $-6,5^{\circ} \mathrm{C}$. La capacité des serpentins doit être basée sur une différence de température entre l'air entrant et l'air sortant qui ne soit pas supérieure à $5^{\circ} \mathrm{C}$. Parfois, on ne comprend pas qu'un serpentin d'une puissance de $12700 \mathrm{~kJ} / \mathrm{h}$ quand il fonctionne sous une différence de température de $5,5^{\circ} \mathrm{C}$ développe $19000 \mathrm{~kJ} / \mathrm{h}$ sous une différence de température de $8,5^{\circ} \mathrm{C}$. Cependant, pour éviter la congélation et la dessiccation des fruits et des légumes dans l'entrepôt, il est essentiel que les serpentins aient une capacité de réfrigération suffisante pour bien fonctionner sous de faibles différences de température.

À cause de leur commodité et de leur plus grande efficacité à déplacer l'air on préfère souvent les blocs refroidisseurs installés au plafond, munis de ventilateurs à hélice, aux gros systèmes centraux à serpentins et soufflantes avec conduites de distribution. Pour un débit d'air donné, les ventilateurs à hélice développent un tiers 
environ de la puissance des ventilateurs centrifuges des grands évaporateurs, c'est-à-dire $900 \mathrm{~kJ} / \mathrm{ha}$. Avec des blocs refroidisseurs, il est donc pratique d'utiliser des ventilateurs débitant jusqu'à $11 \mathrm{~m} 3 / \mathrm{min}$ par $12700 \mathrm{~kJ} / \mathrm{h}$ de capacité des serpentins. Un grand volume d'air permet d'obtenir une réfrigération rapide, une température uniforme et un haut degré d'humidité.

Voir le tableau 11 pour la conversion des températures et le tableau 12 pour les facteurs de conversion de la chaleur.

Tableau 10. Établissement des besoins de réfrigération

\begin{tabular}{lc} 
Sources de chaleurs & $\begin{array}{c}\text { Quantité } \\
\text { de chaleur } \\
(\mathrm{kJ} / \mathrm{h})\end{array}$ \\
\hline
\end{tabular}

1. Chaleur sensible des fruits de 40 caisses-palettes évaluée précédemment à : $1228920 \mathrm{~kJ} / \mathrm{jour}$ ou

2. Chaleur sensible des 40 caisses-palettes

3. Chaleur de respiration : la chaleur de respiration maximale des fruits en cours de refroidissement est atteinte au bout de 7 jours (tableau 8) et demeure constante aussi longtemps que les entrées quotidiennes de fruits restent les mêmes. Elle est de :

$$
\frac{15400 \times 17800}{1000 \times 24}=
$$

Chaleur de respiration supplémentaire : les fruits qui séjournent plus de 8 jours dans l'entrepôt et qui sont refroidis à $0{ }^{\circ} \mathrm{C}$ produisent également $900 \mathrm{~kJ}$ environ de chaleur de respiration par tonne, mais il n'en est pas tenu compte dans les calculs ci-dessus. Il faut toutefois tenir compte de cette source chaude dans les grands entrepôts ayant une longue période de chargement, mais elle est négligeable dans les petits entrepôts. Nous en tenons compte, cependant, pour expliquer la méthode de calcul. Au bout de 12 jours, il y aura 5 jours d'entrée de fruits refroidis à $0^{\circ} \mathrm{C}$. La chaleur de respiration serait :

$$
\frac{5 \times 15400 \times 900}{1000 \times 24}=\text { environ }
$$

4. Chaleur transmise par les murs :

$280 \mathrm{~m}^{2}($ surface $) \times 1,053 \mathrm{~kJ} / \mathrm{m}^{2} \cdot{ }^{\circ} \mathrm{C} \cdot \mathrm{h} \times 21$ $\left(\right.$ différence de température en $\left.{ }^{\circ} \mathrm{C}\right)=$ 
Quantité de chaleur

5. Chaleur transmise par le plancher :

$$
164 \mathrm{~m}^{2}(\text { surface }) \times 34,2 \mathrm{~kJ} / \mathrm{h} \cdot \mathrm{m}^{2}
$$

On suppose que le plancher en béton repose sur un sol bien drainé et n'est isolé qu'à la périphérie, et que le système de réfrigération de l'entrepôt a fonctionné pendant plusieurs jours avant le chargement. Dans ces conditions, un apport de chaleur par transmission de $34,2 \mathrm{~kJ} / \mathrm{h} \cdot \mathrm{m}^{2}$ est un chiffre raisonnable (102). Si le plancher est isolé, il faut prendre comme valeur de $1 / R$ celle de l'isolant au lieu de celle qui est indiquée dans le calcul et admettre une différence de température de $8{ }^{\circ} \mathrm{C}$.

6. Chaleur transmise par le plafond :

$164 \mathrm{~m}^{2}($ surface $) \times 0,625($ valeur de $1 / R) \times 30$ (différence de température en ${ }^{\circ} \mathrm{C}$ ) $=$

7. Chaleur dissipée par les appareils électriques :

Lampes, $2160 \mathrm{~kJ} / \mathrm{h}(600 \mathrm{w})$ pendant $8 \mathrm{~h}$ Ainsi sur une période de $24 \mathrm{~h}$, la chaleur produite par l'éclairage $=2160 \mathrm{~kJ} / \mathrm{h} \times 8 \mathrm{~h}=$ Moteurs des ventilateurs ( $3 \mathrm{hp}$ ) ou $3 \times 2686 \mathrm{kj} / \mathrm{h}=$

8. Chariots élévateurs, temps en entrepôt estimé à $4 \mathrm{~h}$ à raison d'environ $36900 \mathrm{~kJ} / \mathrm{h}$

Ainsi sur une période de $24 \mathrm{~h}$, la chaleur produite par les chariots élévateurs : $36900 \mathrm{~kJ} \times 4 \mathrm{~h}=$

9. Infiltrations d'air en supposant 3 renouvellements complets de l'air, avec de l'air extérieur à $21^{\circ} \mathrm{C}$ :

$880 \mathrm{~m}^{3}$ (volume de l'entrepôt) $\times 3 \mathrm{~h} \times 45 \mathrm{~kJ} / \mathrm{m}^{3}=4950$

D'après les chiffres indiqués précédemment, $45 \mathrm{~kJ}$ sont introduits chaque fois qu'un $\mathrm{m}^{3}$ d'air à $21^{\circ} \mathrm{C}$ entre dans l'entrepôt 


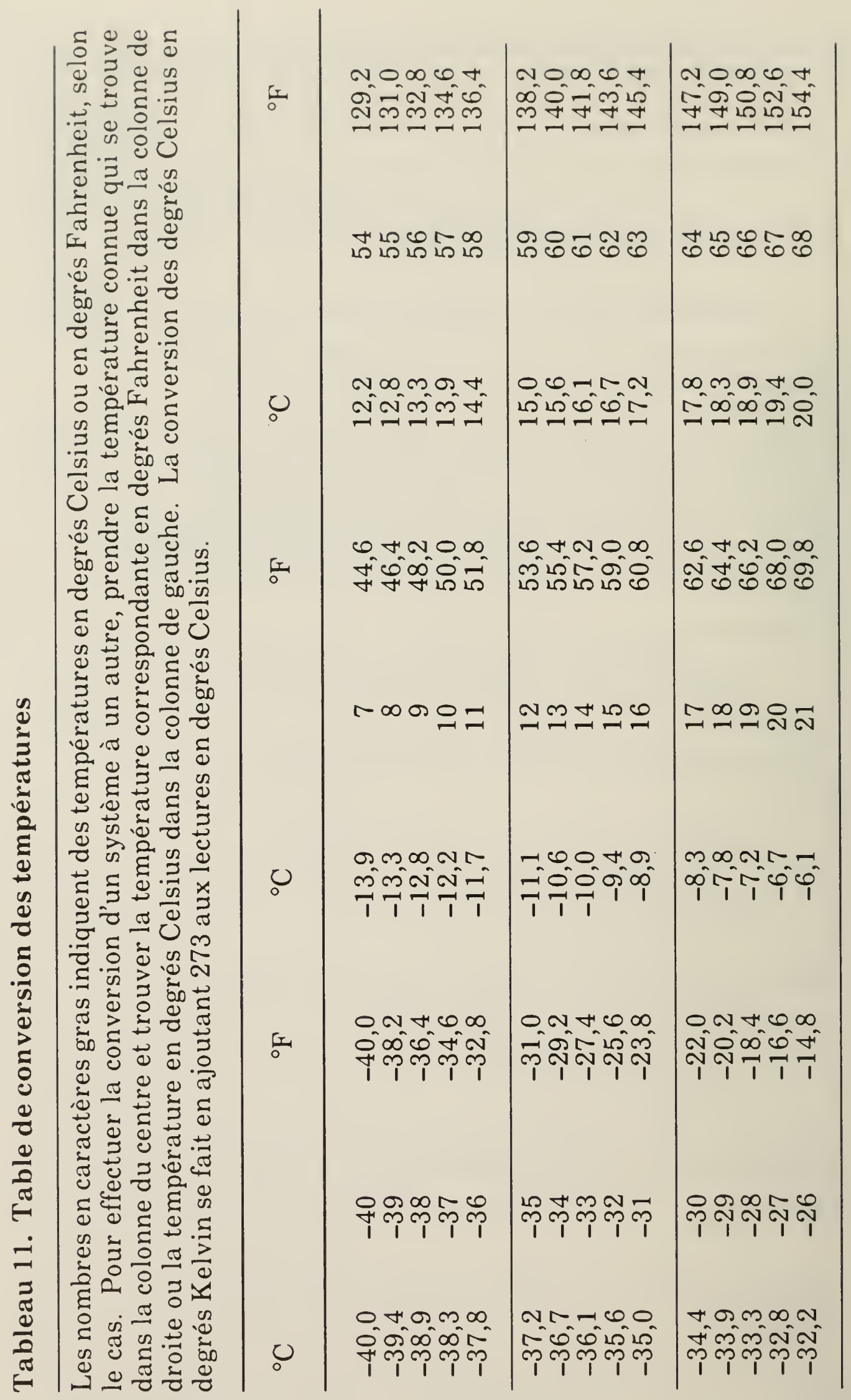




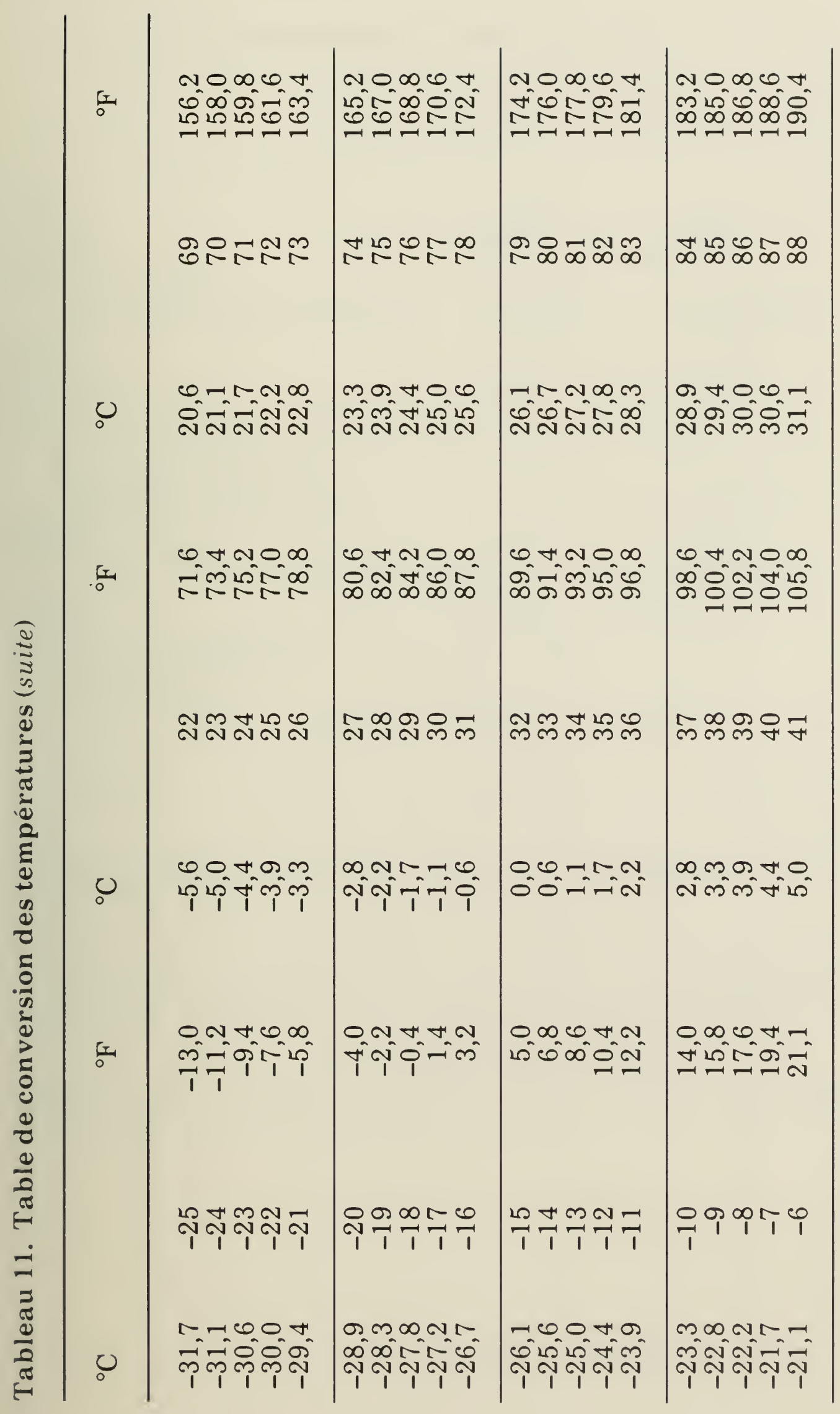




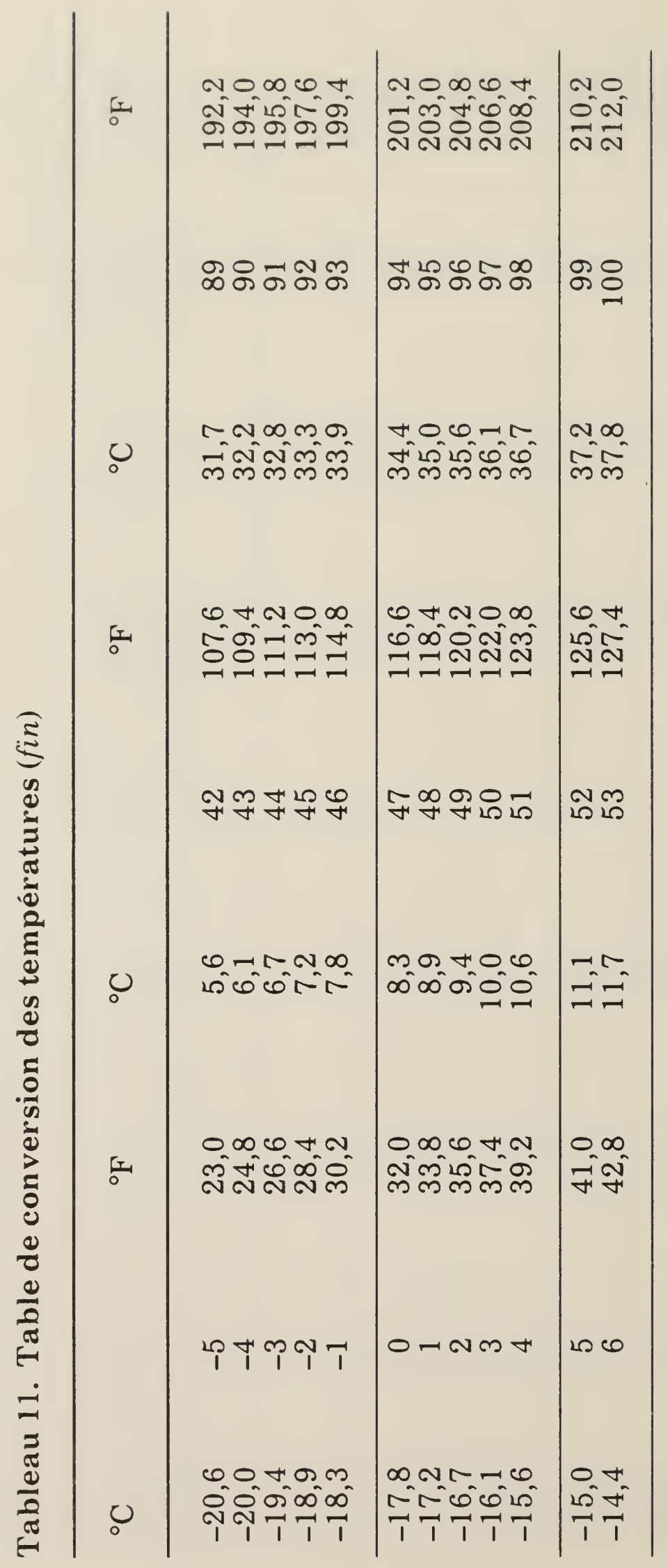


Btu*

$\mathrm{Btu} / \mathrm{pi} 3$

Btu/gal.

Btu.po/h.pi $\left.2 .{ }^{\circ} \mathrm{F}\right)$

\section{$\mathrm{Btu} / \mathrm{h}$}

$\mathrm{Btu} / \mathrm{pi} 2$

$\mathrm{Btu} /\left(\mathrm{h} \cdot \mathrm{pi}^{2}\right)$

$\left.\mathrm{Btu} / \mathrm{h} \cdot \mathrm{pi} 2 \cdot{ }^{\circ} \mathrm{F}\right)$

(coefficient de transmission

thermique totale, $U$ )

(conductance thermique, $C$ )

$\mathrm{Btu} / \mathrm{lb}$

$\mathrm{Btu} /\left(1 \mathrm{~b} \cdot{ }^{\circ} \mathrm{F}\right)($ chaleur spécifique, $C)$

calorie

horsepower (550 - pi.lb f/s)

tonne de réfrigération

(12 $000 \mathrm{Btu} / \mathrm{h})$
1,055

37,3

0,279

0,144

0,293

11,4

3,15

5,68

2,33

4,19

4,19

0,746

3,52

par
$\mathrm{kJ}$

$\mathrm{kJ} / \mathrm{m}^{3}$

$\mathrm{kJ} / \mathrm{L}$

$\mathrm{W} /\left(\mathrm{m} \cdot{ }^{\circ} \mathrm{K}\right)$

$\mathrm{W}$

$\mathrm{kJ} / \mathrm{m}^{2}$

$\mathrm{W} / \mathrm{m}^{2}$

$\mathrm{W} /\left(\mathrm{m}^{\left.2 \cdot{ }^{\circ} \mathrm{K}\right)}\right.$

$\mathrm{W} /\left(\mathrm{m}^{2} \cdot{ }^{\circ} \mathrm{C}\right)$

$\mathrm{kJ} / \mathrm{kg}$

$\mathrm{kJ} /\left(\mathrm{kg} \cdot{ }^{\circ} \mathrm{K}\right)$

$\mathrm{kJ} /\left(\mathrm{kg} \cdot{ }^{\circ} \mathrm{C}\right)$

$\mathrm{J}$

$\mathrm{kW}$

$\mathrm{kW}$

pour obtenir

diviser $\ddagger$

*Unité thermique britannique (Btu). Quantité de chaleur requise pour élever lax température d'une livre d'eau de $1^{\circ} \mathrm{F}$.

† Conductivité thermique $(K)$. Vitesse à laquelle la chaleur se propage à travers divers matériaux de construction; c'est le nombre de Btu traversant un pied carré d'un matériau d'une épaisseur d'un pouce en une heure lorsque la différence de température est de $1^{\circ} \mathrm{F}$.

$\ddagger$ Pour obtenir les mesures impériales, diviser le chiffre de la dernière colonne par celui de la colonne du centre. 


\section{BIBLIOGRAPHIE}

1. American Society of Heating, Refrigeration, and Air-conditioning Engineers 1966. ASHRAE guide and data book; applications. New York, N.Y. 1024 pp.

2. American Society of Heating, Refrigerating and Air-conditioning Engineers 1981. The ASHRAE handbook of fundamentals. Atlanta, Ga. 1896 pp.

3. Anderson, M.G.; Poapst, P.A. 1983. Effect of cultivar, modified atmosphere and rapeseed oil on ripening and decay of mature-green tomatoes. Can. J. Plant Sci. 63:509-514.

4. Anderson, R.E. 1982. Long-term storage of peaches and nectarines intermittently warmed during controlled-atmosphere storage. J. Am. Soc. Hortic. Sci. 107:214-216.

5. Anderson, R.E.; Hardenburg, R.E.; Vaught, H.C. 1963. Controlled atmosphere storage studies with cranberries. Proc. Am. Soc. Hortic. Sci. 83:416-422.

6. Apeland, J. 1966. Factors affecting non-parasitic disorders of the harvested product of cucumber. Acta Hortic. 4:102-104.

7. Atkinson, F.E.; Fisher, D.V. 1953. Harvesting, storing and ripening Bartlett pears for canning. Can. Food Ind. 25(4):37-38.

8. Ballinger, W.E.; Kushman, L.J. 1970. Relationship of stage of ripeness to composition and keeping quality of highbush blueberries. J. Am. Soc. Hortic. Sci. 95:239-242.

9. Barger, W.R. 1961. Factors affecting temperature reduction and weight-loss in vacuum-cooled lettuce. U.S. Dep. Agric. Mark. Res. Rep. 469. 19 pp.

10. Barger, W.R. 1963. Vacuum precooling - a comparison of the cooling of different vegetables. U.S. Dep. Agric. Mark. Res. Rep. 600. 12 pp.

11. Bartsch, J.A.; Blanpied, G.D. 1983. Refrigerated storage for horticultural crops. Cornell Univ. Agric. Eng. Ext. Bull. 448:51-55. 
12. Bartsch, J.A.; Blanpied, G.D. 1984. Cooling rates of apples in tight and spaced stacking patterns. Cornell University, Ithaca, N.Y. $11 \mathrm{pp}$.

13. Bauman, H. 1974. Preservation of carrot quality under various storage conditions. Acta Hortic. Tech. Comm. (ISHS) 38:327-338.

14. Ben-Arie, R.; Lavee, S.; Guelfat-Reich, S. 1970. Control of woolly breakdown of 'Elberta' peaches in cold storage by intermittent exposure to room temperature. J. Am. Soc. Hortic. Sci. 95:801-803.

15. Bennett, A.H.; Smith, R.E.; Fortson, J.C. 1965. Hydrocooling peaches. U.S. Dep. Agric. and Univ. Georgia Exp. Stn. Agric. Info. Bull. 293. $12 \mathrm{pp}$.

16. Bennett, A.H.; Sawyer, R.L.; Boyd, L.I.; Cetas, R.C. 1960. Storage of fall-harvested potatoes in the northeastern late summer crop area. U.S. Dep. Agric. Mark. Res. Rep. 370. 45 pp.

17. Bérard, L.S. et Vigier, B. 1985. Entroposage du chou d'hiver. Bulletin technique No 10. Conseil des Productions Végétales, MAPAQ, Québec. 19 p.

18. Bérard, L.S.; Vigier, B.; Crête, R. and Chiang, M.S. 1985. Cultivar susceptibility and storage control of grey speck disease and vein streaking, two disorders of winter cabbage. Can. J. Plant Pathol. 7:67-73.

19. Bérard, L.S. 1985. Effect of CA on several storage disorders of winter cabbage. Proceedings Fourth National Controlled Atmosphere Research Conference Raleigh, N.C., Horticultural Report 26, pp. 150-159.

20. Bérard, L.S.; Vigier, B. 1986. Effects of cultivar and controlled atmosphere storage on the incidence of black midrib and necrotic spot in winter cabbage. Phytoprotection 67:63-73.

21. Blanpied, G.D. 1969. A study of the relationship between optimum harvest dates for storage and the respiratory climacteric rise in apple fruit. J. Am. Soc. Hortic. Sci. 94:177-179.

22. Blanpied, G.D.; Hickey, K.D. 1963. Concord grape storage trials for control of Botrytis cinerea and Penicillium sp. Plant Dis. Rep. 47:986-992. 
23. Blanpied, G.D.; Samaan, L.G. 1982. Internal ethylene concentrations of 'McIntosh' apples after harvest. J. Am. Soc. Hortic. Sci. 107:91-93.

24. Bramlage, W.J.; Couey, H.M. 1965. Gamma radiation of fruits to extend market life. U.S. Dep. Agric. Mark. Res. Rep. 717. $27 \mathrm{pp}$.

25. Brearley, N.; Breeze, J.E.; Cuthbert, R.M. 1964. The production of a standard comparator for the skin color of mature cherries. Food Technol. 78:1477-1479.

26. Brecht, P.E.; Kader, A.A.; Morris, L.L. 1973. The effect of composition of atmosphere and duration of exposure on brown stain of lettuce. J. Aml. Soc. Hortic. Sci. 98:536-538.

27. Burton, W.G. 1958. Suppression of potato sprouting in buildings. Agriculture (Lond.) 65:299-305.

28. Burton, W.G.; Horne, T.; Powell, D.E. 1959. The effect of gamma irradiation upon the sugar content of potatoes. Eur. Potato J. 27:105-116.

29. Ceponis, M.J.; Cappellini, R.A. 1979. Control of postharvest decays of blueberry fruits by precooling, fungicide, and modified atmospheres. Plant Dis. Rep. 63:1049-1053.

30. Chen, P.M.; Mellenthin, W.M.; Kelley, S.B.; Facteau, T.J. 1981. Effects of low oxygen and temperature on quality retention of 'Bing' cherries during prolonged storage. J. Aml. Soc. Hortic. Sci. 106:533-535.

31. Claypool, L.L.; Pangborn, R.M. 1972. Influence of controlled atmosphere storage on quality of canned apricots. J. Am. Soc. Hortic. Sci. 97:636-638.

32. Cloutier, J.A.R.; Clay, R.; Manson, M.; Johnson, L.E. 1959. Effect of storage on the carbohydrate content of two varieties of potatoes grown in Canada and treated with gamma radiation. Food Res. 24:659-664.

33. Daubeny, H.A.; Pepin, H.S. 1974. Variations among red raspberry cultivars and selections in susceptibility to the fruit rot causal organisms Botrytis cinerea and Rhizopus spp. Can. J. Plant Sci. 54:511-516. 
34. Daubeny, H.A.; Pepin, H.S. 1977. Evaluation of strawberry clones for fruit rot resistance. J. Aml. Soc. Hortic. Sci. 102:431-435.

35. Denby, L.G. 1967. The handling, storing and shipping of vegetables. Agric. Can. Res. Stn. Summerland, B.C. Publ. 44. $35 \mathrm{pp}$.

36. Dewey, D.H. 1962. Factors affecting quality of Jonathan apples stored in controlled atmospheres. Proceedings 16 th International Horticultural Congress, Brussels, Belgium, $1: 278$.

37. Dewey, D.H.; Billings, W.E.; Pflug, I.J. 1957. Progress report on the controlled-atmosphere storage of Jonathan apples. Q. Bull. Mich. State Univ. Agric. Exp. Stn. 39:691-700.

38. Eaves, C.A. 1960. A modified atmosphere system for packages of stored fruit. J. Hortic. Sci. 35:110-117.

39. Eaves, C.A.; Hill, H. 1940. Functional disorders of apples. Agric. Can. Publ. 694 (Tech. Bull. 28).

40. Eaves, C.A.; Hill, H. 1959. A dry scrubber for CA apple storages. Trans. ASAE (Am. Soc. Agric. Eng.) 2(1):127-128.

41. Eaves, C.A.; Forsyth, F.R.; Lockhart, C.L. 1969. Recent developments in storage research at Kentville, Nova Scotia. Can. Inst. Food Technol. J. 2:46-51.

42. Eaves, C.A.; Forsyth, F.R.; Leefe, J.S.; and Lockhart, C.L. 1964. Effect of varying concentrations of oxygen with and without $\mathrm{CO}_{2}$ on senescent changes in stored McIntosh apples grown under two levels of nitrogen fertilization. Can. J. Plant Sci. 44:458-465.

43. Eaves, C.A.; Lockhart, C.L.; Stark, R.; Craig, D.L. 1972. Influence of preharvest sprays of calcium salts and wax on fruit quality of red raspberry. J. Am. Soc. Hortic. Sci. 97:706-707.

44. Edney, K.L. 1964. Some factors affecting the rotting of stored apples by Gloeosporium sp. Ann. Appl. Biol. 53:119-127.

45. Edney, K.L.; Nadh-Wortham, J.R.H. 1950. Ripening of tomatoes. J. Hortic. Sci. 25:183-189. 
46. Fellers, C.R.; Esselen, W.B. 1955. Cranberries and cranberry products. Mass. Agric. Exp. Stn. Bull. 481. 62 pp.

47. Fisher, D.V. 1939. A three year study of maturity indices for harvesting Italian prunes. Proc. Am. Soc. Hortic. Sci. 37:183-186.

48. Fisher, D.V., and Britton, J.E. 1940. Maturity studies with sweet cherries. Sci. Agric. 29:497-503.

49. Fisher, D.V.; Porritt, S.W. 1951. Apple harvesting and storage in British Columbia. Agric. Can. Publ. 724. 47 pp.

50. Fisher, D.V.; Britton, J.E.; and O'Reilly, H.J. 1943. Peach harvesting and storage investigations. Sci. AGric. 24:1-15.

51. Fisher, D.V.; Palmer, R.C.; Porritt, S.W. 1953. Pear harvesting and storage in British Columbia. Agric. Can. Publ. 895. $22 \mathrm{pp}$.

52. Forsyth, F.R.; Eaves, C.A.; Lightfoot, H.J. 1969. Storage quality of McIntosh apples as affected by removal of ethylene from the storage atmosphere. Can. J. Plant Sci. 49:567-572.

53. Franklin, E.W. 1965. The waxing of turnips for the retail market. Agric. Can. Publ. 1120. 4 pp.

54. Freeman, J.A.; Pepin, H.S. 1977. Control of postharvest fruit rot of strawberries by field sprays. Can J. Plant Sci. 57:75-80.

55. Furry, R.B.; Isenberg, F.M.R.; Jorgensen, M.C.; Carroll, J.E. 1973. Pilot studies on the use of catalytically generated atmospheres for the storage of cabbage, Brassica oleraceae L. Pap. 73-3506. Winter meeting American Society of Agricultural Engineers.

56. Gerhardt, F.; English, H. 1945. Ripening of the Italian prune as related to maturity and storage. Proc. Am. Soc. Hortic. Sci. 46:205-209.

57. Graham, S.O.; Patterson, M.E.; Allen, B. 1967. Bruising as a predisposing factor in the decay of stored cranberries. Phytopathology 57:497-501.

58. Gray, H.E. 1950. Farm regrigerated storages. Cornell Ext. Bull. 786.48 pp. 
59. Groeschal, E.C.; Nelson, A.E.; Steinberg, M.P. 1966. Changes in the color and other characteristics of green beans stored in controlled refrigerated atmosphere. J. Food Sci. 31:488-496.

60. Guillou, R. 1960. Coolers for fruits and vegetables. Calif. Agric. Exp. Stn. Bull. 773. 65 pp.

61. Hall, C.B. 1961. The effect of low storage temperatures on the color carotenoid pigments, shelf-life and firmness of ripened tomatoes. Proc. Am. Soc. Hortic. Sci. 78: 480-487.

62. Haller, H. 1941. Fruit pressure testers and their practial application. U.S. Dep. Agric. Circ. 627. 22 pp.

63. Hansen, E. 1961. Climate in relation to post harvest physiological disorders of apples and pears. Ann. Rep. Oregon State Hortic. Soc. 53:54-58.

64. Hansen, E. 1965. Storage requirements for pears. Symposium on fruit storage, Portland, Oregon. Am. Soc. Heat. Regrig. Air-cond. Eng. 4-7.

65. Hansen, E.; Mellenthin, W.M. 1962. Factors influencing susceptibility of pears to carbon dioxide injury. Proc. Am. Soc. Hortic. Sci. 80:146-153.

66. Hardenburg, R.E. 1967. Wax and related coatings for horticultural products, a bibliography. U.S. Dep. Agric. ARS 5. 15 pp.

67. Hardenburg, R.E.; Anderson, R.E. 1961. Polyethylene box liners for storage of Golden Delicious apples. U.S. Dep. Agric. Mark. Res. Rep. 461. 35 pp.

68. Hardenburg, R.E.; Anderson, R.E. 1962. Chemical control of scald on apples grown in eastern United States. U.S. Dep. Agric. Mark. Res. Rep. 538. 48 pp.

69. Hartman, J.D.; Isenberg, F.M. 1956. Waxing vegetables. N.Y. State Agric. Exp. Stn. Cornell ext. Bull. 965. 4 pp.

70. Harvey, J.M.; Pentzer, W.T. 1960. Market diseases of grapes and other small fruits. U.S. Dep. Agric. Mark. Serv. Handb. 189. $37 \mathrm{pp}$.

71. Hedberg, P.R. 1977. Techniques for long-term storage of table grapes. Aust. J. Exp. Agric. Anim. Husb. 17:866-8970. 
72. Heinze, P.N., et al. 1964. Storage and transportation of potatoes. Potato Handb. 9:30-34.

73. Herrick, J.F.; Sainsburty, G.F.; Carlsen, E.W.; Hunter, C.L. 1964. Packing and storage houses - layout and design. U.S. Dep. Agric. Mark. Res. Rep. 602. 43 pp.

74. Hruschka, H.W.; Kushman, L.J. 1963. Storage and shelf life of packaged blueberries. U.S. Dep. Agric. Mark. Res. Rep. 612.

75. Hudek, E.P. 1964. Storage requurements of potatoes. Proceedings Canadian Potato Industry Conference Vol. 7, pp. 77-83.

76. Hudson, D.E.; Tretjen, W.H. 1981. Effects of cooling rate on shellife and decay of highbush blueberries. Hort. Science 16:656-657.

77. Huelson, W.A. 1954. Sweet corn. Economics crops Vol. 4. Interscience Publishers, New York. N.Y. 409 pp.

78. Isenberg, F.M.; Ang, K.K. 1963. Northern grown onions curing, storing and inhibiting sprouting. Cornell Ext. Bull. 1116. $15 \mathrm{pp}$.

79. Isenberg, F.M., and Sayles, R.M. 1969. Modified atmosphere storage of Danish cabbage. Proc. Am. Soc. Hortic. Sci. 94:447-449.

80. Isenberg, F.M.R. 1979. Controlled atmosphere storage of vegetables. Hortic. Rev. 1:337-395.

81. Jones, A.H.; Desmarais, J.G.; Winfield, K.E. 1956. How efficient are fungicidal paints? Can. Paint Varn. Mag. 30(5):30-35, 52-54.

82. Kappel, R. 1977. Einfluss von Dungung Erntetermim, Aufbereitung und Lageratmosphare auf die Qualitat von Lagerblumenkohl (Brassica oleracea L. convar. botrytis (L.) Alef. var. botrytis L. Technischen Universitat München. Bayern. (Diss. Wieherstephen).

83. Kasmire, R.F.; Van Maren, A.F. 1961. Facts on hydrocooling sweet corn. Univ. Calif. Agric. Ext. Serv. AXT-12. 9 pp.

84. King, E.M. 1959. Swede turnip culture. Hortic. Circ. B.C. 85. $7 \mathrm{pp}$. 
85. King, E.M. 1961. Storage onions. Hortic. Circ. B.C. 90.6 pp.

86. King, E.M. 1962. Asparagus production in British Columbia? Hortic. Circ. B.C. 96.8 pp.

87. Knee, M.; Smith, S.M.; Johnson, D.S. 1983. Comparison of methods for estimating the onset of the respiration climacteric in unpicked apples. J. Hortic. Sci. 58:521-526.

88. Lau, O.L. 1983. Storage responses of four apple cultivars to a "rapid CA" procedure in commercial-controlled atmosphere facilities. J. Am. Soc. Hortic. Sci. 108:530-533.

89. Lau, O.L. 1983. Effects of storage procedures and low oxygen and carbon dioxide atmospheres on storage quality of 'Spartan' apples. J. Am. Soc. Hortic. Sci. 108:953-957.

90. Lau, O.L.; Looney, N.E. 1982. Improvement of fruit firmess and acidity in controlled-atmosphere-stored 'Golden Delicious' apples by a rapid $\mathrm{O}_{2}$ reduction procedure. J. Am. Soc. Hortic. Sci. 107:531-534.

91. Leberman, K.W.; Nelson, A.I.; Steinberg, M.P. 1968. Postharvest changes of broccoli stored in modified atmospheres. II. Accidity and its influence on texture and chlorophiyll retention in the stalks. Food Technol. 22:146-149.

92. Lentz, C.P.; Rooke, E.A. 1957. Use of the jacketed room system for cool storage. Food Technol. 11:257-259.

93. Lentz, C.P.; Rooke, E.A. 1964. Rates of moisture loss of apples under regrigerated storage conditions. Food Technol. 18:119-121.

94. Lentz, C.P.; Phillips, W.R. 1960. Use of the jacketed room system for fresh fruit and vegetable storage. Proceedings 10 th International Congress in Refrigerating Vol. 3, pp. 303-314.

95. Lidster, P.D. 1981. Some effects of emulsifiable coatings on weight loss, stem discoloration, and surface damage disorders in 'Van' sweet cherries. J. Am. Soc. Hortic. Sci. 106:478-480.

96. Lidster, P.D. 1982. Low oxygen atmospheres to maintain apple quality in storage. Pages 109-120 in Proceedings 3rd National Controlled Atmosphere Research Conference Symposium 
Series No. 1, Oregon State University, School of Agriculture, Timber Press, Beaverton, Ore.

97. Lidster, P.D.; Estabrooks, E.N.; Craig, W.E. 1981. Refrigerated storage of apples and pears. Atl. Hortic. Comm. Publ. AHC-42. AHC-4.2. 16 pp.

98. Lidster, P.D.; Forsyth, F.R.; Lightfoot, H.J. 1980. Low oxygen and carbon dioxide atmospheres for storage of McIntosh apples. Can. J. Plant Sci. 60:299-301.

99. Lidster, P.D.; Lightfoot, H.J.; McRae, K.B. 1983. Production and regeneration of principal volatiles in apples stored in modified atmospheres and air. J. Food Sci. 48:400-402, 410.

100. Lidster, P.D.; McRae, K.B.; Sanford, K.A. 1981. Responses of 'McIntosh' apples to low oxygen storage. J. Am. Soc. Hortic. Sci. 106:159-162.

101. Lidster, P.D.; Muller, K.; Tung, M.A. 1980. Effects of maturity on fruit composition and susceptibility to surface damage in sweet cherries. Can. J. Plant Sci. 60:865-871.

102. Lipton, W.J. 1958. Effect of temperature on asparagus quality. Proceedings Conference on Transportation of Perishables, Davis, Calif., pp. 147-151.

103. Lipton, W.J. 1965. Post-harvest responses of asparagus spears to high carbon dioxide and low oxygen atmospheres. Proc. Am. Soc. Hortic. Sci. 86:347-356.

104. Lipton, W.J. 1967. Market quality and rate of respiration of head lettuce held in low oxygen atmospheres. U.S. Dep. Agric. Mark. Res. Rep. 777. 9 pp.

105. Lipton, W.J. 1977. Recommendations for CA storage of broccoli, brussells sprouts, cabbage, cauliflower, asparagus and potatoes. Proceedings 2nd National Controlled Atmosphere Research Conference, Michigan State University Horticultural Report 28, pp. 277-280.

106. Lipton, W.J.; Harris, C.M. 1974. Controlled atmosphere effects on the market quality of stored broccoli (Brassica oleracea L. Italica group). J. Am. Soc. Hortic. Sci. 99:200-205. 
107. Liu, F.W 1979. Interaction of daminozide, harvesting date, and ethylene in CA storage on 'McIntosh' apple quality. J. Am. Soc. Hortic. Sci. 104:599-601.

108. Lockhart, CL.; Eaves, C.A.; Chipman, E.W. 1969. Suppression of rots on four varieties of mature green tomatoes in controlled atmosphere storage. Can. J. Plant Sci. 49:265-269.

109. Lockhart, C.L.; Forsyth, F.R.; Stark, R.; Hall, I.V. 1971. Nitrogen gas suppresses microorganisms on cranberries in short term storage. Phytopathology 61:335-336.

110. Lougheed, E.C. 1969. Controlled atmosphere storage of potatoes. Proceedings National Controlled Atmosphere Research Conference, Michigan State University Horticultural Report 9, pp. 98-102.

111. Lougheed, E.C.; Dewey, D.H. 1966. Factors affecting the tenderizing effect of modified atmospheres on asparagus spears during storage. Proc. Am. Soc. Hortic. Sci. 89:336-345.

112. Lutz, J.M.; Hardenburg, R.E. 1968. The commercial storage of fruits, vegetables and florist and nursery stock. U.S. Dep. Agric., Agric. Handb. 66. 94 pp.

113. Maas, J.L. 1978. Screening for resistance to fruit rot in strawberries and red raspberries: A review. HortScience 13:423-426.

114. Marshall, D.C.; Padfield, C.A.S. 1962. The freezing point of pears. J. Hortic. Sci. 32(2):106-114.

115. Massey, Jr., L.M.; Chase, B.R.; Starr, M.S. 1981. Impact-induced breakdown in commercially screened 'Howes' cranberries. J. Am. Soc. Hortic. Sci. 106:200-203.

116. Meheriuk, M.: Porritt, S.W. 1972. The effects of waxing on respiration, ethylene production, and other physical and chemical changes in selected apple cultivars. Can. J. Plant Sci. 52:257-259.

117. Mellenthin, W.M.; Chen, P.M.; Kelly, S.B. 1980.. Low oxygen effects on dessert quality, scald prevention, and nitrogen metabolism of 'd'Anjou' pear fruit during long term storage. J. Am. Soc. Hortic. Sci. 105:522-527. 
118. Mencarelli, F.; Lipton, W.J.; Peterson, S.J. 1983. Responses of zucchini squash to storage in low- $\mathrm{O}_{2}$ atmospheres at chilling and nonchilling temperatures. J. Am. Soc. Hortic. Sci. 108:884-890.

119. Mitchell, F.G.; Guillou, R.G.; Parsons, R.A. 1972. Commercial cooling of fruits and vegetables. Calif. Agric. Exp. Stn. Man. 43. $44 \mathrm{pp}$.

120. Morris, L.L.; Kader, A.A. 1977. Commodity requirements and recommendations for transport and storage-selected vegetables. Proceedings 2nd National Controlled Atmosphere Research Conference, Michigan State University, Horticultural Report 28, pp. 266-276.

121. Morris, J.R.; Cawthorn, D.L.; Buescher, R.W. 1979. Effects of acetaldehyde on postharvest quality of mechanically harvested strawberries for proessing. J. Am. Soc. Hortic. Sci. 104:262-264.

122. Morrison, W.W. 1962. Fresh cabbage from grower to retailer. U.S. Dep. Agric. Mark. Bull. 21. 9 pp.

123. Nelson, K.E.; Gentry, J. P. 1966. Two-stage generation of sulphur dioxide within closed containers to control decay of table grapes. Am. J. Enol. Vitic. 17:290-301.

124. Nuttall, V.W.; Lyall, L.H.; MacQueen, K.F. 1961. Some effects of gamma radiation on stored onions. Can. J. Plant Sci. 41:805-813.

125. Ogle, W.H.; Christopher, E.P. 1957. The influence of maturity, temperature and duration of storage on quality of cantaloupes. Proc. Am. Soc. Hortic. Sci. 70:319-324.

126. Olsen, K.L. 1980. Rapid CA and low oxygen storage of apples a new concept for long storage of Golden Delicious and more effective storage of Red Delicious apples. Proc. Wash. State Hortic. Assoc. 76:121-125.

127. Olsen, K.L.; Schomer, H.A. 1964. Oxygen and carbon dioxide levels for controlled atmosphere storage of Starking and Golden Delicious apples. U.S. Dep. Agric. Mark. Res. Rep. 653.

128. Ontario Agricultural College. 1960. Potato production in Ontario. Ont. Dep. Agric. Publ. 534. 64 pp. 
129. Ontario Agricultural College. 1960. Table turnips (rutabagas). Ont. Dep. Agric. Publ. 502. 14 pp.

130. Parks, N.M. 1960. Gamma irradiation of potatoes; storage tests. Pages 18-23 in Gamma irradiation in Canada. Atomic Energy of Canada Ltd., Ottawa, Ont.

131. Parsons, C.S. 1960. Effect of temperature, packaging and sprinkling on the quality of celery. Proc. Am. Soc. Hortic. Sci. 75:463-469.

132. Patchen, G.O. 1971. Storage of apples and pears. U.S. Dep. Agric. Mark. Res. Rep. 924.51 pp.

133. Patterson, M.E. 1982. CA storage of cherries. In Controlled Atmospheres for Storage and Transport of Perishable Agricultural Commodities. Oreg. State Univ. Sch. Agric. $1: 149-154$.

134. Patterson, M.E.; Workman, J. 1962. The influence of $\mathrm{O}_{2}$ and $\mathrm{CO}_{2}$ on the development of apple scald. Proc. Am. Soc. Hortic. Sci. 80:130-135.

135. Patterson, M.E.; Doughty, C.C.; Graham, S.O.; Allan, B. 1967. Effect of bruising on postharvest softening, color changes and detection of polygalacturonase enzyme in cranberries. Proc. Am. Soc. Hortic. Sci. 90:498-505.

136. Pendergrass, A.; Isenberg, F.M. 1974. The effect of relative humidity on the quality of stored cabbage. HortScience 9:226-227.

137. Pentzer, W.T.; Allen, F.W. 1944. Ripening and breakdown of plums as influenced by storage temperature. Proc. Am. Soc. Hortic. Sci. 44:148-156.

138. Peters, P.; Maltry, W.; Zeutschel, K.H.; Gattermann, E. 1978. Senkung der faulnisverluste bei speisezwiebeln durch $45 \mathrm{C}-$ Warmebchand-lung. Gartenbau 25(9):261-263.

139. Phan, C.T. 1974. Use of plastic films for storage of carrots. Acta Hortic. 38:345-350.

140. Pierson, C.F.; Ceponis, M.J.; McColloch, L.P. 1971. Market disease of apples, pears and quinces. U.S. Dep. Agric., Agric. Handb. 376. $112 \mathrm{pp}$. 
141. Phillips, W.R. 1957. Construction and operation of a home storage for fruits and vegetables. Agric. Can. Publ. 743. 15 pp.

142. Phillips, W.R. 1963. Gamma irradiation of apples. Can. Food Ind. 34(8):38-40.

143. Phillips, W.R.; Parks, N.M. 1957. Potato storage. Agric. Can. Publ. 882. $18 \mathrm{pp}$.

144. Phillips, W.R.; Poapst, P.A. 1952. Storage of apples. Agric. Can. Publ. 776. 43 pp., and supplement (1959): Controlled atmosphere storage of apples. $17 \mathrm{pp}$.

145. Phillips, W.R.; Poapst, P.A. 1960. Starch test guide for harvesting McIntosh apples. Agric. Can. Publ. 776. 43 pp.

146. Phillips, W.R.; Browne, F.S.; Poapst, P.A. 1952. Precooling celery. Can. Refrig. J. 18(1):19-23.

147. Phillips, W.R.; Lentz, C.P.; Rooke, E.A. 1961. The use of the jacketed room system for the storage of apples. Can. Refrig. Air Cond. 27(12):20-23.

148. Phillips, W.R.; Poapst, P.A.; Rheaume, B.J. 1955. The effect of temperature near $32^{\circ} \mathrm{F}$ on the storage behaviour of McIntosh apples. Proc. Am. Soc. Hortic. Sci. 65:214-222.

149. Platenius, H. 1939. Wax emulsions for vegetables. Bull. Cornell Univ. Agric. Exp. Stn. 724. 42 pp.

150. Poapst, P.A., Ward, G.M.; Phillips, W.R. 1959. Maturation of McIntosh apples in relation to starch loss and abscission. Can. J. Plant Sci. 39:257-263.

151. Porritt, S.W. 1964. The effect of temperature on post harvest physiology and storage life of pears. Can. J. Plant Sci. 44:568-579.

152. Porritt, S.W. 1965. Effect of cooling rate on storage life of pears. Can. J. Plant Sci. 45:90-97.

153. Porritt, S.W. 1966. Some engineering and operational aspects of controlled atmosphere storage. Can. Agric. Eng. 8:19-22.

154. Porritt, S.W.; Mason, J.L. 1965. Controlled atmosphere storage of sweet cherries. Proc. Am. Soc. Hortic. Sci. 87:128-130. 
155. Porritt, S.W.; Meheriuk, M. 1968. The influence of controlled atmosphere storage on quality of apples. Can. Inst. Food Technol. J. 1(3):94-97.

156. Porritt, S.W.; McMechan, A.D.; Williams, K. 1963. Note on a flotation method for segregation of water core apples. Can. J. Plant Sci. 43:600-602.

157. Porritt, S.W.; Meheriuk, M. 1970. Chemical control of scald on waxed apples. Can. J. Plant Sci. 50:313-317.

158. Porritt, S.W.; McMechan, A.D.; Meheriuk, M. 1969. Control of apple scald. Agric. Can. Publ. Res. Stn. Summerland, B.C. Publ. SP 51.

159. Porritt, S.W.; Meheriuk, M.; Lidster, P.D. 1982. Postharvest disorders of apples and pears. Agric. Can. Publ. 1737. 66 pp.

160. Prasad, K.; Stadelbacher, G.j. 1973. Control of postharvest decay of fresh raspberries by acetaldehyde vapour. Plant Dis. Rep. 57:795-797.

161. Prasad, K.; Stadelbacher, G.J. 1974. Effect of acetaldehyde vapor on postharvest decay and market quality of fresh strawberries. Phytopathology 64:948-951.

162. Ramsey, G.B.; Smith, M.A. 1961. Market diseases of cabbage, cauliflower, melons and related crops. U.S. Dep. Agric., Agric. Hand. 194. $49 \mathrm{pp}$.

163. Ramsey, G.B.; Friedman, R.A.; Smith, W.A. 1959. Market diseases of beets, chicory, endive, escarole, globe artichokes, lettuce, rhubarb, spinach and sweet potatoes. U.S. Dep. Agric., Agric. Handb. 194. 49 pp.

164. Ramsey, G.B.; Wiant, J.S.; McCollock, L.P. 1952. Market diseases of tomatoes, peppers and eggplants. U.S. Dep. Agric. Agric. Handb. 28. 43 pp.

165. Ramsey, G.B.; Wiant, J.S.; Smith, M.B. 1949. Market diseases of fruits and vegetables - potatoes. U.S. Dep. Agric. Misc. Publ. 98. 60 pp.

166. Redit, W.H.; Hamer, A.A. 1961. Protection of rail shipments of fruits and vegetables. U.S. Dep. Agric. Agric. Handb. 195. $108 \mathrm{pp}$. 
167. Richardson, L.T.; Phillips, W.R. 1949. Low temperature breakdown of potatoes in storage. Sci. Agric. 29:149-166.

168. Sainsbury, G.F. 1959. Heat leakage through floors, walls and ceilings of apple storages. U.S. Dep. Agric. Mark. Res. Rep. 3156. $65 \mathrm{pp}$.

169. Sainsbury, G.F. 1961. Cooling apples and pears in storage rooms. U.S. Dep. Agric. Mark. Res. Rep. 474. 55 pp.

170. Sawyer, R.L. 1962. Chemical sprout inhibitors. Potato Handb. $7: 5-9$.

171. Schales, F.D.; Isenberg, F.M. 1963. The effect of curing and storage on chemical composition and taste acceptability of winter squash. Proc. Am. Soc. Hortic. Sci. 83:667-674.

172. Schomer, H.A.; Pierson, C.G. 1968. The use of wax on apples and pears. Proceedings Washington State Horticultural Association, 1967. pp. 198-200.

173. Scott, L.E.; Hawes, J.E. 1948. Storage of vine-ripened tomatoes. Proc. Am. Soc. Hortic. Sci. 52:393-398.

174. Schowalter, R.H. et al. 1961. Long distance marketing of fresh sweet corn. Fla. Agric. Exp. Stn. Bull. 638. 47 pp.

175. Singh, B.C.; Yang, C.; Salunkhe, D.K.; Rahman, A.R. 1972. Controlled atmosphere storage of lettuce. 1. Effects of quality and the respiration rate of lettuce heads. J. Food Sci. 37:48-51.

176. Smith, M.A.; McColloch, L.P.; Friedman, B.A. 1966. Market diseases of asparagus, onions, beans, peas, carrots, celery and related vegetables. U.S. Dep. Agric., Agric. Handb. 303. 65 pp.

177. Smith, R.B.; Lougheed, E.C.; Franklin, E.W.; McMillan, I. 1979. The starch iodine test for determining stage of maturation in apples. Can. J. Plant Sci. 59:725-735.

178. Smith, W.H. 1952. The commercial storage of vegetables. Food Invest. Leafl. 15. 8 pp.

179. Smock, R.M. 1955. A new method for scald control. Am. Fruit Grow. Mag. 75(11):20. 
180. Smock, R.M. 1958. Controlled atmosphere storage of apples. Cornell ext. Bull. 759. 36 pp.

181. Smock, R.M.; Blanpied, G.D. 1963. Some effects of temperature and rate of oxygen reduction on the quality of controlled atmosphere stored McIntosh apples. Proc. Am. Soc. Hortic. Sci. 83:135-138.

182. Smock, R.M.; Neubert, A.M. 1950. Apples and apple products. Economic Crops, Vol. 2. Interscience Publishers, New York, N.Y. $486 \mathrm{pp}$.

183. Southwick, F.W.; Hurd, M. 1948. Harvesting, handling and packing apples. Cornell Ext. Bull. 750. 37 pp.

184. Steward, J.K. 1963. Effect of cooling method, prepackaging and top-icing on the quality of Brussels sprouts. Proc. Am. Soc. Hortic. Sci. 83:488-494.

185. Steward, J.K.; Couey, H.M. 1963. A practical guide to predicting final temperatures and cooling times. U.S. Dep. Agric. Mark. Res. Rep. 637. 32 pp.

186. Strachan, C.C. 1956. Quality of canned peaches affected by maturity, ripening and storage. Can. Food Ind. 27(7):20-21, 23.

187. Sveine, E.; Klougart, A.; Rasmussen, C.R. 1965. Ways of prolonging the shelf-life of fresh mushrooms. Mushroom Sci. $6: 463-474$.

188. Thomas, T.H.; Gray, D.; Drew, R.L.K. 1977. Potential for outdoor tomato production and storage in the U.S. Acta Hortic. 62:101-108.

189. Toko, V.; Johnston, F. 1962. Effects of storage on post harvest physiology of potatoes used as table stock and seed. Potato Handb. 7:10-17.

190. Tolle, W.E. 1971. Variables affecting film permeability requirements for modified atmosphere storage of apples. U.S. Dep. Agric. Tech. Bull. 1422.

191. Tompkins, R.G. 1962. The conditions produced in film packages by fresh fruits and vegetables and effects of these conditions on storage life. Appl. Bacteriol. 25:290-307. 
192. Townsely, P.M. 1952. Eliminate conditioning period in chip manufacture. Can. Food Ind. 23(6):26-29.

193. Truscott, J.H.L. 1954. Storage root rot of celery. Rep. Hortic. Exp. Stn. Prod. Lab., Vineland, Ont. 1953-1954, pp. 122-127.

194. Truscott, J.H.L. 1956. Peach cooling in the Niagara area. Rep. Hortic. Exp. Stn. Prod. Lab., Vineland, Ont., 1955-1956, pp. 106-111.

195. Truscott, J.H.L. 1960. Bartlett and Bosc pears in controlled atmosphere (gas) storage. Rep. Hortic. Exp. Stn. Prod. Lab., Vineland, 1959-1960, pp. 113-114.

196. Truscott, J.H.L.; Brubacher, L. 1963. Tomato storage. Rep. Hortic. Exp. Stn. Prod. Lab., Vineland, 1963, pp. 61-67.

197. Van den Berg, L.; Lentz, C.P. 1966. Effect of temperature, relative humidity and atmospheric composition on changes in quality of carrots during storage. Food Technol. 20:954-957.

198. Van den Berg, L.; Lentz, C.P. 1972. Respiratory heat production of vegetables during refrigerated storage. J. Am. Soc. Hortic. Sci. 97:431-432.

199. Van den Berg, L.; Lentz, C.P. 1974. High humidity storage of some vegetables. Can. Inst. Food Sci. Technol. J. 7:260-262.

200. Van den Berg, L.; Lentz, C.P. 1977. High humidity storage of vegetables. Acta Hortic. (The Hague): 62:197-208.

201. Wang, C.Y.; Mellenthin, W.M.; Hansen, E. 1971. Effect of temperature on development of premature ripening of Bartlett pears. J. Am. Soc. Hortic. Sci. 96:122-126.

202. Wankier, B.N., Salunkhe, D.K.; Campbell, W.F. 1970. Effects of controlled atmosphere storage on biochemical changes in apricot and peach fruit. J. Am. Soc. Hortic. Sci. 95:604-609.

203. Weichmann, J. 1977. Physiological response of root crops to controlled atmospheres. Proceedings 2nd National Controlled Atmosphere Research Conference, Michigan State University, Horticulture Report 28, pp. 122-136.

204. Weir, F.J. 1957. Home storage of vegetables. Manit. Dep. Agric. Publ. 297. 8 pp. 
205. Wells, J.M. 1970. Modified atmosphere, chemical, and heat treatments to control postharvest decay of California strawberries. Plant Dis. Rep. 54:431-434.

206. Whiteman, T.M. 1957. Freezing points of fruits, vegetables, and florist stocks. U.S. Dep. Agric. Mark. Res. Rep. 196. 32 pp.

207. Woodward, J.R.; Topping, A.J. 1972. The influence of controlled atmospheres on the respiration rates and storage behaviour of strawberry fruits. J. Hortic. Sci. 47:547-553.

208. Wright, R.C. et al. 1931. Effect of various temperatures on the storage and ripening of tomatoes. U.S. Dep. Agric. Tech. Bull. 268. $35 \mathrm{pp}$.

209. Yamaguchi, M.; Pratt, K.; Morris, L. 1957. Effect of storage temperature on keeping quality of onion bulbs and on subsequent darkening of dehydrated flakes. Proc. Am. Soc. Hortic. Sci. 69:421-426.

210. Zehnder, L.R. 1975. Effects of storage temperatures and atmospheres on the quality and physiology of cauliflower (Brassica oleracea L. var. botrytis DC.) Ph.D. Thesis, Cornell University, Ithaca, N.Y. 
Facteur

approximatif

Unité métrique

de conversion

Donne

Linéaire

millimètre $(\mathrm{mm})$

$\times 0,04$

$\times 0,39$

centimètre $(\mathrm{cm})$

$\times 3,28$

metre $(\mathrm{m})$

$\times 0,62$

pouce

pouce

pied

kilomètre $(\mathrm{km})$

mille

\section{Superficie}

centimètre carré $\left(\mathrm{cm}^{2}\right)$

mètre carré $\left(\mathrm{m}^{2}\right)$

kilomètre carré $\left(\mathrm{km}^{2}\right)$

$\times 1,2$

$\times 0,39$

hectare (ha)

$\times 2,5$

pouce carré verge carrée mille carré acre

\section{Volume}

centimètre cube $\left(\mathrm{cm}^{3}\right) \quad \times 0,66$

mètre cube $\left(\mathrm{m}^{3}\right)$

$\times 35,31$

$\times 1,31$

pouce cube pied cube verge cube

Capacité

litre (L)

$\times 0,035$

$\times 22$

$\times 2,5$

pied cube

gallons

boisseaux

\section{Poids}

gramme (g)

kilogramme $(\mathrm{kg})$

$\times 0,04$

$\times 2,2$

$\times 1,1$

once

tonne $(\mathrm{t})$

livre

tonne courte

\section{Agricole}

litres à l'hectare

$\times 0,089$

$\times 0,357$

$\times 0,71$

$\times 0,014$

$\times 0,45$

$\times 0,89$

$\times 0,014$

$\times 0,405$

gallons à l'acre pintes à l'acre chopines à l'acre onces liquides à acre tonnes à l'acre livres à l'acre onces à l'acre plants à l'acre 


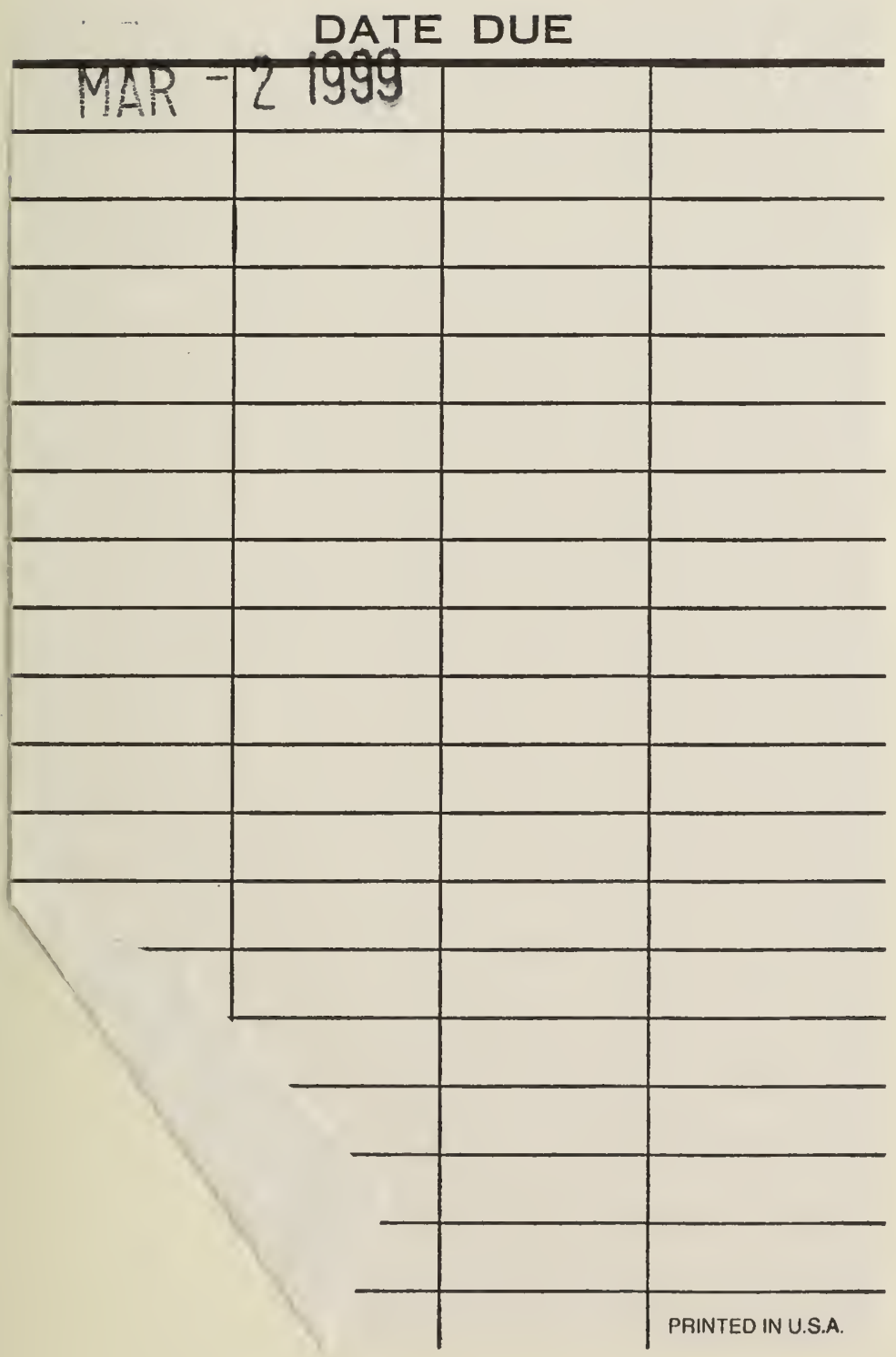


